\title{
Understanding smallholder farmers' food security and institutional arrangements in view of climate dynamics: \\ Lessons from Mt. Kenya region
}

by

Beth Wanjiru Mburu

A thesis submitted to the Faculty of Graduate and Postdoctoral Affairs in partial fulfillment of the requirements for the degree of

Doctor of Philosophy

in

Geography

Carleton University

Ottawa, Ontario

(C) 2016, Beth Wanjiru Mburu 


\section{Abstract}

Globally, an estimated 800 million people are currently experiencing hunger. Food insecurity remains a major concern, especially in developing countries. In sub-Saharan Africa, smallholder farmers, who are both food producers and consumers, manage $80 \%$ of all farms but face many challenges including; shrinking farm sizes, limited financial resources and dynamic farming environments. Food insecurity persists among smallholders as various uncertainties together with climate change impacts exacerbate existing vulnerabilities. However, smallholders have the potential to contribute significantly to food security at community through national scales. This research aims to provide a better understanding of food security determinants among smallholders with a focus on how they use various institutional arrangements to augment their livelihoods. Through focus group discussions and on-farm interviews, the research engaged with smallholders and non-farmers from Embu, Mt. Kenya region in central Kenya. Guided by insights from political ecology, the research assessed smallholders' narratives on perceptions of and experiences with food security, institutional arrangements, climate variability, and climate change. The findings offer strong evidence that smallholders' livelihoods are inextricably reliant on their food production. Fulfilling other livelihood needs, e.g. school fees, often receives priority over satisfying a household's dietary requirements. Cropping seasons rather than longer timescales dictate smallholders' decision-making and planning. Resultantly, everyday uncertainties and challenges tend to subsume climate change threats while climate variability poses more impacts on their seasonal productivity. The conventional definition of food security posed by the Food and Agricultural Organization aligns only partially with the realities of farmers in the Embu region. Smallholders place greater emphasis on two food security dimensions, 
availability and access, paying considerably less attention to utilization and stability. While engaging formal institutions, smallholders have greater agency as members of informal groups than as individuals. This research proposes leveraging current formal and informal institutional arrangements to bolster smallholders' food security outcomes as well as improve their adaptive capacity to climate variability and change. It recommends supporting smallholders through providing relevant agro-climatic information, offering functional financing, brokering new knowledge, assisting in scenario planning for risk management, and reducing access barriers in pre-production processes. 


\section{Acknowledgements}

This journey has revealed my ability to adapt and reinvent myself. Whatever direction my career takes hereafter, the art of balancing looming deadlines while reining in my stellar procrastination skills will be an asset. I would like to acknowledge the people who have shaped my path and ensured I steered steadily towards my True North.

I am deeply obliged to my supervisor Prof. Mike Brklacich for his patience and guidance. Mike, your mentorship throughout my doctoral journey has helped me unmask many blind spots. As the African adage states, "What an elder sees while seated, a child cannot see while standing on their toes". In your unique way, you have allowed me to grow into scholarship and find my voice as I embraced new concepts in social science. Your support has fashioned my time at Carleton to be truly interdisciplinary and helped shape my insights on global-to-local perspectives.

To members of my doctoral advisory committee, Prof. Blair Rutherford and Dr. Evans Kituyi, I remain indebted to your succinct and helpful guidance that has helped refine the scholar in me. Your attention to detail and commitment to my success have bolstered my self-esteem and established new standards to which I will continue to hold my work. I also wish to acknowledge Dr. Stephen Twomlow who has advised me along the way and linked me to consultancy positions that have supplemented my income as well as offered me an opportunity to enhance my professional experience during my PhD.

This work would not have been possible without the full support I have received from the Department of Geography and Environmental Studies at Carleton. Besides administrative and academic support, I remain indebted for the financial support I received from the department and the university at large. Some of the financial awards I have held include; the Graduate 
Scholarship, Dr. Thomas Betz Memorial Award, Canadian Standards Association Pat Keindel Graduate Scholarship in Climate Change, Ina Hutchison Award in Geography, Richard J. Van Loon Scholarship, Torrance Graduate Research Award, and the Philip E. Uren Memorial Fellowship. I remain forever grateful to the various benefactors of these funds.

The inspiration for this research is drawn from interactions with smallholder farmers during my tenure at Equity Group Foundation. Under the visionary leadership of Dr. James Mwangi, I witnessed firsthand how institutions can improve on the lives and livelihoods of farmers. During my doctoral fieldwork, my experiences were enriched by smallholder farmers who remain the heroes in the storylines of my dissertation. In many ways, I took a lot more from them than I was able to give back. Their resolve to make the best of their resources encouraged me not to settle for less and will guide the direction of my career. I wish to acknowledge the support of Boniface Kikuvi and Hussein Njeru "Ringo" who were instrumental in helping me get in touch with farmers for the study. Many thanks to Mr. and Mrs. Mundia, my most gracious hosts, who accommodated me while I carried out fieldwork in Embu. With every trip back to Nairobi from Embu, they filled the car trunk with farm produce for me to take to my parents. As the Irish saying goes, May the sun shine warm upon your face. And rains fall soft upon your fields.

It has been an honour to work alongside my friends Murefu, Edith and other colleagues at EED Advisory in building a consultancy portfolio. The Kenyan community in Ottawa has been of great social support and the various events I participated in allowed me to feel 'normal' and develop socially. I am also grateful to Mamta, Salim and others with whom I created friendship ties that will long outlive my time in Ottawa. 
To my fellow PhD sojourners Nyambura Githaiga and Wangui Kimari, we were right about this thing: "this too shall pass" and "hatujakorogewa hapa - we have not been cemented here"! Through the many 'shut-up-and-write' sessions, which were more of 'chat-and-write', we worked towards improving our drafts and shared episodes from our personal lives. I am grateful for the camaraderie we have built that taught us to believe in ourselves and be our own greatest cheerleaders. I also remain grateful to the peer academic support of Trung Nguyen and Gabrielle Hardy, with whom I shared a supervisor.

The support from my family has anchored my doctoral journey. To my parents Sam and Fidelis, your faith in me has gone a long way into the making of my character. You have supported the pursuit of my dreams wherever they took me and I remain forever grateful for that. To my siblings Jesse, Reuben and Loise, I am thankful to your support and honoured to be counted as family among you.

Finally, I dedicate this work to my nieces Natalie, Claire, Heidi and Samara. Keeping track of your milestones from afar has been both my motivation and the ultimate sacrifice of my PhD. May the only limits you know be those that you set for yourself. 


\section{Table of Contents}

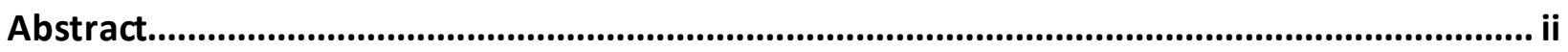

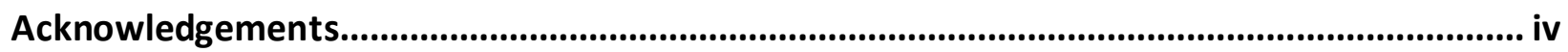

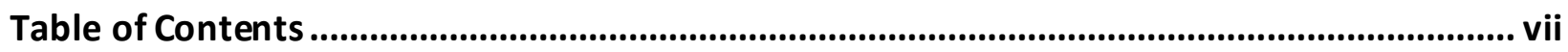

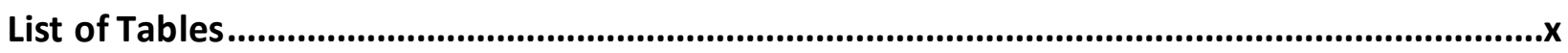

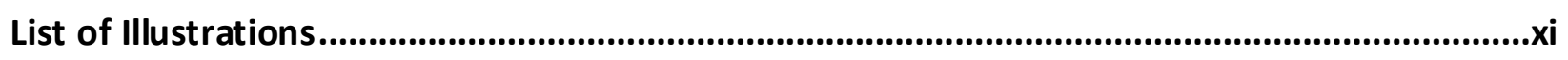

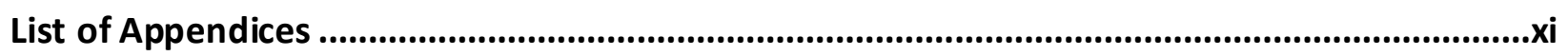

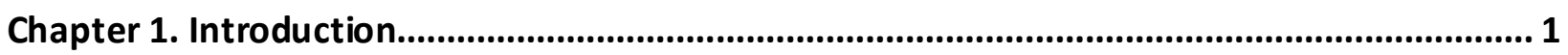

1.1. Smallholders' food security and institutional arrangements in a changing climate ........... 1

1.2. Thesis rationale and methodology overview .......................................................... 5

1.3. Organization of the dissertation ........................................................................... 8

Chapter 2. Food security and smallholder farmers: A local struggle in a globalizing world ....... 9

2.1. Food security dimensions, global and regional perspectives ...................................... 11

2.1.1. Global trends ............................................................................................. 13

2.1.2. The case of food security in sub-Saharan Africa ............................................... 15

2.1.3. Food security and natural resources ............................................................... 18

2.1.4. Evaluating the progress and taking stock ......................................................... 19

2.1.5. Limitations in estimating extent of food insecurity ............................................. 21

2.2. The local context and smallholders' perspective .......................................................... 22

2.2.1. Smallholders in focus: Why do they matter? ........................................................ 23

2.2.2. Investments in livelihoods and knowledge: addressing poverty and hunger ............ 24

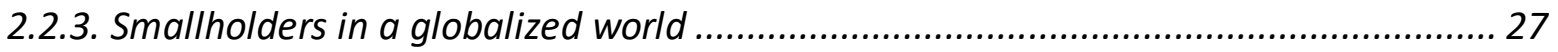

2.3. Climate change and smallholders ............................................................................. 29

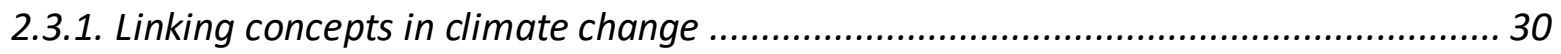

2.3.2. Sensitivity to climate change and related effects ............................................... 31

2.3.3. Smallholders and perceptions of risk and vulnerability ....................................... 32

2.3.4. Climate change and behaviour modification ..................................................... 33

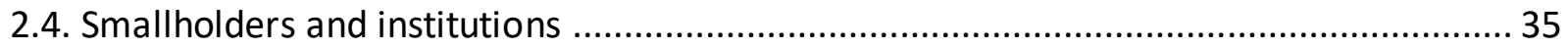

2.4.1. Informal institutions and social networks among smallholders ............................ 36

2.4.2. Social networks and climate change............................................................... 36

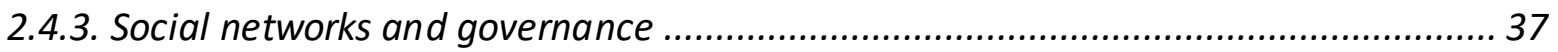

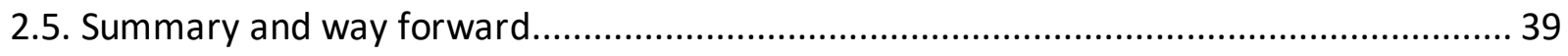

Chapter 3. Theoretical underpinnings and development of the research framework ............. 41

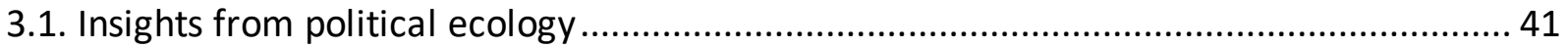

3.1.1. Social identities influence perceptions of risk and vulnerability ............................. 42

3.1.2. Decision-making under conditions of uncertainty ................................................. 44

3.1.3. Examining complexities and interactions across scale ...................................... 45 


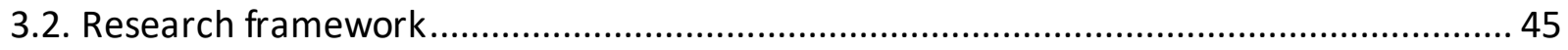

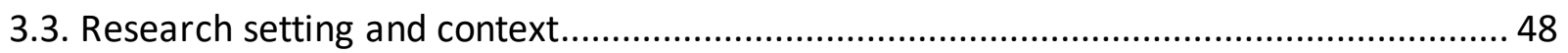

3.3.1. Operating principles and ethical considerations..................................................... 48

3.3.2. Embu, Mt. Kenya region: description and justification for suita bility ........................ 50

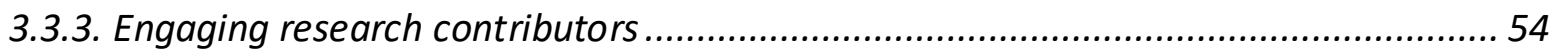

3.3.4. Implementation: research design meets research realities..................................... 58

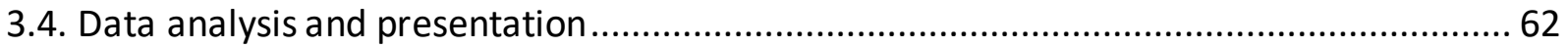

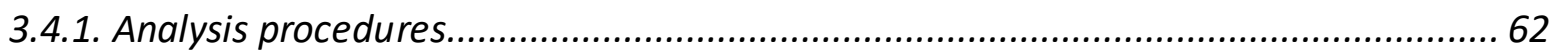

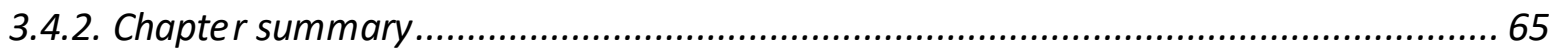

Chapter 4. Food security and related concerns among Mt. Kenya smallholders.......................66

4.1. Negotiating and strengthening livelihoods: The foundation and evolution of farming.... 66 4.1.1. 'Surviving' or 'thriving': Transitions from conventional to agribusiness farming .......66 67

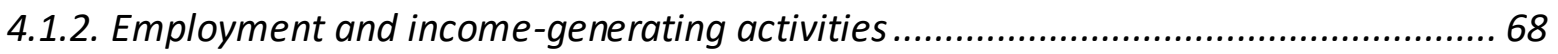

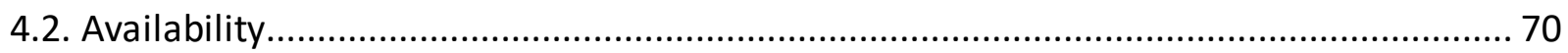

4.2.1. Pre-production processes: availability and acquisition of inputs ............................ 70

4.2.2. Post-production processes: harvests and harvest management .............................. 80

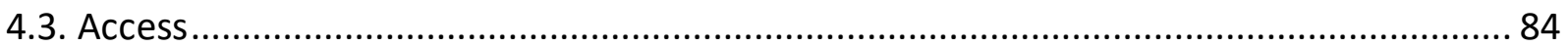

4.3.1. Cost of farming, incomes and purchasing power .................................................. 84

4.3.2. Markets

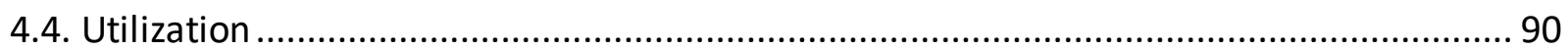

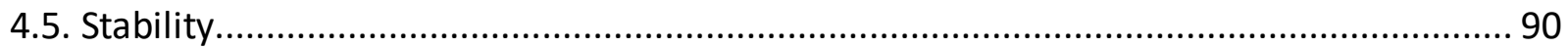

4.6. Advancing food security scholarship through experiences of Mt. Kenya smallholders.... 91

4.6.1. Smallholders' food security is nested within their livelihood strategies .................... 91

4.6.2. Pre-production processes key to food security ........................................................ 93

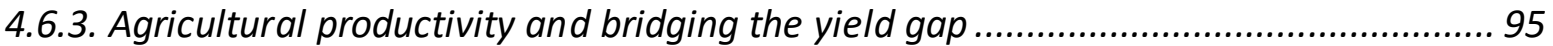

4.6.4. Utilization and stability remain elusive among smallholders .................................. 99

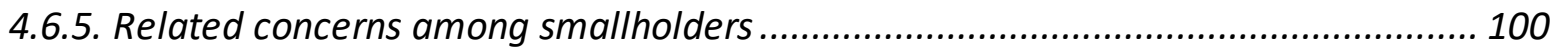

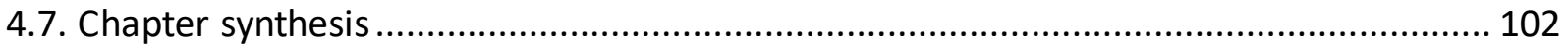

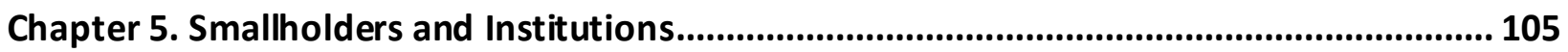

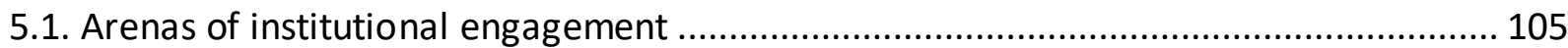

5.1.1. Acquisition of inputs and farm or household resources........................................ 106

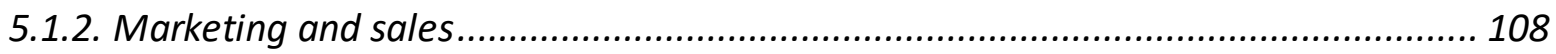

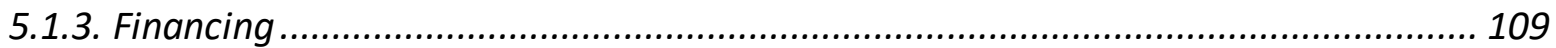

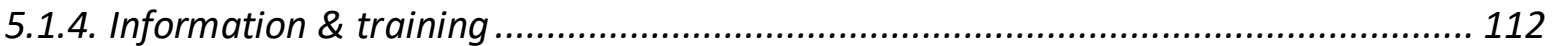

5.2. Dynamics of institutional arrangements................................................................... 113

5.3. Smallholders' concerns with institutional arrangements ............................................. 115

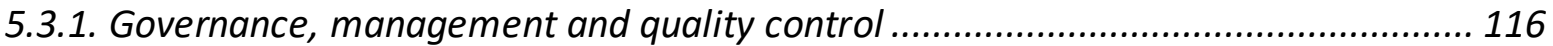

5.3.2. Smallholder vulnerabilities and power differentials ............................................ 118

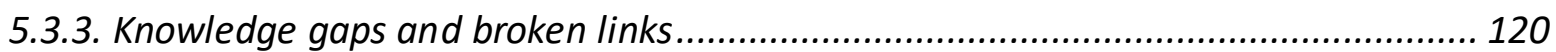


5.4. Broader scholarship and institutional arrangements among Mt. Kenya smallholders ... 123

5.4.1. Livelihoods are entrenched within social networks ............................................ 124

5.4.2. Lessons in governance from informal groups applicable to formal institutions....... 125

5.4.3. Reworking institutional financing and knowledge brokering .............................. 129

5.5. Chapter synthesis ................................................................................................. 132

Chapter 6. Climate change: The experience and perceptions of smallholders ....................... 134

6.1. Smallholders' chronicles on weather and climate ...................................................... 134

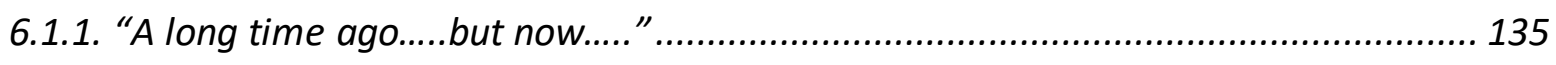

6.1.2. The story shapers: God, fate and luck ............................................................. 137

6.1.3. Perceived effects of and related responses to weather and climate change .......... 140

6.2. Broader scholarship on climate change and relevance to smallholders ......................... 144

6.2.1. Climate and weather trends in the region ........................................................ 144

6.2.2. Climate information: attributes and dissemination .......................................... 147

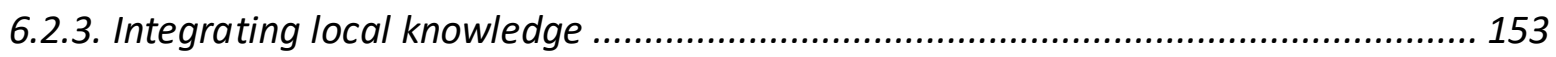

6.3. Climate change adaptation and lessons from heuristic approaches............................. 155

6.3.1. Vulnerability and risk perceptions inform coping mechanism ............................. 155

6.3.2. Climate change does not occur in a vacuum ..................................................... 158

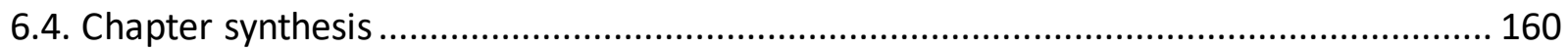

Chapter 7. Re-imagining food security: Lessons from Mt. Kenya smallholders...................... 163

7.1. Lessons from empirical findings............................................................................. 163

7.1.1. Dynamics and dimensions of food security among Mt. Kenya smallholders .......... 163

7.1.2. Institutional arrangements and food security dimensions .................................. 167

7.1.3. Climate change realities more nuanced than everyday uncertainties ................... 169

7.2. Leveraging institutional arrangements for gains in smallholders' food security ............ 170

7.2.1. Information, knowledge and learning ......................................................... 173

7.2.2. Understanding risks and dealing with uncertainties ........................................ 176

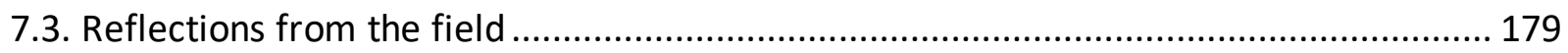

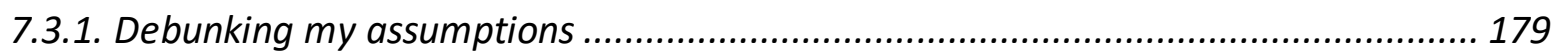

7.3.2. If I was to do this again.... ............................................................................ 180

7.4. Conclusion and suggestions for future directions ............................................... 182

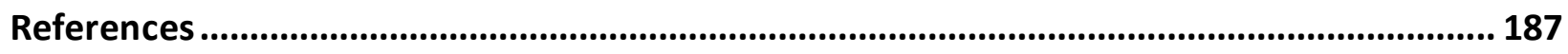

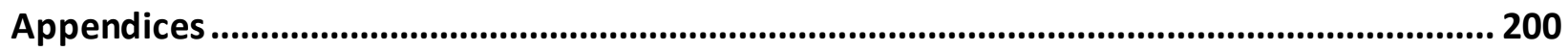




\section{List of Tables}

Table 2.1: Summary on the dimensions of food security - concepts and indicators ................. 12

Table 2.2: Number of chronically hungry (in millions) across the world. .................................... 14

Table 2.3: Number of undernourished in total population (in millions) between 1990-1992 and 2014-2016 in other developing countries and in sub-Sa haran Africa ...................... 16

Table 2.4: Number of undernourished people (in millions) for base period 1990-1992 ............ 22

Table 3.1: The main agro-ecological zones (AEZs) in Kenya ................................................ 52

Table 3.2: The seven moisture belts that span the main zones ........................................... 52

Table 3.3: Timeline of research project activities and key features.......................................56

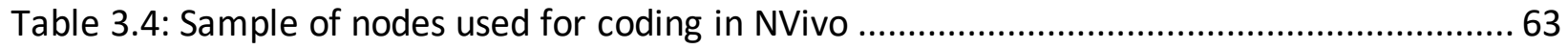

Table 4.1: Yields realized by select farmers or expected as "a good harvest" (hypothetical from

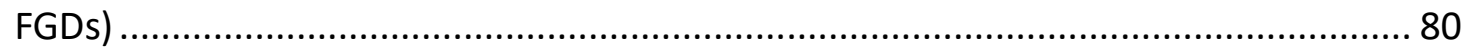

Table 4.2: Expected maize yield projections by seed companies .......................................... 96

Table 4.3: Summary of smallholders' concerns related to food security ............................... 103

Table 4.4: Summary lessons from Mt. Kenya smallholders and advancing scholarship ........... 104

Table 5.1: Examples of interplay between institutions for livelihood and food security ........... 114

Table 6.1: The different ways farmers relate to and describe God in their everyday life.......... 139

Table 6.2: Smallholders' perceived effects of and related (on-farm) responses to changes in

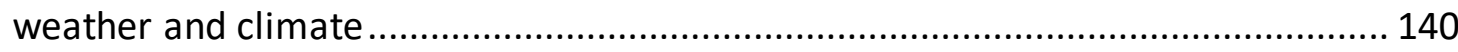

Table 6.3: Examples of trade-offs or distressed liquidation with reasons given by select smallholders. 160

Table 7.1: Potential attributes of informal and formal institutions to be leveraged in vertical bridging ..... 


\section{List of Illustrations}

Figure 2.1: Number of undernourished in other developing countries and sub-Saharan Africa. 16

Figure 3.1: AEZs in Embu County with ellipse showing catchment region of smallholders in the study.

Figure 3.2: Percentage distribution of participating farmers across six age groups ................... 55

Figure 3.3: Distribution of participating farmers by gender and age group..............................55

Figure 3.4: Matrix indicating use of research methods to address sub-questions ................... 58

Figure 4.1: Hypothetical household food security scenario generated during an FGD .............. 85

Figure 5.1: Common financial arrangements among most 'Chamas' (informal groups) ........... 112

Figure 6.1: A word tree created with a text search query in NVivo on references to "God" from interview transcripts of smallholder farmers. ..................................................... 138

Figure 6.2: Monthly rainfall data at the Embu agricultural research centre for 1979, 1989, 1999 and 2008.

Figure 6.3: Rainfall amounts per dekad in MAM seasons of 2013 and 2014. 146

Figure 6.4: Climate information attributes. Darkest shade indicates overlap sought by farmers

\section{List of Appendices}

Appendix A. Sample questions for smallholder farmers and non-farmer informants............ 200

A.1. Sample questions for focus group discussions ....................................................... 200

A.2. Sample questions for one-on-one interviews ...................................................... 200

A.3. Sample questions for non-farmer informants.......................................................... 201

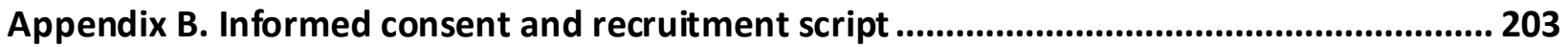

B.1. Script for recruiting farmers for group discussions and interviews ............................ 203

B.2. Script for recruiting non-farmers via phone or email................................................. 204

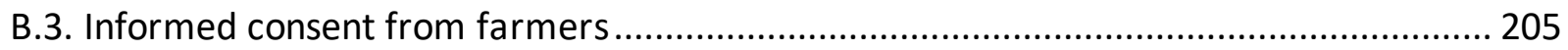

B.4. Informed consent from non-farmers........................................................................ 206

Appendix C. Example of agro-climatic advisory pamphlet for seasonal forecast .................... 208 


\section{Chapter 1. Introduction}

\subsection{Smallholders' food security and institutional arrangements in a changing climate}

An expected increase of $40 \%$ in the world population by 2050 will necessitate a corresponding $70 \%$ increase in agricultural productivity across developing countries in order to meet future food demands (Bruinsma, 2009). Although rapid population growth in the past led to an expansion of agriculture to meet the increasing demand for food (Ericksen et al., 2009), emerging threats such as climate change challenge the speed and cost at which higher agricultural production can be implemented (Burke \& Lobell, 2010b). This is especially pertinent to many regions in the developing world. In sub-Saharan Africa, the predicted population growth to 1.68 billion over the next 40 years is expected to exacerbate food insecurity and land degradation, increase the poverty levels, and place additional strain on natural resources (Gaiser et al., 2011; Gockowski \& van Asten, 2012). In the wake of the 2008 global food crisis, 21 of the 36 countries that faced food insecurity were in Africa (UNCTAD, 2009).

While climate change is a global phenomenon, there is sufficient research indicating that the severity of its effects varies across regions (Gaiser et al., 2011; Kotir, 2011; Liu et al., 2008; Thornton et al., 2011). Moreover, even within affected countries, the spectrum of both climate change effects and food insecurity varies across different population groups. Adverse impacts of climate change are already evident in sub-Saharan Africa (SSA), a region that is also dealing with other challenges (such as civil unrest, religious warfare and political instability) both within and across borders. These socio-economic dynamics raise further questions on the ability of the continent to sustain human life adequately without compromising the environment or posterity's needs. 
At the heart of these dynamics lie smallholder farmers who are both food producers and consumers managing relatively small parcels of land. Smallholders manage $80 \%$ of all farms in SSA (Wiggins \& Keats, 2013). In many of these countries such as Kenya, these farmers contribute significantly to their country's agricultural production and economic growth yet remain vulnerable to the aforementioned challenges. Smallholder farmers tend to avoid risks in the face of emerging uncertainties from climate change and variability (Vermeulen et al., 2012), e.g. by engaging in other non-farm income generating activities, which may lower agricultural productivity. Bottom-up assessments of food security and climate change at the household level offer a better understanding of the vulnerabilities faced by smallholder farmers (Pielke et al., 2007). Smallholder farmers produce food to meet both their dietary as well as other livelihood needs. Rather than focusing on climate change and its impacts on agricultural production exclusively, understanding its effects on the livelihoods of smallholder farmers is paramount if food security is to be achieved (Vermeulen et al., 2012).

Outside the household, smallholder farmers engage with others in the community both formally through transactional arrangements with organizations and informally through social networks with peers. These interactions can be broadly referred to as institutional arrangements. Institutions can be defined as "systems of established and embedded social rules that structure social interactions" (Hodgson, 2006, p. 13). Organizations are a form of institutions but have defined roles, leadership structures, and boundaries that define members and non-members (Hodgson, 2006). This research identifies the non-legal institutional arrangements among smallholder farmers as 'informal' while the interactions with organizations as 'formal'. 
Organizations and their institutional policy frameworks play a major role in structuring the delivery of agricultural-related services to smallholder farmers (Agrawal, Kononen, \& Perrin, 2009; Eidt, Hickey, \& Curtis, 2012; Young, 2010). They also influence both individual learning and collective behavior of smallholder farmers (Pelling et al., 2008). Besides the provision of services and inputs to smallholder farmers, institutions can play a role in encouraging involvement, selflearning and improvement, motivate behaviour adjustment, and mobilize resources as well as nurture leadership skills in order to promote climate change adaptive capacity (Gupta et al., 2010). Studies also indicate that smallholder farmers influence each other's decision-making (Kiptot et al., 2006) and may be evidenced through similar choices in changing practices. As suggested by Amaru and Chhetri (2013), adaptation to climate change is "in part a function of the flow of knowledge between various institutions and communities and the capacity for collective action among institutions" (p. 129). Therefore, examining smallholder farmers' interactions through both formal and informal arrangements is important for multi-stakeholder planning in the agricultural sector and provides a better understanding on the role of social capital. Whereas many studies and programs exist focusing on ways to increase smallholders' productivity, there is room for additional research on the social dimensions of smallholding.

Scientifically established weather patterns may exert a lower influence on farmers' behaviour than their perceptions of climate change and risk (Bryan et al., 2013). This observation points to two key issues that offer an opportunity on how this disparity can be addressed. First, there lies a potentially bigger role to be played by formal institutions through, for example, offering training modules to farmers on how best to interpret and act on climate data from models (Ziervogel \& Cartwright, 2011) thereby increasing the likelihood of obtaining the expected produce. This 
support from formal institutions would allow smallholders to move from reactionary coping strategies to anticipatory actions often associated with higher level institutions (Osbahr et al., 2008).

The second issue rests in understanding the decision-making processes by smallholder farmers. Smallholders live in the same area where they farm and are therefore positioned uniquely to observe the onset of changes in their environments. Their decisions on whether to respond to these changes (or not) are driven by among other factors their priorities, capacities, level of information and risk perception. Smallholders in a region may have a range of practices that vary due to existing power differentials within the community (Ziervogel \& Calder, 2003). Households within a community possess or have access to different capacities and endowments, which in turn influence the types of practices they choose to build their livelihoods. Since decision-making on livelihood activities occurs at the household level, these differentials lead to heterogeneous priorities (Sultana \& Thompson, 2004) among smallholders within the same community. This heterogeneity should inform initiatives meant to bolster smallholder's food and livelihood security. Whatever mix of livelihood activities practiced, this research hypothesizes that a solid decision-support system would allow a majority of smallholders to make informed choices that could potentially increase their chances to achieve food security.

There have been many global and national initiatives by international organizations, nongovernmental agencies, civil society and the private sector in addressing food insecurity. Some of these initiatives include among others, The Hunger Project, End World Hunger - CARE, Zero Hunger Challenge - United Nations, Initiative to End Hunger in Africa - USAID, and the KARIMcGill Food Security Project. These initiatives need to increasingly take into account the 
perspectives and contexts in which smallholders make decisions about food production. Whereas the contextual lessons of a study in one region may be irrelevant in another, some generic implications can be drawn and applied. The use of a case study offers a better understanding on the dynamics of smallholder farming with emphasis on food security, institutional arrangements and climate change. It is in this context that this research was conducted among Mt. Kenya smallholder farmers in Embu County, Kenya. The study area depicts several aspects that smallholders in sub-Saharan Africa have to contend with including limited financial resources, shrinking farm sizes, over population and high costs of agricultural inputs among others.

\subsection{Thesis rationale and methodology overview}

This research argues that food security goals as well as successful climate change adaptation measures will remain elusive if the existence of power imbalances, gender differentials, and socio-economic capabilities are not acknowledged (Deressa et al., 2009; Terry, 2009). While gender differentials were not included in the scope of the research, interactions with smallholders revealed power imbalances and socio-economic dimensions of smallholder farming.

\section{Rationale and research questions}

The perspectives and perceptions of smallholder farmers formed the basis of this research. The aim was to assess conditions under which smallholders can best utilize institutional arrangements to boost their food production and subsequently livelihood security in order to address on-going, entrenched concerns such as limited resources, competing household needs as well as emergent concerns such as climate change. It seeks to address and contribute to three research gaps. First, is the need to provide evidence that places emphasis on the manner in which food and livelihood security are entrenched and intertwined in smallholders' agricultural production activities. 
Second, while thematic areas of food security and climate change have received wide attention in research, there is a need to offer more insights on how these are perceived and addressed at household and local levels. Third, the dynamics of institutional arrangements among smallholder farmers have yet to receive broad review, especially in light of their roles in supporting food security under conditions that are in constant flux. This research on Mt. Kenya smallholders is therefore guided by the following overarching question: Are the current institutional arrangements among smallholder farmers sufficient to bolster their food security in view of climate variability and climate change threats? To address this, several sub-questions were developed to aid in the creation of distinct interwoven building blocks.

The first sub-question is: What are the existing food security concerns among Mt. Kenya smallholder farmers? Responses to this question will contribute to an understanding of how smallholders in the region define food security, what is the current baseline, what the related food security concerns are and how they approach challenges faced in achieving food security.

The second sub-question is: What are the current institutional arrangements among Mt. Kenya smallholder farmers and how do they support them? Here, smallholders will offer insight into how they work with various formal institutions as well as participate in informal arrangements to support their livelihoods. Do they use different institutional arrangements to meet different needs? Are some arrangements more important and easier to deal with than others?

The third sub-question is: What are the existing climate variability and change concerns among smallholder farmers? This question probes smallholders on their understanding of climate variability and change. Do they have examples of how this is evidenced in their region? Has it 
affected their farming activities or livelihoods? What are the responses they have chosen as a result if any?

Collectively, an analysis of responses to these questions will offer a better understanding on the dynamics of smallholder farming. The results were synthesized to offer broader lessons on improvement of food security outcomes among smallholders that can be applied in different regions sharing similar contexts.

\section{Overview of methodology}

The research was guided by broader themes such as the well-established and widely-used food security dimensions. While relying on insights from political ecology, the research used framings of uncertainties, social identity and scale to link between existing scholarship and the empirical findings. A constructivist approach was employed as it allowed for a better understanding of smallholders' realities from their narratives. Using a case study approach, the research focused on a region that lies southeast of Mt. Kenya in Embu County. The fieldwork was carried out during two trips in May - October 2013 and August - September 2014. It engaged a group of smallholder farmers who practice mixed farming, spread across an area with varying topography and agroclimatic conditions. Through focus group discussions and one-on-one interviews conducted onfarm, the farmers' responses were captured in audio recordings as well as in note form. As well, interviews with several non-farmers who work closely with smallholders were conducted. The audio recordings were then transcribed and later coded using NVivo software to identify emerging themes. These themes offered a platform to perform further analysis of the research findings and are discussed in detail in this thesis. 


\subsection{Organization of the dissertation}

In the next chapter, an in-depth background of food security and smallholder farming is offered. Chapter 2 also offers an overview of the literature concerning smallholders and climate change as well as institutional arrangements. In Chapter 3, the research framework is presented covering both theoretical underpinnings as well as the methodological approach. The presentation of empirical findings occurs in the next three chapters in a similar format: each chapter begins with the findings from the field and thereafter offers a discussion on broader scholarship. Chapter 4 provides research findings on food security among smallholder farmers in Mt. Kenya. In Chapter 5, the findings on institutional arrangements are presented while Chapter 6 discusses the concerns on climate variability and change among the farmers. Chapter 7 is a synthesis of the research findings that reflects on the overarching research question. It draws on theoretical framings, empirical findings and broader scholarship in an attempt to tie the three together. The chapter also offers broader reflections on the contributions of this research and poses recommendations for future consideration. 


\section{Chapter 2. Food security and smallholder farmers: A local struggle in a globalizing world}

During the tail end of the Second World War, concerns for global food security emerged coinciding with the signing of the Food and Agriculture Organization's (FAO) constitution (Davis, 1945). However, it took over a decade for the foundational debates on food security to emerge and were perhaps best captured during a 1958 conference ${ }^{1}$ where Charles Darwin, grandson to the renowned evolutionist, presented a talk on the relationship between human population and food security. To frame this chapter, three of his major points are worth revisiting as a precursor to discussing current dynamics of food security.

First, he cited the projection by demographers that the world population would stand at 4 billion come 2000 (Darwin, 1958). While seemingly robust, this estimation proved to be quite modest as the world population stood at over 6 billion, with 1.2 billion people living in developed areas and the majority, 4.9 billion people, living in less developed regions (United Nations Population Division, 1998).

Second, Darwin stated that there will always be 'too many mouths to feed' irrespective of how much food is produced, further speculating that 50 years from then, more than $50 \%$ of the estimated 4 billion people would be hungry (Darwin, 1958). However, based on the United Nations Food and Agricultural Organisation's (FAO) 2008 report on food insecurity, Darwin's second prediction was also inaccurate. On the backdrop of soaring food prices the previous year,

\footnotetext{
${ }^{1}$ This was during the Second Pugwash Conference on arms race that was held in Lac Beauport, Quebec.
} 
the report indicated that 923 million people around the globe were chronically hungry (FAO, 2008 b), representing about $14 \%$ of the global population of 6.7 billion.

Third, Darwin was concerned about the inability of food production to keep pace with population growth. Not surprisingly, his views aligned with neo-Malthusian beliefs that while increase in per capita food production was arithmetic, population growth was expected to be exponential (Pinstrup-Andersen \& Watson II, 2011). Darwin observed that between 1947 and 1953, world agricultural production increased by $8 \%$ while over the same period, the world population grew by $11 \%$ (Darwin, 1958). On this basis, Darwin passionately advocated for population growth control measures as the pathway towards everyone having adequate food (Darwin, 1958).

History has not treated Darwin kindly on several fronts. The last half of the 1990 s saw world food production outpacing population growth. The food available per capita per day in 1969-71 was 2,410 kilocalories but later increased in the period 1997-99 to 2,800 kcal (FAO, 2001). Global population grew impressively by 45\%, between 1990 and 2010, but nevertheless, global per capita food production increased by $15 \%$ (Pinstrup-Andersen \& Watson II, 2011). While this feat of global food production more than keeping pace with rising population is remarkable, it masks the challenges of the chronically hungry and obscures the reasons why hunger persists for many millions. If the world is able to produce an adequate supply of food, why is food insecurity still a major concern around the globe?

A comprehensive response to this question is both complex and beyond the scope of this thesis. However, this chapter is dedicated to shedding light on a significant proportion of the world's population and agricultural producers - the smallholder farmers - who are so close to food yet food security remains elusive for a majority of them. The chapter has five sections that seek to 
elucidate the plight of smallholders and their food security. Section 2.1 will provide an overview of food security and insecurity from global to regional levels, discussing both the trends and general concerns. Section 2.2 will then focus on the local context by showcasing smallholder farmers and issues that remain pertinent to their food security and livelihoods. Section 2.3 has a primer on climate change as a threat-multiplier and highlights how it compounds the challenges to smallholders' livelihoods. Section 2.4 will then explore how social networks and institutions play a role in smallholders' livelihoods and start to tease out how such can be of support in addressing some of their challenges. In the last section 2.5, concluding remarks are offered together with identified research gaps that will be explored in subsequent chapters of the thesis.

\subsection{Food security dimensions, global and regional perspectives}

Broader perspectives of food for human sustenance are often framed within food systems approaches or food security dimensions. The food systems approach is governed by a set of fourstaged activities, namely producing, processing and packaging, distributing and retailing, and consuming food (Ericksen et al., 2010). This research used the food security dimensions framing as it is better suited for assessments at the household level rather than the food systems approach. The research assessed how these dimensions resonate with views from smallholder farmers regarding food security. A good place to start is the definition of food security that was coined during the World Food Summit in 1996: 'A situation that exists when all people, at all times, have physical, social and economic access to sufficient, safe and nutritious food that meets their dietary needs and food preferences for an active and healthy life'. Carved out of this definition are the four dimensions of food security, namely, availability, access, utilization and stability (FAO, IFAD, \& WFP, 2015). 
A primer on the concepts of food security dimensions and relevant indicators is offered and summarized in Table 2.1 below.

Table 2.1: Summary on the dimensions of food security - concepts and indicators

\begin{tabular}{|c|c|c|}
\hline Dimension & Concepts & Indicators \\
\hline Availability & $\begin{array}{l}\text { Focuses on the supply of food, its } \\
\text { production and stock levels. }\end{array}$ & $\begin{array}{l}\text { Assesses quantity, quality and diversity: } \\
\text { - Dietary energy supply (DES) } \\
\text { - Share of calories from cereals, tubers and roots } \\
\text { - Average supply of animal-source protein } \\
\text { - Average value of food production }\end{array}$ \\
\hline \multirow[b]{2}{*}{ Access } & \multirow{2}{*}{$\begin{array}{l}\text { Rests on two pillars of physical and } \\
\text { economic access. Physical access is } \\
\text { determined by the availability and } \\
\text { quality of infrastructure. Economic } \\
\text { access is determined by disposable } \\
\text { income and people's purchasing } \\
\text { power. }\end{array}$} & $\begin{array}{l}\text { a) Physical: focus on infrastructure } \\
\text { - Road \& railway density } \\
\text { - Percentage of paved roads over total roads }\end{array}$ \\
\hline & & $\begin{array}{l}\text { b) Economic: } \\
\text { - Domestic food price index } \\
\text { - Prevalence of undernourishment } \\
\text { - Share of food expenditure for the poor } \\
\text { - Depth of food deficit }\end{array}$ \\
\hline \multirow[b]{2}{*}{ Utilization } & \multirow[b]{2}{*}{$\begin{array}{l}\text { Is hinged on how the body makes use of } \\
\text { the consumed food, which in turn } \\
\text { determines one's nutritional status. }\end{array}$} & $\begin{array}{l}\text { a) Ability to utilize food: } \\
\text { - Access to sources of water } \\
\text { - Access to Sanitation }\end{array}$ \\
\hline & & $\begin{array}{l}\text { b) Outcomes of food utilization: } \\
\text { - Nutritional failures of children under } 5 \text { years - } \\
\text { wasting, stunting, underweight } \\
\text { - Prevalence of anaemia and Vitamin A deficiency } \\
\text { in children under } 5 \text { years } \\
\text { - Prevalence of anaemia and Vitamin A deficiency } \\
\text { in pregnant women }\end{array}$ \\
\hline
\end{tabular}

a) Vulnerability - factors that measure the exposure to food security risk:

- Cereal dependence ratio

This dimension applies across the

- Area under irrigation above three. It is concerned with the

Stability temporal interruptions to the other

- Value of staple food imports as a percentage of total merchandise exports three dimensions and is determined by exposure to various risks.

b) Shocks - the incidence of:

- Food price volatility

- Fluctuations in domestic food supply

- Political instability

- Variability in per capita food production/supply

Derived from: European Commission (EC) \& FAO, 2008; FAO, IFAD, \& WFP, 2013, 2014, 2015 
Smallholders' responses on food security were analyzed according to the four dimensions. Of interest will be whether the four dimensions receive equal or unequal attention at the household level.

\subsubsection{Global trends}

During the World Food Summit (WFS) in 1996, a goal was set to halve the number of people who were undernourished in 1990-92, some 835 million people, by the year 2015 (FAO, 1999). The next section relies on the FAO's annual The State of Food Insecurity in the World (SOFI) ${ }^{2}$ reports to track levels of hunger and related population attributes on a global scale and to measure progression towards the overall goal of halving hunger over a 25 -year period. While progress has been made, the sections below make a case for the need to review the food security dimensions in order to fast track the fight against widespread hunger.

Although food is classified as a global commodity (Burke \& Lobell, 2010a), it is evident that the world has had a challenge in meeting its food security needs. The distribution and depth of hunger is not static in either spatial or temporal scope. For instance, market forces or changes in the climate have been documented to cause a shift in the vulnerability of populations as well as responsibilities in safeguarding food security (FAO, 2008a). As evident in Table 2.2, progress has occurred in reducing the number of hungry people overall. In mid-2016, it is however clear that the target set in 1999 to lower the number of hungry people globally to 400 million remains elusive.

\footnotetext{
2 The measurement of food security is both controversial and difficult (Burke \& Lobell, 2010a). The SOFI reports however provide a rich and reliable resource to track world food hunger and insecurity - at global, regional and to some extent national levels. The FAO uses the terms "chronically hungry" and "undernourished" interchangeably to identify people facing food insecurity.
} 
Table 2.2: Number of chronically hungry (in millions) across the world.

\begin{tabular}{ccccc}
\hline Year ending & $\begin{array}{c}\text { Developed } \\
\text { Countries }\end{array}$ & $\begin{array}{c}\text { Countries in } \\
\text { Transition }\end{array}$ & $\begin{array}{c}\text { Developing } \\
\text { Countries }\end{array}$ & Total \\
\hline 1981 & -- & -- & 920.0 & -- \\
1992 & 20.0 & -- & 990.7 & 1010.6 \\
1997 & 17.5 & -- & 774.0 & 791.4 \\
1998 & 34.0 & -- & 792.0 & 826.0 \\
1999 & 11.0 & 27.0 & 777.0 & 815.0 \\
2000 & 11.0 & 30.0 & 799.0 & 840.0 \\
2001 & 18.0 & -- & 901.0 & 919.0 \\
2002 & 21.2 & -- & 908.4 & 929.6 \\
2003 & 9.0 & 25.0 & 820.0 & 854.0 \\
2005 & 13.0 & -- & 885.0 & 898.0 \\
2006 & 15.2 & -- & 857.7 & 872.9 \\
2007 & 15.4 & -- & 926.9 & 942.3 \\
2008 & 10.6 & -- & 839.4 & 850.0 \\
2009 & 15.0 & -- & 852.0 & 867.0 \\
2010 & 15.2 & -- & 863.0 & 878.2 \\
2011 & 15.7 & -- & 824.9 & 840.5 \\
2012 & 15.7 & -- & 805.0 & 820.7 \\
2013 & 15.7 & -- & 826.6 & 842.3 \\
2014 & 14.6 & -- & 790.7 & 805.3 \\
20164 & 14.7 & -- & 779.9 & 794.6 \\
\hline 50462 & & & & \\
\hline
\end{tabular}

Source: Compiled from UN FAO SOFI reports

A quick assessment of the global status on world hunger reveals that a great disparity exists both on the extent of hunger and the concentration of the populations facing hunger. In wealthier nations, food producers benefit from existing social safety nets. Some of the existing safety nets include facilities for borrowing, financial markets that function well enough to mitigate loses e.g. through the provision of insurance, and support from government to maintain livelihoods (Burke \& Lobell, 2010b). It is no surprise that the focus of interventions and agricultural policies differs in developed versus developing regions. For instance, researchers indicate that wealthier countries are concerned about the safety of food and the convenience of consumers while the

\footnotetext{
${ }^{3}$ In practice, it is customary for the UN FAO to present three-year averages in order to smooth out effects of temporary shocks as well as lower random errors (Pinstrup-Andersen \& Watson II, 2011). However, SOFI reports provide data for a single year. For this table, the "year ending" represents the year with data drawn from most the recent SOFI report which provides information for that particular year or end of the three-year period.

4 Projection for the period 2014-2016.
} 
poorer nations are more focused on food security and the livelihoods of smallholder farmers (Amekawa et al., 2010).

Although national food security is not necessarily wholly dependent on local food production (Challinor et al., 2007), developing countries are more predisposed to having poor and insufficient measures that can overcome shortages in overall food supply (Burke \& Lobell, 2010b) and mitigate against hunger. As indicated in Table 2.2, the greater proportion of the world's hunger is found among developing regions thus justifying the FAO's reports' focus on highlighting hunger in these regions. The following section evaluates the trends in global food security as well as examining the status of sub-Saharan Africa (SSA).

\subsubsection{The case of food security in sub-Saharan Africa}

Progress has been recorded in reducing the number of undernourished populations globally and this is especially commendable across several developing countries. However, there are over a hundred countries that are categorized as 'developing nations' and a combined assessment masks existing disparities and the uneven distribution of hunger within the group. As evidenced in Figure 2.1, this is certainly true in the case of sub-Saharan Africa. 


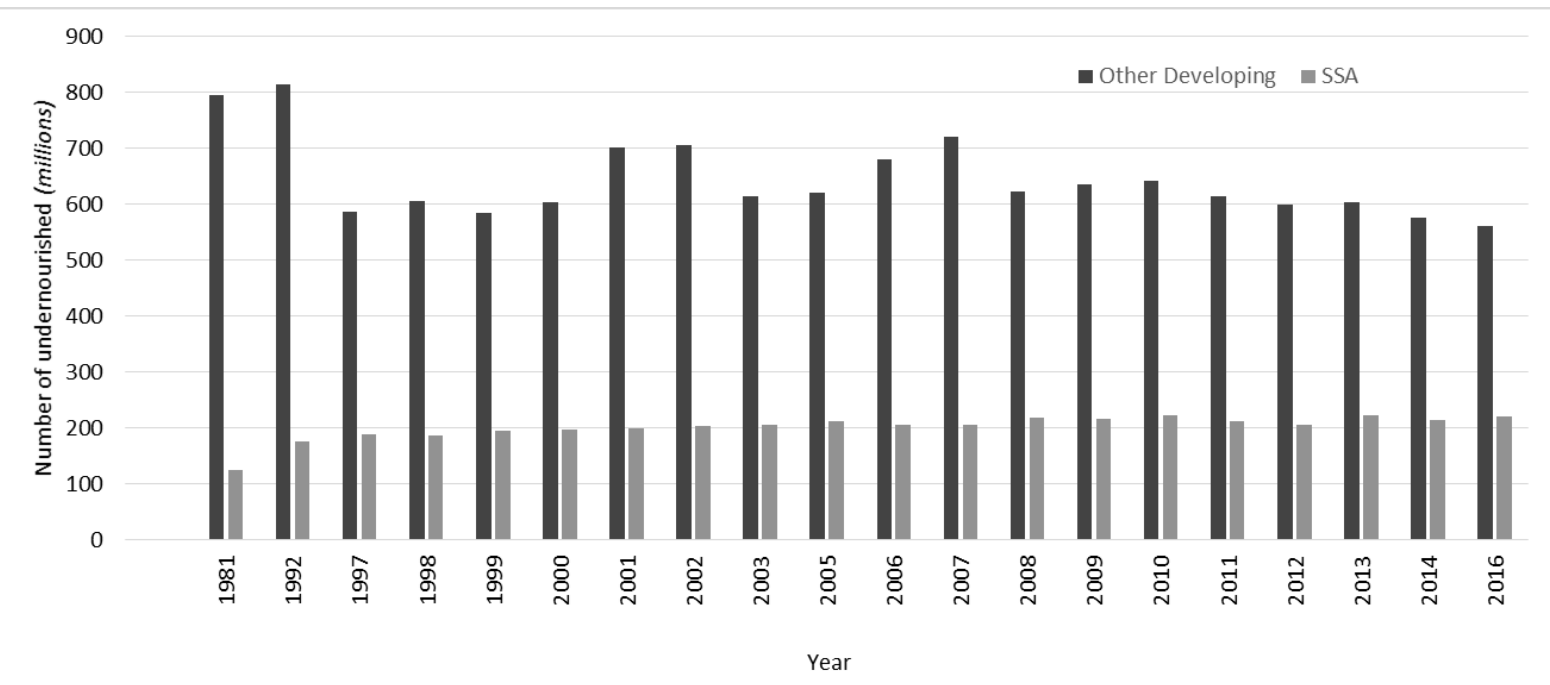

Figure 2.1: Number of undernourished in other developing countries and sub-Saharan Africa. Source: UN FAO SOFI reports

Sub-Saharan Africa (SSA) on average contributes about a quarter of the undernourished people in developing countries but actually accounts for about $16 \%$ of the population in the developing world (Population Reference Bureau, 2015). Overall, SSA falls outside the global trend of improvements in food security since 1981. Food insecurity became more entrenched in SSA in the 1980 s and 1990s and has remainded relatively constant over the past 25 years as experienced by about 200 million people in the region (Table 2.3). This is in sharp contrast to other developing countires where fluctuations occurred between 1981 and 2007 but recorded a steady decline in hunger in the last decade.

Table 2.3: Number of undernourished in total population (in millions) between 1990-1992 and 2014-2016 in other developing countries and in sub-Saharan Africa

\begin{tabular}{ccc}
\hline Period & \multicolumn{2}{c}{ Number of undernourished } \\
\hline $1990-1992$ & Other Developing Countries & Sub-Saharan \\
$2000-2002$ & 815.0 & 175.7 \\
$2005-2007$ & 704.8 & 203.6 \\
$2010-2012$ & 720.9 & 206.0 \\
$2014-2016$ & 599.3 & 205.7 \\
\% Change & 559.9 & 220.0 \\
Trend & $\mathbf{- 3 1 . 3}$ & $\mathbf{2 5 . 2}$ \\
Source: (FAO, IFAD, \& WFP, 2015) & $\downarrow$ & $\uparrow$
\end{tabular}


The prevalence of hunger adds another dimension to our understanding of food insecurity. A measure of the prevalence of hunger in each region's population indicates that, in sub-Saharan Africa, there is a higher proportion of the population that are hungry in comparison to other developing regions as a whole. On a global scale, one in every nine people is undernourished while in sub-Saharan Africa the ratio is one in every four (FAO, IFAD, \& WFP, 2014). Overall, the prevalence of hunger in other developing countries has decreased more than it has in subSaharan Africa.

The focus on reducing numbers rather than prevalence remains an elusive goal and many developing countries are yet to reach it. In 2000, one hundred and eighty nine member states of the United Nations ratified the Millennium Development Goals (MDGs) with various targets set for 2015. Under the first MDG, the target of halving the proportion of undernourished people has been termed less ambitious than that crafted during the Wold Food Summit of halving the number of undernourished (FAO, IFAD, \& WFP, 2013). According to the latest SOFI edition, a majority of the developing countries tracked had achieved the MDG1 hunger prevalence target. Out of 129 countries, 72 had reached the MDG target while only 29 had met the WFS target (FAO, IFAD, \& WFP, 2015). By the end of 2015, it is expected the WFS goal of reducing undernourishment to 400 million will be missed by approximately 285 million people (FAO, IFAD, \& WFP, 2015). Clearly, the WFS targets for reducing food insecurity remain aspirational.

Globally, food consumption patterns are changing giving rise to two trends of convergence and adaptation (Ericksen et al., 2009; FAO, 2004). Dietary convergence refers to the growing similarity of diets around the world especially narrowing down to staple foods such as wheat and rice. Correspondingly, dietary adaptation arises from changing high-pressure lifestyles especially in 
urban areas that propel people to consume more meals outside the home as well as an increase in the consumption of highly processed foods (FAO, 2004). According to Pinstrup-Andersen and Watson II (2011) the focus on convenience of food is also on the rise among urban areas in developing countries and is often positively related to an increase in incomes.

The last four decades has seen an increase in the spread of food insecurity, food availability per capita, obesity, and the prevalence of nutritional deficiencies, as well as an increase in the diversity of diets (Pinstrup-Andersen \& Watson II, 2011). Most notably, the demand for meat and other highly refined products increases as levels of affluence rise. With a projected population growth to 9 billion by 2050, the demand for both cereals and meats is expected to rise by over 50\% (Hanjra \& Qureshi, 2010). Thus, the obesity paradox - a rise in cases of malnutrition recorded in developed countries where food availability and access are not a major challenge. Some authors have however linked obesity and malnutrition to poverty status in developed countries (Tanumihardjo et al., 2007). In developing countries, while obesity may be considered a 'luxury problem', other diet related illnesses are on the rise, e.g. cases of diabetes are expected to soar to 228 million come 2025 (FAO, 2004). These points underscore the need to holistically review food security dimensions without ignoring the influence of economic factors on nutrition choices (FAO, WFP, \& IFAD, 2012).

\subsubsection{Food security and natural resources}

The link between food security and natural resources also merits attention. For food producers, two of the most important natural resources are water and land for cultivation and habitation (especially for smallholders). Rapid population growth has been the cause of land degradation in many areas and this worsens food insecurity (Gaiser et al., 2011). Additionally, extensive water 
resource use by agriculture and other sectors is a growing concern ranging from critically low levels in California due to intensive farming to the depletion of natural "water towers" ${ }^{5}$ in many catchment areas in developing countries such as Kenya. For instance estimates from a decade ago indicated that Africa used $85 \%$ of its water in agriculture (Denton, 2002). Rising demand from non-agricultural uses such as in expanding industries and urban areas (Hanjra \& Qureshi, 2010) puts additional pressure on water resources which in turn limits the quantities available for agricultural use, thereby constraining food security further (Kang, Khan, \& Ma, 2009). Compounding this further, the global rural-to-urban population ratio that stood at 70:30 in 1950 will change to $30: 70$ by 2050 . Most of the growth is expected to occur in developing countries (Misselhorn et al., 2012), putting additional pressure on scarce water resources. The shortage of water for household use has direct and significant effects on the health and sanitation of especially children and people who may be vulnerable from pre-existing conditions such as diseases. Similarly, the occurrence of drought can often escalate into conditions of famine due to human-driven factors such as over-cultivation, which compromises the ability of soils to retain moisture (Amekawa, 2011). It is therefore warranted when Hanjra and Qureshi (2010) raise the alarm on water usage pointing out that the scarcity projections made for 2025 were actually realized in 2000.

\subsubsection{Evaluating the progress and taking stock}

While progress towards reducing world hunger has been made, many agencies at global through local scales are still struggling to work out a strategy that will ensure that both the number of

\footnotetext{
5 "Mountains and highlands are often referred to as natural "water towers" because they provide lowlands with essential freshwater for irrigation and food production." (Viviroli \& Weingartner, 2008, p. 15).
} 
hungry people and prevalence of hunger continue on a downward trend and eventually be eradicated. Keeping the momentum on this trend remains a challenge as rising populations and increasing food demand implies that over the next four decades, global food production must increase by over $100 \%$ (Hanjra \& Qureshi, 2010). Three other considerations in addressing the adaptation of food systems to emerging challenges emerge from subsequent sections of this chapter. These include: that an increase in agricultural yields needs more than technical solutions; that trade-offs occur at multiple scales; and that proper governance is necessary in food systems (Ericksen et al., 2009).

Several recommendations have been made in each of the FAO annual SOFI reports together with food policy initiatives at regional and national levels. However, the problem of world hunger persists and is unlikely to be permanently solved in the near future. In regions such as subSaharan Africa where the number of hungry people has been on the rise, current political will is weak and there is a lack of serious and consistent commitment by member governments to combat hunger (FAO, WFP, \& IFAD, 2012; Mayne, 2006). The Maputo Declaration signed in 2003 by African governments to allocate $10 \%$ of national expenditure budgets to agriculture by 2008 (FAO, 2003) and achieve a 6\% annual growth in agriculture (Wiggins \& Keats, 2013) is still offtrack as many nations have yet to meet their obligations. This is of great concern for two main reasons. First, Reilly and Schimmelpfenning, (2000) estimate that it takes between 15 to 30 years to realize full returns on agricultural investments. Therefore, delaying the compliance with investment commitments in present the day pushes back the date to register gains in subSaharan Africa hunger reduction. Second, evidence exists that food insecurity in many parts of Africa is already driven by climate change, whose major role lies in revealing underlying 
vulnerabilities (Challinor et al., 2007). A further discussion on climate change as a threatmultiplier to smallholders' food security is in Section 2.3.

Food security assessments at regional and global levels do not reveal how risk among vulnerable populations is distributed or how it changes. It is however evident that considerable variability exists within regions and as well as in the countries (Gregory, Ingram, \& Brklacich, 2005). Since vulnerability can either be transient or chronic, any measure of food insecurity needs to remain sensitive to risk redistribution (Adger, 2006; FAO, 2008a). This shift in risk and vulnerability continually reshapes food insecurity maps driven by non-food factors. For example, over half of all malnutrition is driven by diseases such as HIV/AIDS and malaria (Brown \& Funk, 2008). Ignoring these factors casts a veil on the real causes of vulnerability and makes addressing food insecurity a challenge. Now, it is evident that several factors are at play when discussing food insecurity and reasons why it persists. The understanding of these factors emerge best from the perspectives of smallholder farmers who are both food producers and consumers.

\subsubsection{Limitations in estimating extent of food insecurity}

Improvements in food security must be supported by measurements at multiple scales. At national levels, aggregate numbers are critical in informing policy decisions and relevant improvements. At local levels however, it is necessary to understand various individual and household level dynamics at play that influence food security outcomes.

In its sixth publication of SOFI, FAO admitted that limitations exist in their methodology to provide global estimates. Their numbers rely on national parameters such as country food balance sheets and levels of inequality - a slight variation of which can cause a significant change in the estimates (FAO, 2004). Scholars such as Liu et al. (2008) have critiqued FAO's use of balance 
sheets due to the method's high sensitivity to assumptions which may be occasioned by changing estimates. It therefore comes as no surprise that in subsequent annual SOFI publications, FAO makes efforts to provide more recent estimates that differ from numbers previously provided.

Table 2.4: Number of undernourished people (in millions) for base period 1990-1992

\begin{tabular}{llllllllllllrr}
\hline $\begin{array}{c}\text { SOFI } \\
\begin{array}{c}\text { Report } \\
\text { Year }\end{array}\end{array}$ & $\mathbf{2 0 0 1}$ & $\mathbf{2 0 0 2}$ & $\mathbf{2 0 0 3}$ & $\mathbf{2 0 0 4}$ & $\mathbf{2 0 0 5}$ & $\mathbf{2 0 0 6}$ & $\mathbf{2 0 0 8}$ & $\mathbf{2 0 0 9}$ & $\mathbf{2 0 1 0}$ & $\mathbf{2 0 1 1}$ & $\mathbf{2 0 1 2}$ & $\mathbf{2 0 1 3}$ & $\mathbf{2 0 1 5}$ \\
\hline Developed & -- & -- & -- & -- & -- & -- & 19 & 19 & 17 & 15 & 20 & 20 & 20 \\
Developing & 816 & 819 & 817 & 824 & 824 & 823 & 823 & 826 & 827 & 833 & 980 & 994 & 991 \\
Total & -- & -- & -- & -- & -- & -- & $\mathbf{8 4 2}$ & $\mathbf{8 4 5}$ & $\mathbf{8 4 3}$ & $\mathbf{8 4 8}$ & $\mathbf{1 0 0 0}$ & $\mathbf{1 0 1 5}$ & $\mathbf{1 0 1 1}$ \\
\hline
\end{tabular}

Source: UN FAO, SOFI reports - respective report year as per column heading. Rounded to nearest million

As shown in various SOFI annual reports and summarized here in Table 2.4 above, this change in estimates is most evident for 1990-1992 data - the base period on which the WFS target was set.

\subsection{The local context and smallholders' perspective}

Computations of global and regional hunger are drawn from national data. These data obscure variations at local and households levels (Liuet al., 2008) and as Schmidhuber and Tubiello (2007) assert, national self-sufficiency does not guarantee food security to all residents of that country. They expound that a country that does not produce enough food locally may have monetary and non-monetary resources to buy adequate food for all e.g. Singapore and Hong Kong. However, a country such as India may produce sufficient food within its borders but a large proportion of the population remains food insecure (Schmidhuber \& Tubiello, 2007).

Although the household is used as the most common unit of hunger assessment at local levels, it is not uncommon for it to oscillate in and out of poverty states within short periods affecting their food security (Alwang, Siegel, \& Jørgensen, 2001). Food security remains in a state of flux at all levels. An insight into how this relates to smallholders' households would offer a better framework to assess food security cumulatively from local to global levels. 
It was only after the 1970s that focus on food security shifted from national production and global trade to needs at households and individual levels (Clapp, 2014b; FAO, 2008a). This shift is credited on the work of Amartya Sen who placed emphasis on assets and entitlements at these levels (Watts, 1989). Showcasing the smallholder at the center of global food security concerns would serve as a suitable strategy to unmask the complexity of both global and local food systems and the many elements and agents at play within it (Pinstrup-Andersen \& Watson II, 2011). The sections below will frame aspects of smallholders' livelihoods and the challenges they face. It will emphasize and demonstrate why it is necessary to focus on their plight if success in tackling food insecurity in sub-Saharan Africa and other developing regions is to record steady progress.

\subsubsection{Smallholders in focus: Why do they matter?}

A recent assessment of the world's 570 million farms indicates that over $90 \%$ are owned (through various forms of tenure) by individuals or families and that approximately $84 \%$ of these farms are less than two hectares in size (FAO, IFAD, \& WFP, 2015). In regions such as SSA, smallholders' agricultural production contribution accounts for $84 \%$, producing mostly staple foods (FAO, 2008b). As is the case in many developing countries, these small farms are located in rural areas and remain central in building local economies. Globally, over $80 \%$ of the world's food, in value terms, is generated from small-scale farms (FAO, IFAD, \& WFP, 2015). It is evident that inclusive strategies led by smallholders can not only go a long way in promoting agricultural sectors (Jayne \& Muyanga, 2012) but also play a pivotal role in eliminating hunger across many economies within sub-Saharan Africa.

Smallholders also play a vital role in developing countries' economies. Over the past two to four decades, smallholders' contribution has been acclaimed for the development success in 
countries such as China and Vietnam (FAO, WFP, \& IFAD, 2012). In sub-Saharan Africa, smallholders are more entrenched not only because they contribute the highest to agricultural production but also because, in turn, agriculture contributes most significantly to African economies when compared to other sectors. Estimates of agriculture's contribution to African economies in comparison to other sectors are difficult to compute and inconclusive, largely due to lack of solid data. In recognition of this gap, the Comprehensive Africa Agriculture Development Programme (CAADP) singled out one of its six action areas as to "increase production of and access to quality data and knowledge, and provide information to the public."

(NEPAD, 2013, p. 38). It is however clear and interesting to note that at national levels, as the per capita GDP increases, the importance of agriculture's contribution to the economy decreases (FAO, WFP, \& IFAD, 2012). Similarly, while it remains true that smallholders' main occupation is derived from farming, the importance of agriculture to livelihoods at households levels decreases as people seek more opportunities from non-farm activities (Amekawa et al., 2010). Therefore, the production of food by smallholders only forms a portion of their livelihood activities. The smallholder constantly balances on- and off-farm activities to collectively build their livelihood.

\subsubsection{Investments in livelihoods and knowledge: addressing poverty and hunger}

Several interventions have been made to address hunger and poverty with varying successes. In the 1990s, the focus on poverty reduction in developing countries as part of broader development agendas influenced donors to reduce their investments in agriculture to such an extent that between 1990 and 2005, there was a decrease by $45 \%$ in aid spending on ag riculture (Harris \& Orr, 2014). Studies have shown that well-structured investments in agriculture are four times more likely to reduce poverty in comparison to investments in other sectors (FAO, 2008b) 
- provided inequality in incomes is not excessive (FAO, WFP, \& IFAD, 2012). The reduction of poverty is stipulated in the first MDG and has been the foundation and driver for many rural development programs established in sub-Saharan Africa. As Flora (2010) states, the underlying assumption guiding MDG1 was that a reduction in poverty would lead to an increase in purchasing power and hence a decrease in food insecurity.

The other justification for addressing both poverty and hunger concurrently is because they are both a cause and a result of each other (FAO, 2002). Access to food in developing countries is often constrained by both poverty and low agricultural productivity (Amekawa et al., 2010). Development projects which aim to realize the dual win must however be both sustainable and reach the neediest recipients. For example, in cases where severe hunger calls for emergency interventions such as food aid, FAO recommends the use of poverty maps (FAO, 2003) to effectively target and reach the most vulnerable. Succeeding the MDGs is Agenda 2030 of Sustainable Development which stipulates that: food, livelihoods and natural resources management must be addressed collectively; rural development and investments in agriculture are powerful tools to end poverty and hunger; and agriculture has a major role to play in addressing climate change (FAO, 2016).

It is paramount that poverty reduction be combined with increased access to public goods (FAO, 2006) ensuring that the intended outcomes outlive the project's timeline. One aspect that is likely to guarantee the double win of reducing poverty and food insecurity is the focus on livelihoods. In rural areas of SSA where most smallholders reside, livelihood activities are interconnected and requiring collective support. For example, the World Food Program (WFP) runs some projects in Kenya where they provide aid to the neediest by purchasing food from local smallholders who 
are able to grow it within the same or in a neighbouring community. Some of these projects include the 'Purchase for Progress', 'Food for Assets' and the 'Cash for Assets' programs which are aimed at tackling both food insecurity and poverty ${ }^{6}$. At the very least, these programs aim to move beneficiaries from 'food aid' to 'food assistance'. Similarly, poverty and food security interventions must not be disruptive of local arrangements; e.g. in cases where smallholders households barter produce for the provision of services, they should not be compelled to move to a cash-based economy. The respect for and adherence to existing local arrangements is often a challenge for initiators of development projects in their efforts to reduce poverty and food insecurity. Part of the challenge emanates from the move towards globalization and standardized ways of delivering and implementing projects.

When new knowledge emerges and it becomes necessary to integrate it into smallholders' activities, it should conflate rather than be at conflict with existing norms and practices (Eidt, Hickey, \& Curtis, 2012). Previously, the transfer of knowledge and technology, which was dominantly one-way from researchers to the farmers - and often via intermediaries such as extension workers (Kilelu et al., 2011), proved ineffective as it overlooked insights from farmers (Amekawa, 2011). Besides a lack of a collaborative knowledge sharing platform between the researchers and farmers that would leave the latter feeling insignificant, there is the additional element of illiteracy. In 2004, it was estimated that a majority of the 852 undernourished people lived in rural areas as did most of the 860 million illiterate adults in the same period (FAO, 2004).

\footnotetext{
${ }^{6}$ See: Purchase for Progress (P4P) http://www.wfp.org/purchase-progress/kenya, Food for Assets (FFA) and Cash for Assets (CFA) http://www.cgap.org/sites/default/files/eG2P Kenya.pdf.
} 
There is room to further explore how knowledge, education and experience can be leveraged to enhance smallholders' cognition of changing environments lea ding to improved decision-making.

\subsubsection{Smallholders in a globalized world}

The livelihoods of smallholders are often guided by how they identify with their locale (Coles \& Scott, 2009). Increasingly however, the world is shrinking in the context of time and space as more regions of the world embrace the use of different technologies and systematic linkages that allow for the ease of doing trade. These advances in globalization may give rise to additional risks to smallholders who have to negotiate their livelihoods in economic and trade environments that are constantly in a state of flux. For instance, prior to the 1990s, smallholders in Kenya contributed $70 \%$ to the country's horticultural exports but at the end of that decade, their share had dwindled to only $18 \%$ (FAO, 2004). With the spread of globalization, neoliberal policies were adopted (Amekawa, 2011; Caplan, 2009) in many developing countries and have led to the edging out of smallholders forcing them to consider non-agricultural activities in order to support their livelihoods (Amekawa, 2011). In the case of the Kenyan horticultural smallholders, their share of the contribution shrank as flower growing shifted to $42 \%$ in favour of commercial private farms and $40 \%$ to large farms that were leased or owned directly by importers from developed countries (FAO, 2004). In instances where the latter type of farming occurs (foreign owned and leased farms), the host country may be focused more on attracting and retaining investments rather than ensuring food and livelihood security for its population (Tirado et al., 2010). National policies may therefore lean more towards economic growth than food security.

As producers of food for consumption and for trade, smallholders differ from subsistence farmers and often engage with markets in one form of trade or another. The underlying assumption 
would be that since smallholders rely on food produce to sell and support their livelihoods, they have the incentives to produce as much surplus and hence increase their profit margin. However, a study done in Kenya among maize farmers reveals that production levels are influenced more by the known prices of inputs rather than the anticipated and often unknown prices the produce would fetch at the market $(F A O, 2014)$. Further, external linkages to avenues where smallholders can market their produce are often thin and underdeveloped in developing countries (Miruka et al., 2012).

Estimates indicate that in developing countries, $30 \%$ of farmers can be classified as food insecure (Brown \& Funk, 2008). Inherently, smallholding in the developing world can be termed a 'highrisk' activity (FAO, 2008b) given the uncertainties of weather, inputs and markets that plague it. In spite of this, there is need to acknowledge that smallholders are heterogeneous (Lynam \& Twomlow, 2014) in their capacity and attitudes (FAO, 2014), values and interests (Eriksen et al., 2011) towards farming, as well as their preferences, priorities and practices. Their heterogeneity is majorly a factor of their cultural practices and is as well dictated by their environment. These determining factors may also lay ground for resistance to changes in their practices. For instance, some studies across Africa recorded smallholders' adoption rates of new technologies or improved seed varieties varying from $0 \%$ to $80 \%$ (Burke \& Lobell, 2010b). While the wide range of uptake may be as a result of many factors, smallholders' preferences are a major influence in the success or failure of many projects.

Divergent trade-offs, priorities and preferences of farmers are however not unique to developing countries. In a study conducted in southeastern Arizona where there was a water shortage, a couple that owned a ranch chose to reduce their household water consumption so that their 
cattle could have sufficient water (Coles \& Scott, 2009). In developing countries, a smallholder may not have the option of reducing their own consumption thus resorting to disposing off the cattle i.e. distressed liquidation. In either example, it is clear that variations in farmers' incentives, preferences and priorities lead to different choices and outcomes. This calls for a better understanding on what drives farmers, especially smallholders, with an aim of providing suitable motivation that would in turn push them closer to being food secure.

\subsection{Climate change and smallholders}

Climate change in IPCC usage refers to a change in the state of the climate that can be identified (e.g. using statistical tests) by changes in the mean and/or the variability of its properties, and that persists for an extended period, typically decades or longer. It refers

to any change in climate over time, whether due to natural variability or as a result of human activity. (Intergovenmental Panel on Climate Change (IPCC), 2007, p. 30)

Previously, climate change was considered a scientific event, largely ignoring implications on human systems (Denton, 2002). Although social scientists caught on to the topic several decades after their natural sciences counterparts (Terry, 2009), the urgent need to protect societies and economies from the impacts of climate change were well articulated in the widely circulated Stern Review (Ceccato, Giannini, \& Giupponi, 2011). Some scholars deem the focus on climate change impacts on socio-economic environments as more important than changes in the biophysical environment (Granderson, 2014; Schmidhuber \& Tubiello, 2007). This emphasis may however be ranked lower by for example poor people who face more pressing stressors (Terry, 2009). Thus, the study of vulnerability of societies to the impacts of climate change have gained traction and been explored extensively in literature. It is acknowledged that even within groups, 
levels of vulnerability can vary as dictated by factors such as age, gender and power (Djoudi, Brockhaus, \& Locatelli, 2013). As a result, the framing of 'adaptation to climate change' has been critiqued since it seemingly distances how risk is generated and diverts attention from the causes of vulnerability (Ribot, 2011).

\subsubsection{Linking concepts in climate change}

Formally, the term 'adaptation' was used by anthropologists in the context of environmental variability but its usage in the 1990s evolved to encompass how humans respond to climate change (Engle, 2011; Janssen \& Ostrom, 2006). While advocating for thorough causal analysis on climate change and its effects on humans, Ribot (2011) submits that vulnerability and adaptation are linked by 'risk' where the former causes it and the latter responds to it. Nevertheless, some adaptation actions can also increase risk and give rise to unintended consequences e.g. when humans adapt but at the cost of biodiversity loss (Eriksen et al., 2011) or environmental degradation (Gregory, Ingram, \& Brklacich, 2005).

In reference to socio-ecological systems, the term 'vulnerability' is often cast in a negative tone referring to the system's susceptibility while 'resilience' is defined as the ability to absorb disturbance and changes with the capacity to self-organize (Adger, 2006). Originally, the term vulnerability was coined from studies on poverty and occurrence of natural hazards (Janssen \& Ostrom, 2006). However, different systems and the components within them interact to cumulatively determine vulnerability, e.g. the interaction between livelihoods and existing agricultural policy (Adger, 2006). Knowledge on these interactions is key to informing stronger policies which can in turn support better responses to climate change (Deressa et al., 2009). 
According to Engle (2011) and Folke (2006), an additional link between vulnerability and resilience is brokered by 'adaptability' or 'adaptive capacity', which is framed positively as the ability of a system to prepare in advance or to respond to effects caused by changes and stresses. Primarily, adaptive capacity can be influenced (Marshall, 2010) and is often determined by dominant development indicators such as literacy levels, income, and even quality of institutions (Fankhauser \& Schmidt-Traub, 2011). Consequently, adaptive capacity is often measured at national levels often obscuring the disparities that occur at local levels (Iglesias, Quiroga, \& Diz, 2011). A different view (Pelling et al., 2008) suggests that there is potential in enabling proactive adaptation if measurements of adaptive capacity focuses on process rather than output. This approach would be better suited since different levels of decision-making are necessary for improved livelihoods.

\subsubsection{Sensitivity to climate change and related effects}

The more a household relies on agriculture for their livelihood, the higher their sensitivity to climate change since it is expected to have a significant impact on the sector (Burke \& Lobell, 2010a). Since agriculture in many parts of sub-Saharan Africa still relies on rainfall seasons, the smallholders' activities are as well determined by the rainfall calendar. They are thus more susceptible to climate variations and change. Overall, agricultural production, without farm-level or institutional adaptation, is expected to decline by $9-21 \%$ by 2050 in developing world regions as a result of climate change (Misselhorn et al., 2012) - where the range is occasioned by the different climate change scenarios. However, as Molua (2011) points out, adaptation measures at the farm level in response to perceived or experienced changes can reduce the variability in yields. Some smallholders may be able to adapt to climate change for example by shifting to crops 
that perform relatively well under an altered climate. Farming systems and local consumer preferences are highly linked (Burke \& Lobell, 2010b). Therefore, switching to new crops may occasion a shift in cultural consumption preferences (Brown \& Funk, 2008). If they are able to trade these new food crops for their preferred choices, their level of integration with non-local markets remains key.

In sub-Saharan Africa, market access is said to be the least structured among developing regions which has significant implications for smallholder farmers (FAO, 2008b). Besides, climate change may affect the other regions and depending on how integrated the smallholder's local market is to regional and international ones, spikes in prices for their preferred food cannot be ruled out (Burke \& Lobell, 2010a). Although the instability in food prices may be short-term, these shocks have the ability to render smallholder farmers more vulnerable to long-term poverty traps (FAO, 2011). This is a possible scenario since it is difficult in the absence of safety nets such as insurance for smallholders to weather volatility in food prices (Misselhorn et al., 2012). It poses a challenge especially in the rural areas in developing countries where the poor often spend between $60-80 \%$ of their total income on food (Pinstrup-Andersen \& Watson II, 2011). The case is different in developed countries where farmers rarely go hungry since besides having well-structured safety nets, only a small fraction - as low as $10 \%$ - of income goes into food purchases (Burke \& Lobell, 2010b; Pinstrup-Andersen \& Watson II, 2011).

\subsubsection{Smallholders and perceptions of risk and vulnerability}

It is established that changes in agricultural production from year to year or season to season are more as a result of climate variability (Kang, Khan, \& Ma, 2009) rather than climate change. However, based on their experiences, farmers tend to remember what is important to them 
(Nelson \& Stathers, 2009), thus increasing the likelihood that farmers in a single region may recall different climate patterns. Further, it is not uncommon to observe "confirmation bias" among smallholders causing them to process information selectively in order to strengthen and validate their beliefs (Pahl-Wostl, 2007). Therefore, perceptions on changing climates and the associated risks are more likely to shape a farmer's behaviour than actual scientific measurements (Bryan et al., 2013). Likewise, it would be valid to observe that "people judge risks differently based on their perception of being able to influence risks" (Pahl-Wostl, 2007, p. 563).

As revealed in a study by Lata and Nunn (2012), the gap between perceived and actual risk can be a hindrance to adopting sustainable adaptation practices. For instance, a study by Patt and Schröter (2008) among farmers in Mozambique living close to a floodplain concluded that a resettlement project designed by the government failed since the people's risk perception was different. As Patt and Schröter (2008) suggest, the people's desires were not factored into the program design and perhaps their perception was that the risk of leaving was higher than that of remaining in the floodplain. For climate change adaptation strategies to succeed and remain sustainable, divergent views and power differences must be accommodated (Rodima-Taylor, Olwig, \& Chhetri, 2012). In this example, it is also possible that the people were being defiant to authority and resisting change that was externally required of them by an agency that wielded more power.

\subsubsection{Climate change and behaviour modification}

In sub-Saharan Africa, many smallholders rely on rainfall for agricultural production. The variability of available rainfall from one season to the next increases their vulnerability, more so if they are experiencing poverty - and will as a result seek ways to avoid risk (Vermeulen et al., 
2012). As a risk reducing strategy, many smallholders diversify their livelihoods by engaging in income-generating activities - a risk-aversion behavior that is reinforced when uncertainties caused by climate change arise (Molua, 2011; Morton, 2007).

Over time, farmers have made changes to their farming practices to suit changing weather patterns. The science linking these modifications as responses to actual climate change is still weak (Burke \& Lobell, 2010b). According to Coles \& Scott (2009), it is clear however that while shorter term changes in the climate may affect production, in the long run, the effects are on the smallholder's livelihood. Responses to the shorter term changes are often referred to as 'coping' while those on the longer term as 'adaptation' (Osbahr et al., 2008). It is purported by Tschakert (2013) that those who employ coping strategies expect things to return to normalcy or at least a previous state. While the timing (or stimulus) of adaptation strategies determines whether they are anticipatory or reactive, an assessment of the degree to which they are spontaneous (or intentional) can divulge whether those strategies are planned or autonomous (Smit \& Wandel, 2006).

Climate change undermines the ability to modify future behaviour as a response to anticipated changes based on lessons gained from past experiences (Engle, 2011). In addition, Moser and Ekstrom (2010) mention other barriers to climate change adaptation lie in leadership, resources, communication and information, as well as in values and beliefs. Further, because climate change occurs globally and its effects stretch into posterity, suitable responses not only need to span both spatial and temporal scales (Eriksen et al., 2011) but should also be built into existing sector strategies (Fankhauser \& Schmidt-Traub, 2011) and capitalize on synergies. Since climate change effects become clearly evident after a longer time period (often retrospectively), such knowledge 
may encourage behaviour that focuses only on shorter-term goals and needs especially among rural dwellers (Lata \& Nunn, 2012). Additionally, according to Mitchell and Tanner (2008) more effort is needed to look into the intergenerational transfer of poverty and vulnerability to climate change. By using a multi-scalar approach to addressing climate change, the fallacy-of assuming that targeting one scale causes automatic and positive spillover effects into the next one (Gregory, Ingram, \& Brklacich, 2005) - is likely to be avoided. Indeed, Pelling et al., (2008) caution that spillover effects of adaptation on one scale, both spatial and temporal, can constrain the adaptive capacity of other scales.

\subsection{Smallholders and institutions}

The relationship between smallholders and organizations has been explored widely. Organizations are defined as "structural entities of group, agency, and association, operating at different levels with varying degrees of autonomy and scope of authority" (Amekawa, 2011, p. 135). However, their engagement with informal institutions and social networks among them is highly underdeveloped in scholarly literature. Institutions ${ }^{7}$, both formal and informal, can improve food security outcomes by creating an enabling environment for smallholders. This enabling environment must be structured around four dimensions: (i) policy, programmes and legal frameworks, (ii) mobilizing human and financial resources, (iii) partnerships and coordination mechanisms, and (iv) evidence-based decision making (FAO, IFAD, \& WFP, 2014). This section starts with an exploration on what is known in this topic and the potential for existing

\footnotetext{
7 The rest of the thesis will identify organizations as 'formal institutions' while 'informal institutions' or 'social networks' will depict local arrangements of association among smallholder farmers.
} 
social institutions to better support smallholders in meeting their food security needs as they accomplish other livelihood targets.

\subsubsection{Informal institutions and social networks among smallholders}

Smallholders live in communities within which several familial and social ties exist. These serve as the basis for informal social institutions at local levels. Besides serving as a feature of a common cultural identity, these social linkages also offer central organizing principles (Allen et al., 2012; Never, 2011). In reciprocal fashion, "informal institutions give shape to, whilst being reproduced by, repeated rounds of customary behaviour" (Pelling et al., 2008, p. 869).

Social networks play an important role in increasing smallholders' decision-making capacity and should therefore be targeted when strengthening policies that address climate change (AcostaMichlik \& Espaldon, 2008; Burke \& Lobell, 2010b; Sietz, Lüdeke, \& Walther, 2011). In the adoption of agricultural technology, Deressa et al. (2009) state that social networks can act as conduits for finances and information, and offer cooperation to address common challenges. Social groups among farmers offer solidarity (Laube, Schraven, \& Awo, 2012) and are an effective medium through which innovative agricultural techniques can be conveyed (Eidt, Hickey, \& Curtis, 2012) as well as sharing risk and offering reciprocity especially during periods of crisis (Eriksen et al., 2011; Osbahr et al., 2008; Trærup, 2012).

\subsubsection{Social networks and climate change}

Although climate change can also weaken social networks (Trærup, 2012) or expose existing institutional weaknesses (Mitchell \& Tanner, 2008), literature has increasingly asserted that social institutions play a central role in contributing towards climate change adaptation (Engle, 2011; Granderson, 2014). However, institutions can also inhibit successful adaptation responses 
(Amaru \& Chhetri, 2013; Engle \& Lemos, 2010) since they are also deemed to be inherently conservative (Gupta et al., 2010). As suggested by Gupta et al. (2010), it is necessary for institutions to constantly take advantage of and incorporate new information related to current and projected climate change while remaining proactive if their efforts are to bear fruit.

While climate change effects are cross-sectoral (Lata \& Nunn, 2012), smallholders in developing countries also face greater challenges from climate change since institutional capacity in those regions is deficient (Adger, 2006). The lack of knowledge integration across different institutions (Eidt, Hickey, \& Curtis, 2012), ranging from interactions at global to local levels, can hamper the progress of smallholders. Likewise, indigenous knowledge is important (Gregory, Ingram, \& Brklacich, 2005) and the inclusion of this local knowledge based on experience (Eriksen et al., 2011) can impart new skills (Osbahr et al., 2008) and sustain institutional measures geared towards climate change adaptation.

\subsubsection{Social networks and governance}

Weak social networks give rise to lower cohesion (Buechler, 2009), especially in cases where vulnerabilities exist since smallholders have to navigate several layers to access power and resources and are often left out of decision-making processes (Adger, 2006) ${ }^{8}$. With this recognition, however, it is key to note that being able to speak out about their issues does not ensure that smallholders have contributed towards decision-making.

\footnotetext{
${ }^{8}$ Marginalization among farmers is not unique to sub-Saharan Africa. Coles and Scott (2009) provide an example of Hispanic farmers in southeastern Arizona who experienced challenges accessing the assistance they required.
} 
At local levels, it is not uncommon to have a problem in the design of programs where actors operating at different scales are disconnected (Amaru \& Chhetri, 2013). Agency ${ }^{9}$ needs to exist allowing for full participation and interaction with differing powers, norms and knowledge (Brown, 2011). Framing this in a stronger context, Robinson and Berkes (2011) state that where new challenges emerge requiring adaptation, it is unlikely that any one party will have all the necessary information. This therefore calls for a 'deliberation' (which is more conducive for learning) rather than mere 'participation', as a necessity for the co-production of knowledge, which can begin by seeking consensus on defining and understanding what the challenge is (Robinson \& Berkes, 2011).

The top-down models of passing information from government agencies to communities have often proved ineffective and the would-be beneficiaries unresponsive (Lata \& Nunn, 2012). As an option, an inclusive platform can be modelled from cases where government extension services are replaced by more 'locally responsive information systems' allowing farmers to factor in their priorities (Challinor et al., 2007, p. 391). For Munang and Nkem (2011), such a platform should be a radical departure from top-down approaches to a more 'democratic' space whereas Pelling et al., (2008) call for 'reflexive governance' where all actors have equal opportunities to influence collective decisions.

Informal networks have also been known to influence their members' relationships with formal organizations such as insurance providers (Trærup, 2012). Members of informal networks have

\footnotetext{
${ }^{9}$ For an in-depth report on human agency and environmental systems, see (Biermann et al., 2009)
} 
a sense of trust within their social groups. It is therefore apparent that building trust and legitimacy has the potential to improve adaptation to climate change (Huntjens et al., 2012).

\subsection{Summary and way forward}

In summary, food insecurity is declining but the rates are neither even nor consistent globally. Shifting global patterns, mainly dietary convergence and adaptation, are changing the dynamics of food (in)security. In developed countries where food availability and access are not a challenge, cases of food safety, malnutrition in the form of obesity, plus diet and lifestyle related

diseases are on the rise. In developing countries, food access and availability for all remain a concern but the challenge is compounded by diet related diseases such as diabetes. From either observation, it is apparent that the dimension on utilization merits greater attention.

This background review reveals that existing scholarship largely does not emphasize that smallholders' approach to food security is tied to their livelihood security. The smallholder is more concerned about meeting their livelihood needs from what they produce rather than having the appropriate and recommended number of calories per day so as to be deemed food secure. With the constant states of flux in economies, climate and population dynamics, the food security dimension of stability is still elusive at global and regional levels. For the household and the individual level, the element of stability merits deeper discussion and will be explored in subsequent chapters.

Smallholders in developing regions such as sub-Saharan Africa require an enabling environment to realize and maximize on their full potential. If this is provided, the households and region would make progressive strides towards sustainable food security and improve their quality of 
life. Such an environment should provide for improved decision-making by smallholders with special consideration of their food production as a means for sustaining their livelihoods.

Where climate change concerns emerge, a discussion on risks and uncertainty is warranted. For many smallholders, however, encounters with uncertainties and risks occur daily and they are constantly negotiating and adjusting their activities to mitigate or cope with them. Examples of these include: whether the seeds they plant in a particular season will do well; if the pesticides and fertilizers they acquired are of high quality and will perform as expected; on market timing to get proper prices, credible buyers and good sales for their produce; on harvests being sufficient to convert to money for exchange to meet livelihood expenses, and so on.

Lastly, sustained political commitment by governments is a prerequisite in the fight against hunger (FAO, IFAD, \& WFP, 2014). While this calls for improvements in higher-level governance structures in formal institutions, there is a need to reassess local institutional arrangements. These arrangements are key to advancing gains in food security especially among smallholder farmers. 


\section{Chapter 3. Theoretical underpinnings and development of the research}

\section{framework}

Political and institutional influences may limit a household's livelihood security (Foran et al., 2014). The strengths of political ecology (PE) in unmasking such influences can be employed with the aim of improving livelihood security. The first section of this chapter will focus on concepts developed through PE that can support this research and improve our understanding of livelihoods and how they are negotiated at household and broader levels. In the second section, the research approach and rationale is provided. The third section provides the context of the research setting, participants and ethical considerations. The last section explains how the data analysis was carried out as well as how the results will be presented in the rest of the chapters to come.

\subsection{Insights from political ecology}

The term 'political ecology' was coined in the 1970s in recognition of how environmental issues such as soil degradation had become highly politicized (Neumann, 2005). The term gained momentum when calls for changes of unsustainable ways of life were linked to concerns on posterity's wellbeing (Atkinson, 1991). Political ecology is thus influenced by the broader field of political economy, especially related to agriculture and environmental degradation (Foran et al., 2014). Studies of political economy "focus on the relationship between individual and group preferences, with scale and level issues at its core" (Gibson, Ostrom, \& Ahn, 2000, p. 233). In order to implement changes at different levels (e.g. reduction in soil degradation), there is a need to acknowledge spatial heterogeneity, variability and non-linear causation (Neumann, 2005). However, such challenges cannot be addressed in isolation of the contexts in which they occurred 
(Bryant \& Bailey, 1997). In recognition of negative influences that limit livelihoods, a first step of inclusivity would be to identify marginalized households and develop ways to engage them. A significant second step is to recognize that the empowerment of such households is a process rather than a product (Brown, 2011). This calls for a better understanding of underlying factors including household-level risks (such as switching to new farming technologies and changing farming environments), social identities and perceptions.

\subsubsection{Social identities influence perceptions of risk and vulnerability}

"Social identity refers to an individual's knowledge or sense of belonging...[It] is considered both an aspect of self and social perception as well as an influence on risk perception, perception of information and perception of self-efficacy" (Frank, Eakin, \& López-Carr, 2011, p. 67).

Risk must therefore be assessed beyond physical threats and consider how people understand themselves and the world around them. This implies that perceptions of risk vary, necessitating a case by case basis assessment (Dwyer \& Minnegal, 2006). Additionally, risks can lead to potential benefits as well as cause detrimental outcomes. Lessons from an agroforestry promotion project indicated that poor farmers are more concerned with providing food for their families and knowingly forgo taking risks of venturing into new farming technologies that might have potential benefits (Meijer et al., 2014). Such risks are more likely to be taken up by 'opportunity seekers' who may be enjoying higher levels of food security (Meijer et al., 2014). In

the absence of options such as insurance that reduce negative outcomes, people opt for riskaverse actions which may hinder benefits such as those that would be gained from agricultural diversification (FAO, 2008b, 2011). Risk-aversion is also observed when people have a low 
capacity to cope with significant changes such as spikes in input prices (FAO, IFAD, \& WFP, 2013). However, attitudes are transient, therefore views towards risk do change (Alwang, Siegel, \& Jørgensen, 2001).

Environmental issues and risk are both socially constructed and culturally influenced (Lutes, 1998). Similarly, cultural experiences in combination with historical experiences shape responses to perceived or experienced risk (Forsyth, 2003). 'Cognitive bias' occurs when individuals do not alter their behaviour when they encounter change (Burke \& Lobell, 2010b). For instance, smallholders may not be aware that changes in their environment are due to phenomena such as climate change. They may therefore continue with their old practices as a response to (or irrespective of) the changes. This underscores the importance of unmasking the social dimensions of climate change with the equal weight that scientific analysis enjoys (Granderson, 2014). Analogously, people have been known to portray 'confirmation biases' and selectively seek and process information that is in line with their beliefs (Pahl-Wostl, 2007), further solidifying their perceptions.

Political ecology scholarship is cognizant of the unequal distribution of costs and benefits between weaker and stronger (or wealthier and more powerful) actors - with the former bearing more burdens and the latter reaping greater benefits (Bryant \& Bailey, 1997). Often fueled by self-interest, stronger actors deliberately control the distribution of power leading to increased vulnerability among weaker actors (Adger, 2006). Meaningful progress in addressing these power inequalities can only be achieved by first acknowledging that they exist. 


\subsubsection{Decision-making under conditions of uncertainty}

A broader framing of political ecology "replaces assumptions of equilibrium, predictability and permanence with instability, disequilibrium, chaotic fluctuations and dynamism" (Neumann, 2005 , p. 63). These latter conditions are dominant in the agricultural context through which farmers negotiate their livelihoods. In brief, political ecology allows for the examination of systems that are constantly in a state of flux thus returning to a state of equilibrium would not be possible (Neumann, 2005). These changes and a lack of permanence give rise to levels of uncertainty, thus warranting an examination of how decisions are made under such conditions. A person who is uncertain expresses a lack of confidence on the level of knowledge they possess about a particular issue (Sigel, Klauer, \& Pahl-Wostl, 2010). Risk is applicable when actors are able to assess the likelihood of certain events occurring but "uncertainty applies to contexts in which no such assessment is possible." (Dwyer \& Minnegal, 2006, p. 2).

Assumptions exist on how responses to uncertainty vary. For instance, attempts to address uncertainty in their livelihoods may see farmers at local levels use coping mechanisms that are viewed as reactionary. On the contrary, higher-level institutions appear to practice anticipatory approaches (Osbahr et al., 2008) and plan a priori on how to address external threats. This assumption provides an avenue through which institutions (both formal and informal) can directly influence decisions at the community and household level that buffer livelihoods and increase the potential for food security.

In summary, the basics of decision-making rely on four main factors. First is the trigger or motivation for making the decision. Second is the expected outcome(s) from the decision that is to be made. The third factor is the available information and its related attributes of accessibility 
and accuracy. Lastly, the decision-maker must consider the trade-offs which are often dynamic and change with time. These factors will emerge in later chapters as the analysis of smallholders' responses is presented.

\subsubsection{Examining complexities and interactions across scale}

Events that occur in one place may have far reaching effects in another. Sociologists have made calls that emphasize the contextual understanding of place-based events, e.g. soil erosion, before considering non-place based factors (Neumann, 2005). Thus, while external factors elsewhere can affect local conditions, a deeper assessment of the current situation in the locale of interest remains a prerequisite. Political ecology facilitates the understanding of local activities driven by non-place based forces (Bryant, 2001).

Issues related to food security and climate change span multiple temporal and spatial scales. For example, climate change is driven by global factors and yet its effects are highly localized. In similar vein, the food security of smallholder farmers is affected by (and also affects) external factors. However, their local conditions must be fully understood prior to drawing linkages and examining interactions with external factors that can act as either drivers or inhibitors of food security.

\subsection{Research framework}

"Food offers a useful insight into the world economy and politics because it is central both to accumulation of capital, and to livelihood and community" (Friedmann, 1998, p. 87)

Food security is central in both anchoring livelihoods of producers as well as supporting economies reliant on agricultural productivity. This section links the intellectual roots disc ussed above and offers a research approach used to contextually examine food security among 
smallholder farmers. Previous discussions demonstrated that the production and consumption of food does not occur in a vacuum. Several factors need to be considered if the challenges of food insecurity among smallholder farmers are to be sufficiently addressed. These include:

a) Appreciating that social identities play a significant role in how risk is perceived and responded to;

b) Understanding the decision-making processes especially, under conditions of uncertainty; and

c) Recognizing that complexities across temporal and spatial scale exist and that inherent trade-offs must be considered.

Taken in combination, these factors highlight the complex environments under which smallholder farmers negotiate their livelihoods. At the farm level, smallholders do not treat the uncertainties arising from climate change any differently from those arising from other factors such as fluctuating input prices. The above considerations, tog ether with the background laid in Chapter 2, offer a foundation for this research and inform the approach adopted.

\section{Research problem and questions}

As presented in the background in Chapter 2, food security is a major concern in sub-Saharan Africa and features more prominently among smallholder farmers. Smallholders must surmount numerous challenges to ensure their own food security as well as provide surpluses that they can sell to meet their livelihood needs. Many of the obstacles faced by smallholders are driven by external forces that increase risks of food insecurity due to underlying vulnerabilities. Climate change is said to exacerbate these complex dynamics. However, smallholders do not live in isolation, but rather, in communities. As such, they have engaged in various institutional 
interactions to meet their food security and livelihood needs. A deeper understanding of these challenges merits a case study on smallholders. On this basis, the overarching research question is formulated as follows:

Are the existing institutional support arrangements sufficient to strengthen food security among Mt. Kenya's smallholders in view of climate change threats?

The following research sub-questions have been formulated in order to address the question above:

1. What are the existing food security concerns among Mt. Kenya's smallholder farmers?

2. What are the existing climate variability and change concerns among Mt. Kenya's smallholder farmers?

3. How do institutional arrangements in the region support the farmers to bolster food security?

The above sub-questions served as boundaries to the research thus necessitating a suitable approach to guide meaningful data collection, analysis of the problem in context as well as synthesis for broader implications. Answering each of the sub-questions, was intended to create building blocks that would produce a response to the overarching question.

\section{Research approach and rationale}

This research is firmly anchored in the broader fields of food security and climate dynamics (variability and change). It probes the perceptions and experiences of food security concerns at the household level. The research is guided by the food security dimensions of availability, 
access, utilization and stability. A household unit ${ }^{10}$ in this research is defined as the group of individuals, either living within the same homestead or outside of it, but whose primary food and other livelihood needs are met from the unit's farm and off-farm resources. Gains in agriculture are positively correlated to high levels of social capital (Trærup, 2012). Therefore, this research seeks to understand how various forms of social capital through institutional arrangements influence a household's livelihood and food security. The discussions on climate dynamics will be guided by the concepts of uncertainty, risk and vulnerability as framed by political ecology.

\subsection{Research setting and context}

In this section, the research area is described as well as an overview of the research contributors and how they were engaged is presented.

\subsubsection{Operating principles and ethical considerations}

Five principles that guided this research are discussed in the section below along with highlights on ethical considerations.

Reciprocity: While engaging with the various research contributors, maintaining the dual role of both a researcher and a learner was necessary. As a researcher, I shared my research knowledge and experience in order to enrich the contributors' understanding of broader contexts of the research topic. As a learner, the role mandated listening openly and objectively to contributors'

\footnotetext{
${ }^{10}$ While there is not a universal definition of a 'household unit', the reality of sub-Saharan Africa is that households are often comprised of dispersed individuals who engage in diverse livelihood activities. This approach for framing a household unit places as much emphasis on the dynamic network of peoples, often in multiple communities. Nevertheless, there is often an identifiable node that links the members. In this research, the focus is on the farm as the identifiable node. For broader discussions on the 'household as a unit', see Ellis (1998) and Watts (1989).
} 
contributions and asking questions for purposes of clarification rather than challenging viewpoints.

Transparency: Interactions with contributors were transparent. From the onset, I explained the purpose and expectations of the research as well as the potential gains we all stood to realize from participating in the study. In no instance were 'trick questions' or misleading information given to the contributors for benefit of the research.

Confidentiality: The research guaranteed that the responses provided by the contributors would not be shared in a manner that would identify them. Whereas in cases of focus group discussions some of the contributors knew each other given that they were drawn from neighboring regions, the research did not require their responses to self-identify for purposes of distinguishing individuals.

Sensitivity: The research remained sensitive to the needs and commitment of the contributors. For instance, care was taken to avoid extensive discussion sessions or lengthy interviews. Further, the research was conducted during a season when the farmers were less busy on the farms thus incurring minimal interruptions to their daily workload. Additionally, during focus group discussions (FGDs), response mediation was important to ensure that each of the contributors had an equal opportunity to offer their inputs.

Compliance: Prior to the recruitment of research contributors in 2013 , the research adhered to the required compliance guidelines set by Carleton University's Research Ethics Board (CUREB) as well as those stipulated by the Government of Kenya. In both instances, application for the research permits was successful. In the case of CUREB, annual reviews of the research permit have been successfully submitted over the last two years. As such, the research has maintained 
the required levels of compliance that complement the guiding research principles described above. Examples of compliance include, the signing of consent forms with research contributors (see Appendices B.3 and B.4), the adherence to confidentiality by coding participants' information and storage of digital records in password-secure devices.

\subsubsection{Embu, Mt. Kenya region: description and justification for suit ability}

A brief history on settlement and the rural development in the study region can be traced to the colonial period. ${ }^{11}$ During Britain's colonial rule in Kenya between 1895 and 1963, the best agricultural lands, White Highlands, were earmarked for European settlement (Soja, 1968) while Africans were confined to overpopulated reserves (Ogutu, 1993). There was resistance from the indigenous population giving rise to the Mau Mau Emergency. At the height of the Emergency in 1954, the Swynnerton Plan was launched - "A plan to intensify the development of African agriculture in Kenya". This was however focused on the cash crop producing areas of the country (Soja, 1968), mainly the highlands, and further secluded the arid region whose potential for agriculture was deemed low.

Kenya's history of land resettlement is not unique; as in other colonies, land allocation under the colonial period favoured European settlers in regions that were "not in beneficial occupation" or not "effectively occupied" as stipulated under the British Crown Lands Ordinance of 1902 (De Blij, 1964; Ogutu, 1993; Soja, 1968). Under this ordinance, European settlers could secure grants to own 640 acres of land. The Swynnerton plan was used as an economic and political tool to control the land that belonged to Africans. Its objectives were two prong; to replace the African land

\footnotetext{
11 In this section, a few highlights of post-colonial Kenya that influence smallholder farming are summarised. The aim here is to provide the reader with context that will assist with interpreting results from this research. See Thurston (1987) and Alila (1977) for a more substantive history on pre- and post-colonial agricultural policy in Kenya.
} 
rights structure with an Anglo-Saxon and to consolidate scattered parcels of land into larger ones for better husbandry (Githinji \& Cullenberg, 2003). There is strong evidence that this selection of the best agricultural lands by the Europeans led to the confinement of indigenous people to areas that were less desirable and because of high population densities, there was increased erosion and declining food yields (Ogutu, 1993; Slater, 1973). These dynamics led to the outmigration or resettlement in other regions such as Embu that lay outside the White Highlands and the established African reserves.

After Kenya gained its independence in 1963, the government put in place several policies to stimulate agricultural growth and increase smallholder farmers' productivity. This included carrying out land reforms, providing agricultural extension services and availing funding for research (Freidberg \& Goldstein, 2011). Between 1964 and 1972, Kenya's first president instituted land reforms that distributed over 400,000 hectares to smallholder farmers from large farms that had previously been owned by white settlers. This led to a growth in market agricultural output by $6.4 \%$ (Githinji \& Cullenberg, 2003). After independence, Kenya was divided into eight provinces. Embu was established as the administrative capital for Eastern Province and was a hub for processing agricultural commodities such as tobacco and coffee (Maxon \& Ofcansky, 2000).

Presently, Kenya is divided into 47 counties, which were enacted in the new constitution promulgated in 2010. Previously, the 8 provinces, which were the largest administrative units, comprised of districts that were further sub-divided into divisions. After the new constitution, districts were merged to create the new counties, which effectively saw some provinces divided into several counties. Additionally, the divisions were reorganized to form sub-counties, which 
then form the counties. For example, Embu County has 5 sub-counties and 11 divisions. The county system of governance and administrative boundaries only came into effect after the 2013 general elections. The field work supporting this research occurred during the early days of this administrative transition and the delivery of agricultural support was also in flux.

Besides other attributes, e.g. administrative and socio-economic, regions can be defined by climatic attributes into agro-ecological zones (AEZs). According to Jaetzold, Schmidt, Hornetz, \& Shisanya (2006), agro-ecological zones (AEZs) are established based on a combination of temperature, precipitation, evaporation and suitability for the growth of Kenya's main crops. Kenya is divided into seven main AEZs based on the annual mean temperatures (Jaetzold et al., 2006) as shown in Table 3.1 below.

Table 3.1: The main agro-ecological zones (AEZs) in Kenya

\begin{tabular}{llllllll}
\hline & TA & UH & LH & UM & LM & L/IL & CL \\
Tropical & Upper \\
Alpine & Highland & Lower & Highland & $\begin{array}{l}\text { Upper } \\
\text { Midland }\end{array}$ & $\begin{array}{l}\text { Lower } \\
\text { Midland }\end{array}$ & $\begin{array}{l}\text { Lowland/ } \\
\text { Inner } \\
\text { Lowland }\end{array}$ & $\begin{array}{l}\text { Coastal } \\
\text { Lowland }\end{array}$ \\
$\begin{array}{l}\text { Annual Mean } \\
\left.\text { Temp ( }{ }^{\circ} \mathrm{C}\right)\end{array}$ & $2-10$ & $10-15$ & $15-18$ & $18-21$ & $21-24$ & $>24$ & $>24$ \\
\hline
\end{tabular}

Source: Jaetzold et al. (2006)

Further, as shown in Table 3.2, there are seven belts based on moisture index and annual rainfall that span the main zones.

Table 3.2: The seven moisture belts that span the main zones

\begin{tabular}{|c|c|c|c|c|c|c|c|}
\hline Attribute & $\begin{array}{c}1 \\
\text { Humid }\end{array}$ & $\begin{array}{c}2 \\
\text { Sub-humid }\end{array}$ & $\begin{array}{c}3 \\
\text { Semi- } \\
\text { humid }\end{array}$ & $\begin{array}{c}4 \\
\text { Transitio } \\
\text { nal }\end{array}$ & $\begin{array}{c}5 \\
\text { Semi-Arid }\end{array}$ & $\begin{array}{c}6 \\
\text { Arid }\end{array}$ & $\begin{array}{c}7 \\
\text { Perarid }\end{array}$ \\
\hline Potential & \multicolumn{3}{|c|}{ High to Medium } & \multicolumn{4}{|c|}{ Marginal to Low } \\
\hline Land area (\%) & & 12 & & 5 & 15 & 22 & 46 \\
\hline Moisture index (\%) & $>80$ & $65-80$ & $50-65$ & $40-50$ & $25-40$ & $15-25$ & $<15$ \\
\hline Annual rain (mm) & $1100-2700$ & $1000-1600$ & $800-1400$ & $600-1100$ & $450-900$ & $300-550$ & $150-350$ \\
\hline
\end{tabular}

Source: Jaetzold et al. (2006) 
The research was conducted in Embu County, which lies on the South Eastern side of Mount Kenya. The county's North Western apex starts at the tip of Mt. Kenya spreading outwards and downwards to the lower regions. The study area from which the research contributors were drawn was in the Upper Midland zone and included belts 1 through 4 (humid, sub-humid, semihumid and transitional).

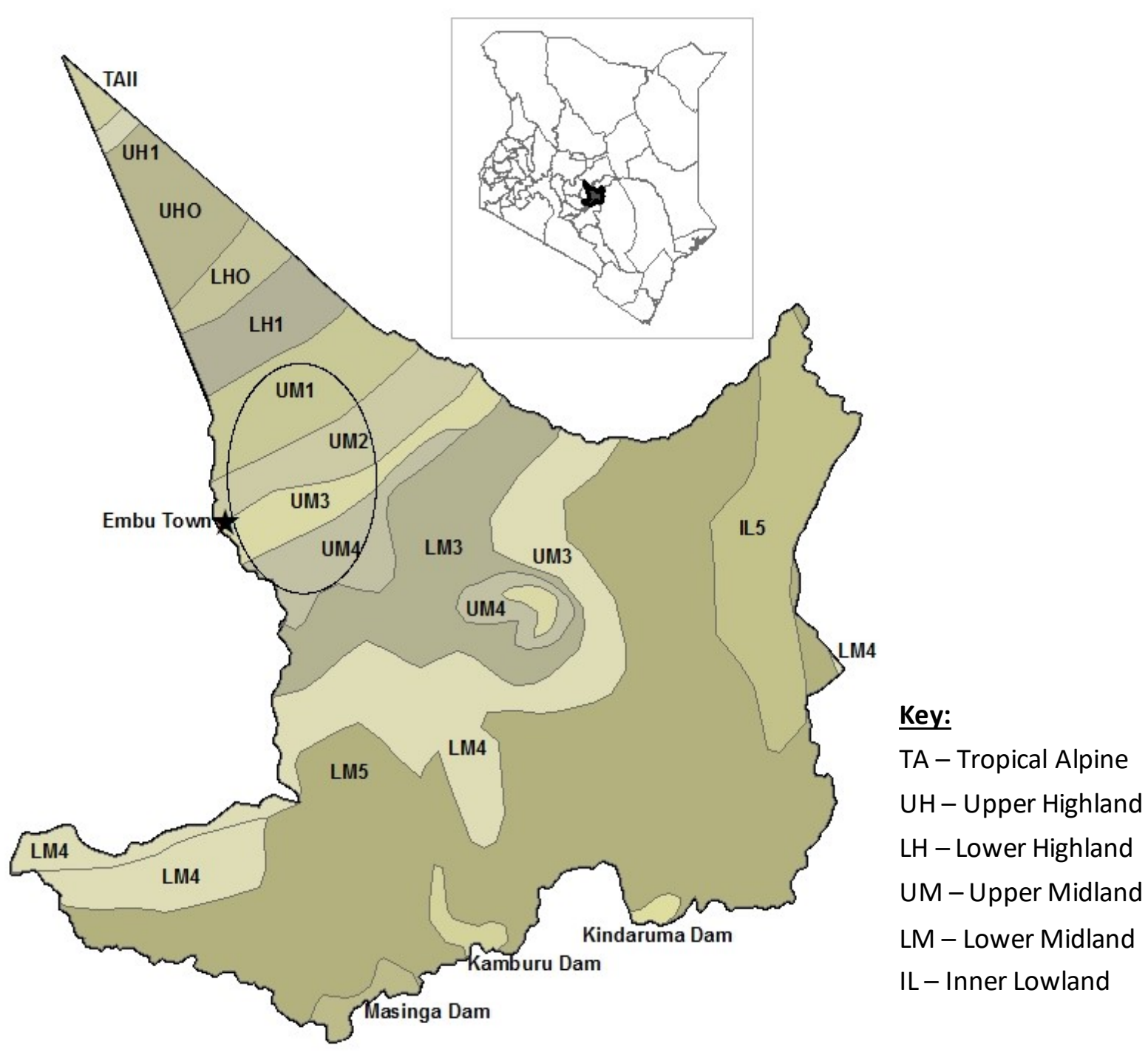

Figure 3.1: AEZs in Embu County with ellipse showing catchment region of smallholders in the study. Numbers indicate respective moisture belt. Inset: Map of Kenya with Embu County highlighted.

Created with ArcGIS using Kenya administrative base map from http://www.diva-qis.org/ and AEZ base map on temperature and crop suitability by the International Livestock Research Institute (ILRI) GIS services 
This research region is demarcated by the ellipse in Figure 3.1, which bears the map of Embu County with the different AEZs indicated. Within the catchment area defined by the ellipse, participants' farms lay at altitudes that roughly ranged from between 1250-1770 meters above sea level. The Upper Midland zone allows for the practice of mixed farming. While the length of the growing period may vary slightly, the catchment area has a bimodal pattern of rainfall. The long rain season is between the months of March, April and May (MAM), while the short rains fall between October and December (OND). These prevailing ranges of temperatures and rainfall pattern are conducive for farmers in the region to engage in both livestock and crop farming.

\subsubsection{Engaging research contributors}

The research engaged fifty research contributors, $80 \%$ of whom were smallholder farmers (20 men and 20 women) drawn from the region described above. Guided by the research question, the smallholders were selected on the basis of their exposure to working with both formal and informal institutions. The smallholders were drawn from several villages within the catchment area shown in Figure 3.1 above, which include Gatondo, Iveche, Githimu, Kairuri, Kamiu, Kangaru, Kimangaru, Manyatta, Njukiri and Nthambo among others. An additional consideration in farmer selection was proximity and easy physical access to amenities such as paved roads, markets, government services, schools and sources of agricultural inputs and information. Some of the amenities vital for farmers' agricultural practices include, a national agricultural research centre, county and district headquarters for administration and agricultural services, a depot for the National Cereals and Produce Board (NCPB), the county's largest agricultural produce market as well as a centralized public transport terminus. Hence, all farmers lived and farmed within relatively close commuting distance to Embu town, which serves as the county headquarters. 
The farmers were distributed across six age groups as shown in Figure 3.2. Fifty eight percent of the farmers who participated in the research were above 51 years of age which is representative of an ageing farmers' population - a common observation among farming communities in developing countries (FAO, CTA, \& IFAD, 2014).

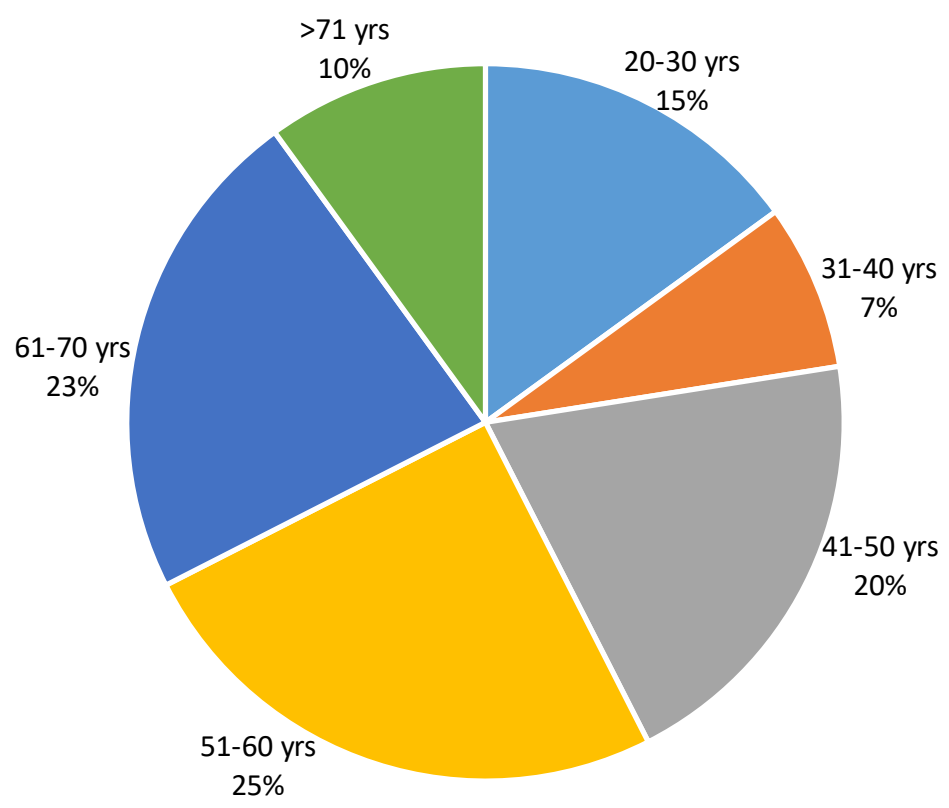

Figure 3.2: Percentage distribution of participating farmers across six age groups

Farmer distribution in the study by gender and age group is shown in Figure 3.3.

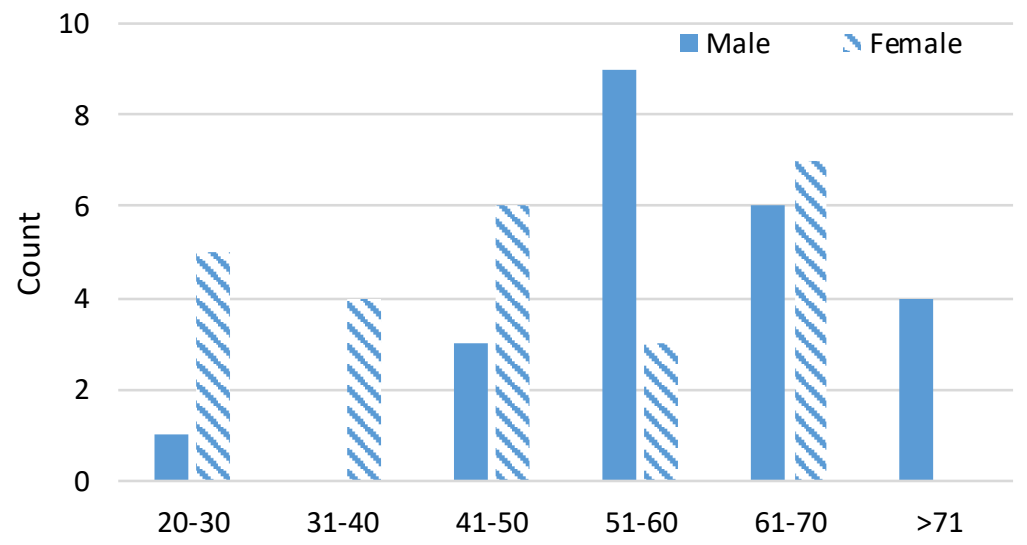

Figure 3.3: Distribution of participating farmers by gender and age group 
Among the 40 farmers, the largest farm size was 2.4 hectares (ha), while the smallest area farmed

was 0.05 ha. The average farm size was 0.64 ha while the median size was 0.51 ha. $80 \%$ of the farms in sub-Saharan Africa (SSA) are said to be less than 2 hectares (Harris \& Orr, 2014). In Kenya, a majority of smallholders farm between 0.2 to 3 hectares of land (Kerer, 2013), therefore the smallholders participating in this research were representative of this small-farms dynamic.

The rest of the research contributors were identified as non-farmer informants who had experienced working with farmers in the catchment area and offered different perspectives. They included representatives from agricultural research institutions, a district agricultural office, financiers and an agrodealer.

Table 3.3: Timeline of research project activities and key features

\begin{tabular}{|c|c|c|}
\hline Timeline & Research activity & Notes \& key features \\
\hline $\begin{array}{l}\text { May - Aug } \\
2013\end{array}$ & $\begin{array}{l}\text { Pre-fieldwork } \\
\text { preparations, } \\
\text { Ottawa \& Embu }\end{array}$ & $\begin{array}{l}\text { - } \text { Reviewed research proposal to refine questions for use in focus } \\
\text { group discussions and interviews } \\
\text { - Obtained necessary ethics clearance from CUREB } \\
\text { - Obtained research clearance Government of Kenya } \\
\text { - Familiarized with study area and organized logistics }\end{array}$ \\
\hline Sep 2013 & $\begin{array}{l}\text { Focus Group } \\
\text { Discussions (FGDs), } \\
\text { Embu }\end{array}$ & $\begin{array}{l}\text { - } 4 \text { FGDs held between } 17^{\text {th }} \text { and } 23^{\text {rd }} \text { September } \\
\text { - Total of } 24 \text { farmers from } 8 \text { villages } \\
\text { - All sessions held in a neutral location. Average } 2 \text { hours } \\
\text { - Audio recording and use of flip charts for note taking }\end{array}$ \\
\hline $\begin{array}{l}\text { Oct } 2013- \\
\text { June } 2014\end{array}$ & $\begin{array}{l}\text { Preliminary data } \\
\text { analysis, } \\
\text { Embu \& Ottawa }\end{array}$ & $\begin{array}{l}\text { - Transcribed audio recordings from FGDs } \\
\text { - Used NVivo software to organize transcripts, identify themes and } \\
\text { code } \\
\text { - Prepared and submitted field summary report to committee for } \\
\text { comments } \\
\text { - Findings incorporated into questions for next round of FGDs and } \\
\text { interviews }\end{array}$ \\
\hline Aug 2014 & $\begin{array}{l}\text { Review FGD, } \\
\text { Embu }\end{array}$ & $\begin{array}{l}\text { - } 1 \text { FGD held on } 1^{\text {st }} \text { August with } 7 \text { farmer contributors selected from } \\
\text { FGDs held in } 2013 \\
\text { - Purpose was two-fold: } \\
\text { a) To ground-truth interpretations of previous findings } \\
\text { b) To discuss any changes since } 2013 \\
\text { - Session informed areas of focus for in-depth interviews }\end{array}$ \\
\hline
\end{tabular}

\footnotetext{
12 Carleton University Research Ethics Board
} 


\begin{tabular}{|c|c|c|}
\hline Timeline & Research activity & Notes \& key features \\
\hline Aug 2014 & $\begin{array}{l}\text { Farmer in-depth } \\
\text { interviews. } \\
\text { Embu }\end{array}$ & $\begin{array}{l}\text { - } 16 \text { interviews held on-farm between } 19^{\text {th }} \text { and } 21^{\text {st }} \text { August } \\
\text { - Sessions were audio recorded and notes hand-written. Average } 30 \\
\text { minutes each } \\
\text { - Farmers drawn from several villages, namely, Rianjeru, Ngomano, } \\
\text { Kangaru, Githimu, Kivutiri, Kamwinja, Kiriari and Kariari }\end{array}$ \\
\hline $\begin{array}{l}\text { Sep } 2013- \\
\text { Aug } 2014\end{array}$ & $\begin{array}{l}\text { Non-farmer informant } \\
\text { interviews, } \\
\text { Embu \& Ottawa }\end{array}$ & $\begin{array}{l}\text { - Several informants working closely with farmers in the region were } \\
\text { interviewed } \\
\text { - Included agrodealer, researchers, agriculture officer } \\
\text { - One session was via Skype, the rest in-person } \\
\text { - Note-taking and audio recording done in sessions }\end{array}$ \\
\hline $\begin{array}{l}\text { Sep } 2014- \\
\text { Jun } 2015\end{array}$ & $\begin{array}{l}\text { Data processing, } \\
\text { Ottawa }\end{array}$ & $\begin{array}{l}\text { - } \text { Identified new themes and built on previous ones } \\
\text { - Used NVivo software to organize themes and identify key findings } \\
\text { e.g. using search and query functions }\end{array}$ \\
\hline $\begin{array}{l}\text { Jul } 2015 \text { - } \\
\text { May } 2016\end{array}$ & $\begin{array}{l}\text { Desk studies and } \\
\text { preparation of draft } \\
\text { manuscript, } \\
\text { Ottawa }\end{array}$ & $\begin{array}{l}\text { - Used themes from field findings as guide into scholarly articles } \\
\text { comparison with field research findings } \\
\text { - Prepared outlines of thesis chapters and discussed with supervisor } \\
\text { prior to drafting full chapters }\end{array}$ \\
\hline
\end{tabular}

The sections below describe how the research contributors were engaged during the data collection process, which included two rounds of fieldwork in 2013 and 2014 . The methods used to engage the smallholders were focus group discussions (FGDs) and in-depth interviews. The key informants were also interviewed and their contributions were enriched by available grey literature and peer-reviewed publications from desk studies.

In summary, each of the data collection methods described in Table 3.3 above were selected for their suitability in answering the research questions and sub-questions and their use was guided by the matrix shown in Figure 3.4. The FGDs and interviews were guided by a set of questions, which can be found in the Appendices section. The questions however served as a lead into the discussions or interviews rather than as strict guidelines to adhere to. Their main purpose was to 
ensure the major thematic areas that were building blocks for the research question were addressed.

\begin{tabular}{|c|c|c|c|c|}
\hline $\begin{array}{c}\text { Research } \\
\text { Sub-Questions }\end{array}$ & $\begin{array}{l}\text { a) Focus group } \\
\text { discussions }\end{array}$ & $\begin{array}{l}\text { b) Farmer in-depth } \\
\text { interviews }\end{array}$ & $\begin{array}{l}\text { c) Non-farmer } \\
\text { informant } \\
\text { interviews }\end{array}$ & d) Desk Studies \\
\hline $\begin{array}{l}\text { 1). What are the } \\
\text { existing food } \\
\text { security concerns } \\
\text { among Mt. } \\
\text { Kenya's } \\
\text { smallholder } \\
\text { farmers? }\end{array}$ & $\begin{array}{l}\text { Discussion on } \\
\text { food security \& } \\
\text { farmer practices }\end{array}$ & $\begin{array}{l}\text { Mapping } \\
\text { household } \\
\text { livelihood } \\
\text { dynamics, risk } \\
\text { perceptions \& } \\
\text { practices }\end{array}$ & $\begin{array}{l}\text { Views on food } \\
\text { security and } \\
\text { working with } \\
\text { smallholder } \\
\text { farmers in the } \\
\text { region }\end{array}$ & $\begin{array}{c}\text { Literature review } \\
\text { on the current } \\
\text { status of food } \\
\text { security in the } \\
\text { region }\end{array}$ \\
\hline $\begin{array}{l}\text { 2). What are the } \\
\text { existing climate } \\
\text { variability and } \\
\text { change concerns } \\
\text { among Mt. Kenya's } \\
\text { smallholder } \\
\text { farmers? }\end{array}$ & $\begin{array}{l}\text { Discussion on } \\
\text { perceived } \\
\text { climate change } \\
\text { and farmer } \\
\text { experiences }\end{array}$ & $\begin{array}{l}\text { At household } \\
\text { levels, discuss } \\
\text { weather or } \\
\text { climate risks } \\
\text { perceptions \& } \\
\text { responses }\end{array}$ & $\begin{array}{l}\text { Views on } \\
\text { climate change } \\
\text { and its effect } \\
\text { on smallholder } \\
\text { farmers in the } \\
\text { region }\end{array}$ & $\begin{array}{c}\text { Literature review } \\
\text { and evidence of } \\
\text { climate change in } \\
\text { the region }\end{array}$ \\
\hline $\begin{array}{l}\text { 3). How do } \\
\text { institutional } \\
\text { arrangements in } \\
\text { the region support } \\
\text { farmers to bolster } \\
\text { food security? }\end{array}$ & $\begin{array}{l}\text { Explore the } \\
\text { types \& levels of } \\
\text { support sought \& } \\
\text { received }\end{array}$ & $\begin{array}{l}\text { At household } \\
\text { levels, identify } \\
\text { vital support } \\
\text { services sought } \\
\text { from formal \& } \\
\text { informal } \\
\text { institutions }\end{array}$ & $\begin{array}{l}\text { Discuss } \\
\text { policies, } \\
\text { priorities \& } \\
\text { cross- } \\
\text { institutional } \\
\text { collaboration }\end{array}$ & $\begin{array}{l}\text { Assess the range } \\
\text { of support } \\
\text { services rendered } \\
\text { to farmers }\end{array}$ \\
\hline
\end{tabular}

Figure 3.4: Matrix indicating use of research methods to address sub-questions

\subsubsection{Implementation: research design meets research realities}

During the field studies, several aspects emerged that highlight the research realities that I had to navigate. While these realities had the potential to set limitations (external conditions) and de-limitations (self-imposed constraints) to the research, I however utilized them to strengthen the credibility and dependability of the research. Essentially, I used them as lessons that shaped the research and I present some of the research realities in this section. 
Transitions in governance: In March 2013 following general elections, Kenya had a new president and an equally new administrative system. After these elections, the county governance system stipulated in the new Constitution (promulgated in 2010 after a national referendum) took effect. At the time of my fieldwork in August 2013, the new administrative units were in place on paper but many county offices remained unestablished. The enactment of the constitution meant that some of the roles of the national government were to be devolved and managed at the county level. For example, the agriculture sector which had previously been administered by the national government at local levels through provincial and district offices was now to be a county level function. However, since the research was conducted in the same year as these new changes, the District Agricultural Officer (DAO) from the previous administration was still in office even though a county head for agriculture had been appointed. Although this dynamic of transitional governance had not been factored in my research design, it displayed conflicts and gaps in institutional administration and governance, which played out with detrimental effects to smallholders. ${ }^{13}$

Managing expectations: There were several instances where I had to manage the expectations of the contributors. As an outsider to the local community, I had to make a conscious effort to explain what my role was and what the contributors should expect of me. By way of establishing trust and introducing myself, I shared my academic and professional background. In some cases, contributors expressed expectations that were outside the scope of my research. For instance,

\footnotetext{
13 For instance, the new county administration had procured and distributed unsuitable maize seed to farmers leading to massive crop losses. The procurement procedures were divergent from the established protocols under the previous district agricultural guidelines (County Assembly of Embu, 2014).
} 
some had hoped that if I was working for or with the government, I could help broker better linkages to services that they sought from various offices.

Navigating age and gender dynamics: As a female researcher, I was mindful of pre-existing gender concerns while working in the field e.g. traditionally, young women do not speak in front of male elders. Similarly, given that majority of the research contributors were much older, I was conscious of positioning myself as a researcher while respecting the gender and age dynamics. Navigating these dynamics required promoting myself first as a learner and placing emphasis that my primary role was to learn from the farmers and other contributors. However, where it was necessary to demonstrate my knowledge, I made an effort to do so. For example, during one of the discussion groups, a farmer asked why they had been planting trees as advised and yet the expected reliable rainfall patterns had not resumed. I took the opportunity to offer a mini-lesson on the dynamics of anthropogenic climate change.

Improving credibility: I made use of various methods as a means of validating my research findings. First, I organized the focus group discussion such that at least two participants were drawn from the same area. Whereas smallholders gave their individual experiences, they also had an opportunity to comment collectively on the livelihood dynamics of their area. Second, the final focus group discussion held in 2014 was a way of validating the data I had collected previously as well as the synthesis I had developed from its analysis. Third, during the fieldwork, I was living with family friends within the catchment area of my research. Spending time in the locale during periods where I was not necessarily collecting data allowed extra time to make complementary observations e.g. on the lifestyles of residents to inform the bigger picture. Fourth, there were many nuances in the farmers' responses that emerged, especially during 
group discussions, which warranted follow-up. For instance, having mixed groups with both genders allowed for one gender to address the other. One observation was that there existed more programs to support women and youth as compared to men. This support had evidently empowered the women, who were not shy to offer their opinions in the presence of men. This was counter to the historical practices in African cultures where men were considered superior and hence their opinions carried more weight than those voiced by women.

Complementary activities: Three major activities occurred during my time in the field that complemented this research. In mid-July 2013, I participated in a three-day residential training on the Agricultural Production Systems sIMulator (APSIM) program. The program focused on how weather and crop information gathered from farmers can be used to create productivity models. The training was conducted in Embu and in the neighbouring Meru district and entailed collecting data from the farmers, simulating the data using APSIM and later communicating the results to the same farmers. Two key lessons from this process were on how to engage with farmers as research contributors as well as ideas on processes that can be used to validate findings. Having occurred prior to my own field research, this training was important in equipping me with techniques which I later applied with my research contributors.

Secondly, during my stay in Kenya for the fieldwork in 2013, I had an opportunity to carry out some consulting work for the International Fund for Agricultural Development (IFAD). This provided me with an ideal working space for my research desk studies at the United Nations Office in Nairobi (UNoN) where IFAD's regional offices are located. Additionally, the output of my consulting work was a background paper on the status of climate change in Kenya, which had a direct contribution to one of my research building blocks. 
Thirdly, two of my consultant colleagues and I were awarded a contract to conduct a training on climate change awareness by an umbrella organization in Kenya that brings together manufacturers and their affiliates. We conducted two well-attended trainings, one in Mombasa and another in Nakuru, where each had over 70 participants. I had developed a carbon footprint calculation exercise that allowed the participants to reflect on their own contribution to climate change. These trainings offered lessons for later engagement with my research contributors especially building on communicating complex dynamics (of climate change) with clarity and in simple terms.

\subsection{Data analysis and presentation}

This section discusses the data analysis procedures followed in the research prior to offering a summary on the chapter.

\subsubsection{Analysis procedures}

Two broad classes of data were generated and used in this research, i.e. primary and secondary. Primary data was gathered from engagement with contributors in audio and hand-written format, while secondary data was obtained 'as is' from grey literature and peer-reviewed publications. Primary data (recorded audio files from FGDs and interviews) required more manipulation and handling and for which NVivo, a software that aids qualitative data analysis, was used. Knowledge on the use of NVivo was garnered by watching video tutorials and following webinars from the manufacturer's website (www.qsrinternational.com). In addition, the following books: Qualitative Data Analysis: Practical Strategies (Bazeley, 2013) and Qualitative Data Analysis with NVivo, $2^{\text {nd }}$ Edition (Bazeley \& Jackson, 2013), offered practical guidelines on the processes. 
For handling of the audio files, the basic steps included:

a) Importing the audio file with the recording of the discussion or interview into NVivo

b) Using the Play/Pause functions, playing the audio file while typing the words as they were spoken. Each speaker's identity was coded in a separate file and their contributions attributed to them i.e. using a separate line for each speaker

c) Once transcription for an audio file was complete, the text was transferred to MS Word format for ease of text correction and formatting.

d) All the transcripts were then printed for a manual read-through and identification of themes. The use of colored highlighters and flags made it easy to mark and distinguish between themes.

e) The edited MS Word transcripts were then transferred into NVivo. Using the identified themes from the manual read-through, coding was carried out by creating nodes where similar points were classified together.

f) Once the coding process was completed for all transcripts, a table with all the nodes was generated and some were re-classified creating 'mother' and 'child' or 'descendant' nodes. A sample of nodes coded in NVivo is shown in Table 3.4 below.

Table 3.4: Sample of nodes used for coding in NVivo

\begin{tabular}{llll}
\hline Node & Description & Source & Reference \\
\hline Resources & Resources that a farmer needs to be productive & 37 & 336 \\
Financial Capital & The financial resources necessary for smallholders & 19 & 41 \\
Inputs & Inputs for both crop and livestock production & 27 & 171 \\
Animal Feeds & Mainly for poultry and other livestock & 11 & 26 \\
Fertilizer \& Manure & Inputs to increase soil fertility & 20 & 75 \\
Hybrid Seeds \& Seedlings & Improved varieties of seeds and seedlings & 13 & 34 \\
Pesticides & Incudes insecticides and herbicides & 12 & 24 \\
Traditional seeds & produced from stocks held from past seasons & 8 & 11 \\
Labor & Mainly manual/human but also livestock e.g. oxen & 12 & 30 \\
Land & That a farmer uses for producing crops and livestock & 8 & 16 \\
Leased Farmland & Additional land leased to increase production & 7 & 17 \\
Water & Includes harvested, piped and irrigation water & 19 & 61 \\
\hline
\end{tabular}


In this example, Resources was the main node with six descendant nodes including labor, land and water. One of the descendant nodes, Inputs, had five different nodes beneath it. The 'sources' column indicates the number of transcript files that have been coded to a certain node while the 'references' column contains the total number of items that have been coded at a certain node.

The process described above for coding and identifying important themes was guided by suggestions made by Krueger and Casey (2009). They propose a cluster of concepts for the coding process, three of which were useful to the process above:

a) Frequency - how often an item or theme was mentioned

b) Extensiveness - how many different people mentioned it

c) Intensity - the level of passion with which a theme was discussed. This was an indicator of the participants' perception of importance

The nodes and themes developed above in turn guided the literature that the research focused on. For instance, the farmers' responses to issues of fertilizer led to a literature search on the same topic from various published sources. The literature sources (mainly as PDF files) were added into the NVivo project and coded at the same nodes identified in the above process. In this manner, responses from the research contributors were analyzed and compared to secondary data from grey literature and other published documents.

The use of queries (searches) in the data analysis process was helpful in identifying areas that had previously not been coded. For instance, the coding of risks that smallholders face was a deductive process, i.e. from the opinions they expressed, implying that the smallholders may not necessarily use the word 'risk' in their descriptions. In the literature sources, however, it was 
possible to run a query for the terms 'farmers' and 'risk' and generate results, which were analyzed and compared to the smallholders' responses coded under the risks node. Therefore, whereas the research findings were generated through analyzing and comparing different themes, the use of NVivo significantly eased and facilitated the process of data handling.

\subsubsection{Chapter summary}

Overall, the research process is about a 'lives lived' approach. Smallholder farmers negotiate their livelihoods in local contexts characterized by limited resources and power. However, they also engage with external factors. There is a need to probe multiple actors to understand how they interact, i.e. both farmers and non-farmers. This research employed a mixed methods approach beginning with desk studies to set the context, moving to focus group discussions to tackle broader questions and later interacting at individual levels with farmers and non-farmers to probe key questions further. The research participants were treated as contributors and their broader views were corroborated by a second FGD to ground-truth initial findings. The research findings presented in Chapters 4 through 6 are framed in this context. Direct quotes from the smallholders are used to give context and emphasis. These quotes are presented in an italicized font and indented format. 


\section{Chapter 4. Food security and related concerns among Mt. Kenya smallholders}

The pursuit of food security remains both a major activity and the basis of core concerns among smallholder farmers. This chapter is dedicated to exploring responses to the research subquestion 'What are the food security and related concerns among smallholders in the Mt. Kenya region'. The chapter examines the underlying issues shaping smallholders' food security while giving them a platform to share their experiences on the question.

Section 4.1 discusses the livelihoods of smallholders. Guided by the established food security dimensions of availability, access, utilization and stability, Sections 4.2 through 4.5 present smallholder farmers' views of food security in the study area. Section 4.6 discusses broader food security scholarship while illuminating how lessons from Mt. Kenya's smallholders expand on existing knowledge. The chapter concludes with a synthesis of the lessons learned.

\subsection{Negotiating and strengthening livelihoods: The foundation and evolution of farming}

The lives of smallholder farmers revolve around sets of activities allowing them to meet their daily needs. Over time, their livelihoods reveal elements of diversity and dynamism - the former is evidenced by increasing the range of activities while the latter is showcased by changing the types of activities. Therefore, smallholder farmers' livelihoods have evolved over time.

Evidence from Mt. Kenya smallholders demonstrates the evolution of farming activities can be viewed as either negotiating or strengthening livelihoods. In the case of negotiating, the smallholders at least engage in farming activities and trade food produce to meet their livelihood 
needs - surviving. At best, they may increase their investments in farming e.g. through irrigation in order to increase their productivity - thriving. Another set of activities appear to be undertaken for purposes of strengthening their farming-derived livelihoods, namely income-generation from wage labour and employment. The next two subsections will explore these attributes of smallholders' livelihoods.

\subsection{1. 'Surviving' or 'thriving': Transitions from conventional to agribusiness farming}

In the conventional approach to farming, a smallholder uses available resources to grow food mainly to meet the family's food needs. The study revealed that older farmers, with lower expenses and physical energy to pursue farming intensively, tend to adopt the conventional approach. The conventional smallholder is biased towards keeping traditional practices alive. As a result, there is a level of resistance to change such as switching from traditional seeds to improved varieties that would offer higher yields.

Focus group discussions and interviews with Mt. Kenya smallholder farmers revealed a transition from conventional to agribusiness farming. The agribusiness-oriented farmer produces food crops to sell for profit. Among the smallholder respondents, those who engaged in agribusiness had a different mindset and motivation driven by the need to generate higher incomes and enjoy a better standard of living. This observation emerged from nuanced responses by conventional smallholders that were distinct from those of agribusiness smallholders. An example of phrasing from the conventional farmers on the costs of farming would be "at least I recover my costs". In contrast, the agribusiness-oriented farmers are more likely to state that "the farm should pay for itself and I make a profit". 
The costs of farming for agribusiness are significantly higher as smallholders tend to invest heavily on inputs such as quality seed and farm applications. The agribusiness-oriented farmers had access to a steady supply of water given that their choice crops were mostly vegetables. For this group of smallholders, their decision to venture into agri-business is driven by two other reasons: meeting a high demand for fast-moving daily food crops; and the ability to farm all year round. Many diets in Kenya often include the consumption of a cooked vegetable at least in one meal. Leafy vegetables such as kales, collard greens and spinach are common table foods. As one participating farmer attested, his production of these vegetables was insufficient to meet the demand of the neighbourhood surrounding his farm where his clientele is drawn. Farming outside the rainfall seasons enables an 'agripreneur' to sell their produce in the absence of a market glut thereby fetching better prices. Within the study area, some business-oriented smallholders shared experiences of seeking best market prices via mobile phone prior to delivering their produce.

\subsubsection{Employment and income-generating activities}

\section{(a) From non-farm activities}

Smallholders in the study reported engaging in non-farm income-generating activities for two main reasons. Some ventured into income-earning activities to capitalize on an existing market or demand while others utilized their skills in a particular trade. A female respondent in her late 60s shared that for thirty years, she cooked and sold foodstuffs to workers at a nearby abattoir. The foods included porridge, sweet potatoes and tea. When her strength waned, she turned over the business to her daughter "so that she too can bring up her children". Another respondent who owns several rental housing units in his compound conveyed that his milk had a ready 
market from his tenants. Better still, he was able to sell it at a higher price than what he would have earned from selling to the local dairy. An example of skilled trade was offered by a male farmer with building experience who occasionally worked as a construction foreman. Besides the 'dry spells' in between job contracts, the other challenge faced by this farmer was the risk of defaulting clients or delayed payments for services rendered.

Among farmers with employment experience, it was of interest on how they compared it to farming. Here, the case of the youngest male participant, in his 20s, offers a good example. As a migrant worker, he moved into the field study area to work as a labourer in the construction of a government institute. After four years, and at the end of the project, he was keen on staying in the area since the land looked fertile and water from an irrigation scheme was readily available. The young man, a successful farmer of vegetables, shared that income derived from farming was more lucrative than wage labour. He also earned better returns from farming in comparison to income from a motorbike taxi business that he and his peers also engaged in. Another farmer was looking forward to retiring from his teaching job in 2015 since juggling both employment and farming had compromised his performance on the latter.

\section{(b) Wage labor from on-farm activities}

In the past, the farmers in the study would barter labour wherein they would work jointly on one farm and then do the same on the other's farm. They however emphasized that this traditional and reciprocal labour practice locally known as 'gũtũmana irĩma' has been abandoned in favour of wage labour. They added that any form of benevolent or free labour was nonexistent in the area. 
Given that rainfall seasons influence agricultural production, the smallholders reiterated that wage labour fluctuates between higher and lower wages. In the rainy season, wages are higher as demand for farm work increases. The converse is true in the drier season with exception of harvest time. Therefore, a strong relationship exists between demand, supply and wage rates. Coffee farmers in the region tend to harvest their berries during the same period. This creates a high demand for harvest laborers, therefore the farmers who afford higher wages receive priority. Often, the labourers move from one farm to the next enquiring about the wages offered prior to committing to the highest payer.

\subsection{Availability}

As summarized from literature in Table 2.1, food availability refers to the production or "supply side" of food. However, responses from smallholders shed light into areas that are pertinent to their production processes but not necessarily well represented in literature. Section 4.2.1 focuses on issues raised by the farmers which rest on the availability and acquisition of inputs i.e. core factors of food production. Section 4.2.2 offers a discussion on post-production processes centered on harvest management.

\subsubsection{Pre-production processes: availability and acquisition of inputs}

A review of literature on food availability indicates that food security assessments begin when

food has already been produced. This focus on the supply can mask the pre-production processes (e.g. acquisition of inputs) required in place before smallholders can produce food. Smallholders gave their experiences with seeds, fertilizer, manure, water, treatments, livestock feeds, labour and land. 


\section{Seeds}

In preparation for planting, which is often triggered by the start of the rainy season, the types of seeds to use remains a paramount issue for smallholders. Financial resources to cover planting costs are lower for farmers who opt to re-use seeds from the previous season. Farmers who choose to plant improved or hybrid seeds often have to allocate part of their planting budget to purchase them. During the focus group discussions, it was evident that the farmers were aware of relative market prices for seeds in their region. However, smallholders do not always have the option of buying cheaper seeds. If they commute a longer distance to make cheaper purchases, they must consider higher transport costs.

There was consensus among the farmers that keeping some stock of traditional maize seeds acts as insurance when the planting season starts and they do not have sufficient funds to purchase improved certified seeds. During lean financial seasons, some farmers plant both improved and traditional seeds. They were however quick to add that the traditional maize seeds no longer perform as well as they did in previous times. They attribute this poor performance to changes in the soil, weather and climate that have caused lower productivity and an increase in disease incidence.

Among the respondents, cases of poor or counterfeit seeds purchased from local dealers were occasionally experienced. Some shared that they had unknowingly purchased well packaged seeds from unscrupulous dealers and only realized their purchases were counterfeit when their crops underperformed or failed. The farmers resort to planting varieties they are familiar with since they already understand the risks. Only one participant from the drier zone of the project area had tackled risk by taking insurance at the point of purchase of her maize seeds. Whereas 
some compensation is received based on indexed calculations, it is only offered on the cost of purchase for the seeds and fertilizer. Therefore, should the crop fail, the compensation would be inadequate for the smallholder to meet their food needs until the next harvest.

Smallholder farmers obtained knowledge on improved seeds and seedlings from interactions with government agricultural officers or through their engagements with various organizations. Smallholders commonly benefited by organizing themselves into groups - with examples ranging from banana seedlings, strawberry and onion farming. The smallholders have occasionally utilized group membership to purchase seeds, nurture them in a common nursery and later transplant seedlings to their individual farms. In other instances, they visit farms and demonstration sites where high yielding varieties are showcased and purchase seeds and seedlings from these sites. However, for other crops such as beans, they opt for traditional seeds which have been passed down through their family's generation.

A deeper level of engagement between organizations and smallholders was apparent for those who farmed French beans mainly in the higher region and with access to irrigation water. This group, received the seeds as part of their inputs package and have the costs deducted once they had delivered the harvests to the company's collection point.

\section{Fertilizer \& manure}

\section{"These days, nothing can grow without fertilizer"}

The older farmers reminisced their past farming days when fertilizer was hardly used. Declining soil fertility led to the introduction of manure and mineral fertilizers. The high cost of fertilizers was echoed numerous times during smallholders' focus group discussions and interviews, with many calling on the government to intervene and lower the costs. 
Smallholders shared experiences with manure use on their farms on both owned and leased land.

On leased farms, owners prohibit the use of manure thereby giving rise to compromised productivity. Discussions did not reveal specific reasons why manure use on leased farmland was restricted by landowners while the use of mineral fertilizer was permitted. However, compromised productivity is also hampered by the inappropriate use of fertilizer. One smallholder who had recently received training on conservation agriculture organized by his church learnt that in some cases, overuse may be the problem. He learnt that a bottle-top equivalent of fertilizer for each plant would be suitable and adequate rather than a fistful of the same.

The most common types of fertilizers used in the region are D.A.P. (diammonium phosphate), N.P.K. (Nitrogen, Phosphorous, and Potash (Potassium)) and C.A.N. (calcium ammonium nitrate). During the focus group discussions, farmers indicated that the use of a certain type of fertilizer is often determined by price, experience and local influence rather than by the suitability based on the soil type. Prohibitive costs of soil testing at the local science laboratories was the main reason why smallholders did not take samples for analysis. Responses from the smallholders indicate a fertilizer usage of 124 kilograms per hectare for maize farming.

\section{Water}

Farmer 1: Like now there is no drought but water rationing has started. Sometimes in the section you are farming, you can start putting some water but before the evening comes, the water is cut off.

Facilitator: Is it from the Council?

Farmer 1: It is from an irrigation scheme project

Facilitator: I had heard about that scheme but about how many people are in it?

Farmer 1: About 370 something

Facilitator: Is the challenge a reduction in water or what? 
Farmer 1: When it was being developed and fitted with pipes, it was supposed to have 284 people. But now it is approaching 400 people.

Facilitator: Was there a provision for more people to be added?

Farmer 1: No, the constitution was against it. Even the ones who were supporting us to install it had cautioned that if we added, and make more holes in the pipes, people would not be able to farm.

Farmer 2: At the intake, there are so many people who have connected the water. So when the dry season comes, there is a shortage of water supply. So you can go for 2 days without water.

The study area lies on the slopes of Mt. Kenya and has a relatively good supply of surface and ground water giving rise to a number of small-scale irrigation schemes. Farmers attested that availability of irrigation water allows for switching planting dates and offers a better return on investments such as fertilizer. Most conceded that water availability and access were their greatest constraints to increased productivity. Surprisingly, this concern was most pronounced among the farmers who already had some guarantee of water supply, namely the irrigation farmers. Many reported that although they enjoyed the benefit of farming outside the rainy season, the consistency of water allocation was becoming a challenge as more and more people were added into their irrigation schemes.

The excerpt above from a focus group discussion reveals several issues. First, the members of this irrigation scheme do not have to rely on water provided by the county council for domestic use. Many farmers reported that there are strict regulations and enforcement on users who divert the domestic water supply for farm use. Therefore, for those in an area that can tap into an irrigation system, the advantage is significant but becomes limited when water access is then rationed. Secondly, whereas there are many small irrigation schemes in the area, the need for expanding access to more farmers remains significant. Therefore, although a constitution and governance rules are in place in most of the irrigation schemes, the demand necessitates a 
compromise on enforcement. In some areas that were visited in the study, smallholders expressed concerns that goodwill is eroded when they have water access yet the neighbouring farm does not enjoy the same. Preserving this goodwill was cited as a reason for the increase in the number of users beyond the originally set limits. The third issue rests on institutional governance. The study area has made progress in establishing Water Resource User Associations (WRUAs) under the Water Resource Management Authority (WRMA) formulated under the 2002 Water Act by the Ministry of Environment, Water and Natural Resources. While the establishment of WRUAs sensitizes local water users on the need to preserve and maintain water catchment areas, some smallholders complained of irrigation projects that failed to take off even after they had made the necessary contributions for several years.

For the majority of smallholders in the area who do not have access to irrigation water, there is the temptation to tap into the water supplied by the Embu Water and Sanitation Company (EWASCO) owned by the Embu Municipal Council. However, this water supply is exclusively for domestic use and is treated. Farmers in the study stated that using this water for crop production has two main risks - being caught using the water illegally and facing consequences (such as disconnection with penalties) and possible damage to the crops due to the chlorine treatment. Given these limitations of lack of irrigation water and restricted use of domestic water, several farmers resort to rain water harvesting using gutters constructed to drain into water tanks. The purchase of water tanks is considered costly and many farmers use group savings to pool together resources and buy water tanks for each member in turn. The competing needs of household water use versus for farming further limit the quantities that can be allocated for the latter. In the study area, smallholders often limit the use of harvested water to small 'kitchen 
gardens' that are located close to the homestead and dedicated for growing vegetables such as kales and spinach - foods that are used for household consumption.

\section{Treatments: herbicides and pesticides}

The incidence of pests and diseases in the farms necessitate the use of treatments such as pesticides or herbicides for pest and weed control. Besides the challenge of high costs, the smallholders stated that some of the treatments were ineffective for two reasons. First, there was evidence of resistance e.g. in the case of 'whitefly' which affects cabbages. Secondly, the farmers' conceded that cases of improper use of the pesticides either by wrong type, improper dosage or wrong timing were common.

Smallholders rely on heuristic knowledge by using the same treatments that they are accustomed to. They acquire new information from the agrodealers where they purchase their inputs and occasionally from agricultural extension workers. Resistant pests and disease strains may be as a result of infrequent update to smallholders' knowledge on effective treatments.

The timing of treatments and disease interventions also emerged as a key concern. Some farmers who reared chickens had suffered huge losses from fast-acting diseases. Often, they had observed symptoms in their stock (such as drooping or laziness) but had not treated their chickens on time. Others suggested that the best way to curb the losses was by pre-treating as soon as there were rumours that a fowl disease outbreak had been reported in a neighbouring region. This points to a gap in information-sharing platforms that would play a crucial role in curbing such losses. 
The smallholders additionally discussed a more serious concern on the timing of treatments which poses immediate threats to the consumers. In a bid to have lucrative and appealing produce that would command best prices at the market, smallholders spray their crops with treatments a day or two before harvesting and selling at the market. This practice occurs mostly on high-demand horticultural produce such as green leafy vegetables and tomatoes. The farmers were aware that the consumers risk ingesting these treatments especially if proper food preparation procedures such as thorough washing were not adhered to.

\section{Livestock feeds}

Rearing livestock such as cows, goats, pigs and chickens is common among smallholder farmers in the study area. As with food crops, livestock rearing meets the home consumption needs as well as generates income from the sale of produce (milk from cows and goats, and meat or eggs from the chickens). All farmers who kept cows practiced zero grazing - the most significant costs were the animal feeds and intensive labour needed. The preferred feeds are a combination of processed animal feeds purchased from stores, Napier grass(Pennisetum purpureum), and maize stovers (the stalks left over after the crop harvest). The smallholders faced challenges associated with high prices of processed feeds. However, in the case of Napier grass and stovers, the biggest challenges were the associated labour and transport costs. The farmers shared that the ideal situation would be when the sale of the livestock or their produce would generate sufficient returns to cater for the costs of feeds and associated labour.

The symbiotic relationship between food cropping and livestock keeping was showcased in the discussions and interviews. Farmers who had received some training on conservation agriculture felt conflicted. On the one hand, they were advised to leave the maize harvest leftovers to decay 
on the farm and enrich the soil until the next season. They viewed this as a trade-off since they use stovers to feed their cattle and reduce costs of purchasing processed feeds. On the other hand, having livestock allows them to benefit from lower purchase costs for fertilizer as they combine it with manure for their cropping. Among the smallholders with livestock, the high costs of feeds and labour was cited as the leading cause of distressed liquidation where they opt to reduce their stocks to levels that they can maintain comfortably.

\section{Labour}

On-farm labour is provided by household members as well as outsourced to casual workers in the area. The farmers stated that they had the ability to work on their farms although they were occasionally constrained in affording wages to pay their labourers. A key concern was that the availability of manual labourers could not be guaranteed in the future since most of the youth are becoming more educated and may opt to work elsewhere rather than on the farms.

\section{Land}

Dividing land is almost coming to an end in our area [group laughter]...Unless you educate a child, right now there is no land you can get in our area. Like this one [speaker points to man seated next to him] is lucky their farm is large and he will get about 1 acre. He has 4 sons and including himself, are those not 5 people? ${ }^{14}$ That acre is just single plots. Those sons have already married. He cannot divide the land. Maybe what he can do is show you where you can build your house... There is no child waiting to inherit land. We try on how we can divide it and are unable to. So it just stays like that. You rise up and go to work elsewhere. So the issue of land inheritance in our place has ceased.

The concern of shrinking farm land sizes was widespread especially among older farmers in the study. They stated that their productivity is severely limited and will continue to be so as land

\footnotetext{
${ }^{14}$ Although the Kenyan law was amended for the inclusion of girls in land inheritance, the practice on the ground remains largely unchanged and is cognizant only of the male offspring. The justification being that the girls will be married off and relocate to other areas where their husbands would have their own land.
} 
fragmentation increases. Further, the lack of sufficient land perpetuates the erosion of traditional practices of inheritance that serve as cultural identifiers. The above quote signals that smallholders are accepting of the societal shifts that are already evident as demonstrated by their consideration of education as substitute inheritance rather than land. In support of this, a female farmer in her 60s was proud to report that her farming had benefitted from her son's input. She had requested him to research online on strawberry farming best practices and was able to apply the knowledge successfully.

Shrinking land sizes have compelled smallholder farmers to seek additional land for cultivation. These additional parcels of land are mostly leased out from farmers who have significantly larger landholdings. Besides cases where leased land may be far from the smallholders home, three additional concerns were raised by the farmers: cost, uncertainty and restrictions. Due to their informal nature, agreements between a smallholder and a lessor are unregulated. Consequently, the costs of leased land vary significantly. In the study, the farmers who paid the least were charged Shillings (Shs.) 1,000 per acre per season ${ }^{15}$ while the highest paid Shs. 5,000 for a 0.25 acre parcel per season. The latter amount is considerably higher since the land parcel is connected to an irrigation scheme. The second concern was uncertainty of lease land availability. The lessor-lessee terms, are on 'a gentleman's agreement' relying on the goodwill of both the farmer and the land owner. Many farmers reported that most times they are uncertain if the farm will be available to them in the next season or not. This translates to an increased risk to their livelihood and food security outcomes. The third concern on restrictions relates to

\footnotetext{
15 Whereas the farmers will state that the charges are per season, the actual duration of leasing the land is six months. Therefore, each year will have 2 leasing seasons i.e. six months each.
} 
limitations that may be put in place by the landowner, e.g. forbidding the planting of certain crops or the use of manure on the leased land. Interrogating possible solutions to these predicaments proved challenging in light of the increasing number of house tenants in the area who add on to the demand for leased land.

\subsubsection{Post-production processes: harvests and harvest management}

The smallholders in the study were all maize farmers. Although there was a significant variation in the land sizes they dedicated to the crop, the two main types planted in the region were Hybrid 614 and Duma 43. Table 4.1 showcases some of the yields realized or expected by farmers in the research area. The table also indicates the household size as declared by the farmers. This size includes all the persons who depend on the farm's agricultural produce to meet their food requirements and other livelihood needs. Upon harvest, the smallholders dry the maize, thresh it from the cobs and pack the grains into 90-kg equivalent bags. From the values given by Farmer 2, 3 and 4, the average maize yield is 9 bags of $90 \mathrm{~kg}$ each per acre. This is equivalent to a productivity of $810 \mathrm{~kg} / \mathrm{ac}$ or approximately 2 metric tons per hectare.

Table 4.1: Yields realized by select farmers or expected as "a good harvest" (hypothetical from FGDs)

\begin{tabular}{llcl}
\hline & Household Size & Land size (acres) & Productivity (90 kg bags) \\
\hline Farmer 1 & 2 adults & 1 & (2) Maize | (1) Beans \\
Farmer 2 & 2 adults \& 3 children & 2 & (10) Maize \\
Farmer 3 & 3 adults \& 1 child & 1 & (15) Maize \\
Farmer 4 & 3 adults & 1 & (7) Maize \\
Farmer 5 & 3 adults \& 1 child & 0.5 & (3) Maize | (2) Beans \\
FGD01 (Hypothetical) & 2 adults \& 3 children & 1 & (10) Maize | (3) Beans \\
FGD02 (Hypothetical) & 2 adults \& 4 children & 0.25 & (2) Maize | (1) Beans \\
FGD04 (Hypothetical) & 2 adults \& 3 children & 1 & (3) Maize | (2) Beans
\end{tabular}

Although the use of improved or hybrid seeds in Kenya has been on the increase, cases of inappropriate seed selection still occur. In one such possible case, one smallholderlamented that 
she lost her whole maize crop the previous season. The farmer (who had been farming there since 1972) had bought maize seeds from an agrodealer and when the seed failed to grow the first time, she replanted the same seeds after a few weeks with no success. An inspection of the packet from the leftover seeds (which she had retained) indicated that the variety is suitable for areas that are between $800-1500$ meters above sea level (m.a.s.I). Given that her farm seats at 1516 m.a.s.l., it is questionable whether the seed was suitable. However, owing to the high levels of fraud among agrodealers, the farmer concluded that the seeds were counterfeit.

\section{Harvest management}

Although food production remains central to securing their livelihoods, smallholders must manage their farm yields in the best manner. In the study area, harvest management is a household level affair and no shared or communal storage facilities exist. Harvest management practices are diverse giving rise to varied experiences. Two harvest seasons exist, between July and August, and between late December and February. For maize produce, the smallholder has an incentive to store the maize for at least four to six months if they are to optimize on best market prices when the supply is low. However, most farmers can only keep it for two months as urgent cash needs compel them to sell, often at lower prices. Farmers understood the detrimental impacts of market gluts to their potential incomes.

According to the smallholders, the second and perhaps most pressing challenge on harvests are the attacks by pests such as weevils. Some farmers purported that there are persistent weevils (which seem to attack a particular maize variety) that can be spotted even prior to the maize being harvested from the field. There was much chatter among discussion group members as 
they lamented how one type of weevil, nicknamed Osama, had terrorized their harvests. The following lively discussion captured part of this challenge:

Facilitator: Let me ask and perhaps the ones who have farmed for a longer time know this. Before, you never used to apply actellic?

Farmer 1: There were still some other applications but not that one. There was a method where maize would be tied on trees and they would not get weevils.

Farmer 2: Right now if you attempt to do the same, your maize will become flour. The weevils are even invading the maize while they are still in the farm.

Farmer 3: Like there is another very dangerous one called "Osama"

Facilitator: What is Osama?

Farmer 3: Osama is another type of weevil. That one grinds the maize like a milling machine.

Farmer 1: It is bigger than the other types. It even eats plastic and even gourds

Facilitator: I will enquire from the agriculture people what its real name is. ${ }^{16}$

Farmer 3: That is the one finishing people.

As damaging as these weevils were purported to be, the smallholders were not investing adequately in proper storage materials. During the discussion session above, one farmer generated the interest of the others in attendance by sharing information on a new type of grain storage bag that was impenetrable by weevils. As the discussion wound up, one female farmer called upon the government to intervene on improved storage practices. Specifically, her plea was for a return to traditional preservation methods that were less pervasive and posed less risk to incidental ingestion of chemicals.

Based on the lack of storage facilities for horticultural produce and their short shelf-life, smallholder farmers in the study expressed the need to have nearby industries to which they could deliver their produce for value-addition. For example the processing of tomatoes into

\footnotetext{
16 The actual name of this weevil is unclear but is suspected to be the Larger Grain Borer (LGB). However, its description as a larger grain borer and characteristics as described by farmers in the study were corroborated by a factsheet titled "Osama destroys maize" authored by the Kenya Agricultural Research Institute (KARI). See http://www.plantwise.org/FullTextPDF/2010/20103333602.pdf Last accessed 3rd August, 2016
} 
pastes or canning for longer shelf-life products. During the study, one farmer revealed that he belonged to a group with fellow smallholders where they had started a self-help cottage industry for value addition of their produce. The model he stated worked very well yielding multiple benefits while balancing demand, supply and marketing. First, as members of the group, they each produced crops that were later processed into snacks or flour e.g. sweet potatoes and bananas. Second, the farmers benefitted from having a ready market to which they could deliver their harvests. Third, they pooled together their labour taking turns to work at their small industry and churn the harvests into sellable goods such as crisps, flour and baked goods. Lastly, they also marketed and sold their value-added produce making larger profits than they would have for the raw food crops. His experience highlights the possibilities of improved livelihoods if smallholders are linked higher up in the food value chain.

\section{What to keep, what to sell}

Like the ones I had here [hybrid chickens], I was being offered Shs. 1,500 each but decided I could not sell. When I calculate how much I buy meat at, I decided to eat mine. I had four cocks which we slaughtered and we ate. When I calculate that I buy a kilo of beef meat for Shs. 400 and then you give me Shs. 1,500, you have bought for me about 3 kilos. I decided to eat with my children.

None of the respondents were self-sufficient i.e., they relied on purchases of some food crops and livestock produce to meet their dietary needs. Although the global phenomenon of dietary convergence (e.g. the preference for processed foods) is evident within the study area, some traditional food crops and indigenous livestock are still highly regarded and command good prices at the market. For example, many farmers reared indigenous or hybrid chickens and while some sold them for good profits, especially during festive seasons such as the New Year and Christmas, others opt to keep for domestic consumption. In the above quote, one may wrongly 
assume that the farmer prefers to buy 3 kilograms of beef rather than one chicken. However, his logic is that were he to provide a meal of chicken (considered a delicacy) to his family, he would have to spend Shs. 1,500 . This cost is significantly high so he would rather rear his own chickens for consumption.

The smallholders preferred to keep their harvests of beans for home consumption. Many Kenyan diets comprise of a staple dish and a 'stew'. The staple dish could be foods such as ugali (made from corn flour, millet or sorghum) or rice and the stew may range from a meat dish, leafy vegetables or some legumes. Beans are prized as a source of protein by mothers and are more affordable than meat. One female farmer shared that most mothers would keep the beans rather than sell and use them as a stew while varying the daily staple food.

\subsection{Access}

Although food may be adequate in quantity, its access at household or individual level may be limited. As per Table 2.1, literature broadly defines food access through two streams - physical and economic. From the engagements with smallholders, issues of food access emerged from discussions on cost of farming, incomes and purchasing power as well as markets.

\subsubsection{Cost of farming, incomes and purchasing power}

The FGDs conducted with smallholders elucidated the extent to which cost of farming was of great concern to them. They offered narratives with examples on how the costs of farming have increasingly been on the rise. These high costs of inputs were blamed for poor farm performance and provided a platform for compromises on proper farm management. Farmers who invested more into their farming were better placed to make higher profits from their farm production. 
Efforts to determine the costs of farming among the smallholders were made during the FGDs.

This was an exercise of 'best estimates' as most smallholders do not keep written records of their expenses. They however had a good sense on costs of farm inputs in the region. Additionally, they could predict if their harvests would yield surpluses sufficient to cover the costs of inputs.

This ability to estimate expected returns proved to be a good validation process as the calculations on cost of food production were discussed.

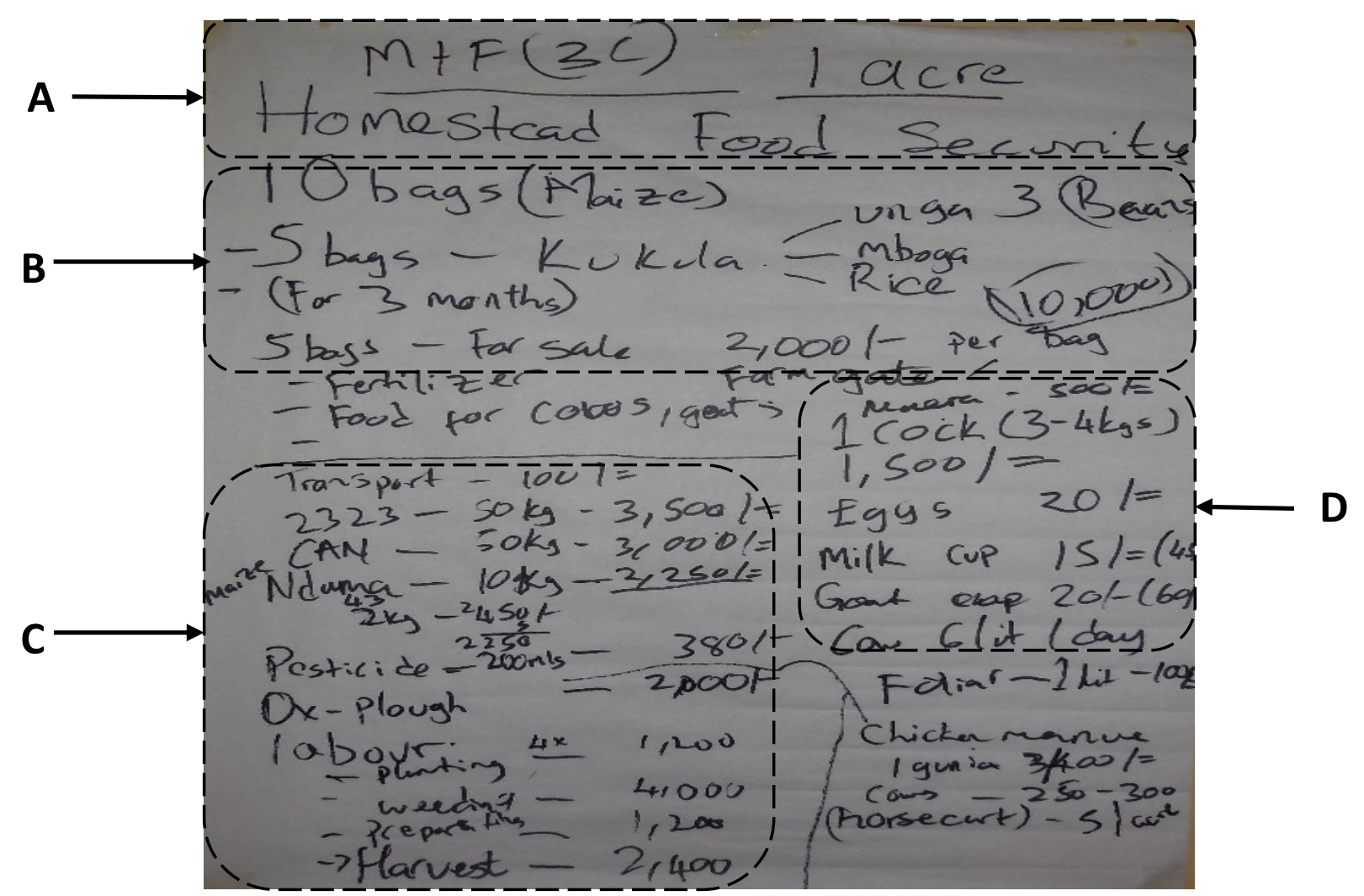

Figure 4.1: Hypothetical household food security scenario generated during an FGD

\section{Notes on Figure 4.1}

A: Household comprising of a male and female adult plus three children farming on one acre

B: Expected seasonal harvest - 10 bags of maize and 3 bags of beans ( $90 \mathrm{kgs}$ each). Family keeps all the beans they harvest but sells 5 bags of maize to meet household needs. Farm-gate price per $90 \mathrm{~kg}$ bag of maize is Shs. 2,000

C: Costs incurred farming an acre of maize and beans in the season - transport, fertilizers (N.P.K. 23:23:0) and top dressing (C.A.N.), Duma maize seed variety, pesticides and labour costs

D: Additional income from livestock in the homestead - one hen (mwera) sells at Shs. 500 while a 3-4 kg cock can fetch Shs. 1,500, a litre of cow milk goes for Shs. 45 while goat milk sells at Shs. 60 
Taking advantage of smallholders' experience in maize farming, a hypothetical scenario was laid out - farming an acre of maize and tallying the various expenses incurred until harvest time. The expected harvests from some of the hypothetical yields are captured in the last three rows of Table 4.1 presented earlier. Figure 4.1 showcases notes taken on a flipchart during one of the focus group discussions where smallholders constructed a hypothetical household food security scenario.

Calculations revealed a deficit between the income generated and the expenses incurred in the above hypothetical scenario. To meet this deficit, farmers seek wage-earning jobs among each other e.g. income from spraying crops and other farm work. While the extra income narrows this deficit, self-sufficiency from one season until the next was a challenge for most of the farmers. To address this challenge, farmers pooled together in social or common-interest groups for additional food security and livelihood support.

\subsubsection{Markets}

On markets, three key components emerged from the smallholders' responses. These include; timing, connectivity and regulations.

\section{Timing}

Farming is good because if you put effort, there is a big profit... I have kales, cabbage, managu (African Nightshade), dhania (coriander or cilantro), spinach, courgette in between. Kales for consumption are bought by local neighbours. It is not even enough because they are many. There are several neighbourhoods here, about five. All come here.... Farming has money because this is for daily business. You will not harvest dhania and they just stay there because everyone eats food daily.

As with other commodities, farm produce is subject to market forces and therefore prone to the rules of supply and demand. From the farmers' responses, there was a distinct difference 
between those who engage in agribusiness versus those who only sell off their surplus harvest (conventional smallholding). The former group was more attuned to the different elements at play and what one needs to consider if they are to fetch a higher price for their produce. The agribusiness-minded farmer tries to maximize their farm productivity and better market experience for maximum profit in two main ways. First, they ensure a steady supply of water so as to farm in and out of rainfall seasons and can target selling at the market when there is less competition. Secondly, they farm produce that would be of high demand in the market and with a wide consumer base. These two approaches are demonstrated in the above quote from an interview with a male farmer who had leased a small parcel of land with irrigation water and chose to grow green leafy vegetables and other condiments.

Another striking aspect of this entrepreneurial farmer was a reverse market system that did not conform to the common practice of the trader taking their goods in bulk to the market and waiting for customers to purchase. A significant portion of his clientele patronized his business right on the farm by coming to buy freshly plucked produce on demand. His market benefits further from the absence of refrigeration units in many of the surrounding households. As a result, the clients can only buy sufficient quantities that would be consumed in a day or twothus forming regular repeat customers

\section{Connectivity}

"You farm blindly". "You don't know how much income you will get".

Integration into local and non-local markets influences farmers' revenues. This was most pronounced among smallholders who grew tea and coffee. Their produce is linked to external 
markets whose pricing is significantly influenced by international forces. Smallholders felt disempowered in maximizing the sales of their produce since they more often than not did not know a priori what prices they would fetch.

Of equal relevance was the issue of transporting produce to the markets. In the region, this remains a significant cost to smallholder farmers who seek better prices by opting to sell at markets rather than secure farm-gate pricing. Farmers rarely coordinate to share transportation of their produce to the markets. However, middlemen perform 'collection runs' to buy produce from several farmers. These brokers make better margins, accrued from the differences between farm-gate and final market pricing. The best evidence from the study was on the brokerage of milk. Farmers deliver milk to local dairies and earn Shs. 35/40 per litre of milk whereas the dairy company later sells it at Shs. 90/100 (after pasteurization and packaging). Besides this, there were experiences of unfulfilled payments from brokers who had collected produce with the promise of paying later.

Kenya has been on the forefront of linking people to services by leveraging mobile phone usage. Among the respondents, none shared having used mobile phone applications. Some stated that where they take their produce is determined by information on best markets through phone calls placed to people in other regions. However, selling in distant markets comes at the risk of being ostracized as an outsider and 'bad-mouthed' by local traders and brokers leading to poor sales of their produce. For perishable produce like tomatoes and cabbages, this risk of low sales is multiplied two-fold. First, even if at the end of the day the farmer is left with a significant quantity that would still be good to sell, they have the added burden of having to transport it back to their homes at cost. Second, if they make this decision and are able to transport their produce, farmers 
have to determine where else to sell for profit. They must also consider that their produce is perishable. In response to this, one horticultural farmer proposed setting up processing plants that would value-add to perishable goods e.g. the conversion of tomatoes into tomato paste, which would have a longer shelf-life.

\section{Regulations}

There was a case that came up in this area. They [local government inspectors] move from one market to another inspecting people's maize. The ones that are not well dried, they take it away and bury. Someone is caught with their maize. When you have put your maize in the market even if it is 10 bags, they take them and go to bury. They dispose it because they have this thing they are calling... [Group interjects "aflatoxin"] Now that issue is very very bad to the farmer because they have not been trained on how to handle that maize and yet to have spent so much money.

Public markets are controlled under the jurisdiction of local county governments. Farmers decried the market levies charged on their produce. The levies are based on the quantities they bring into the market whether or not one has been able to make sales. Regulations are in place to ensure consumer safety. They are implemented through control mechanisms by the local government and focus on the quality of produce sold by smallholders. The examples given by the farmers were the curtailment of milk sales locally and the random market inspections of maize produce for aflatoxin levels. Several farmers lamented arrests by health inspectors who catch them as they sell milk to their neighbours.

The above quote highlights two other issues. The first links to post-harvest management, especially storage and handling, as discussed previously. The issue underscores the existing knowledge gap on harvest handling practices that can reduce post-production losses. Secondly, 
it was apparent that the regulations are often vague, providing an opportunity for abuse by the enforcing officers.

\subsection{Utilization}

"It is not uncommon to see a parent selling eggs so as to buy bread for the children".

The utilization dimension encompasses the ability of an individual to acquire the necessary nutrients from the food they consume (FAO, 2008a). Interactions with smallholders revealed they have a level of awareness regarding nutrition on the basis of their knowledge on what constitutes a balanced diet. However, they stated that food nutrition was not fully practiced at the household level indicating a gap between knowledge and practice. Respondents in the study area exhibited dietary adaptation, which is a global trend. For instance, some mothers shared that their children would prefer sliced bread (processed food) bought at the shops over yams or sweet potatoes (traditional foods) for breakfast.

\subsection{Stability}

Stability implies the maintenance of an uninterrupted state of food security. Food security among smallholders in the study area is unstable. The smallholders define their food security in seasonal timeframes. Hence, temporal perspectives are of primary importance. These temporal perspectives are demarcated by the length of the growing season and by the period between one harvest and the next. Responses to the state of smallholders' food security were more aligned to the question "how much food would you need to last from one season until the next?" in cognition of the temporal perspective. In their response, the farmers would state that they can do their best to farm but underscored the importance good farming conditions that are outside their 
control e.g. adequate rainfall. The smallholders did not have an experience where their food security was guaranteed at all times.

\subsection{Advancing food security scholarship through experiences of Mt. Kenya smallholders}

The preceding five subsections have presented findings from Mt. Kenya smallholders related to their food security. In this subsection, an attempt is made to draw from these findings and highlight how they build on existing food security scholarship.

\subsubsection{Smallholders' food security is nested within their livelihood strategies}

Mt. Kenya smallholders negotiate and strengthen their livelihoods, through diverse and dynamic activities. Smallholders engage in on-farm and off-farm activities geared towards meeting their

food needs and other daily requirements. Their food security is nested within their livelihood strategies and cannot be wholesomely addressed without this recognition. On the one hand, livelihood strategies offer farmers an opportunity to achieve food security. On the other hand, the food that farmers produce must be sufficient to meet both their dietary needs as well as be traded to meet other livelihood needs e.g. school fees. This bi-directional relationship between food security and livelihood security seems to be largely absent based on a review of the dominant literature.

In the transitions from conventional smallholding to agribusiness, Mt. Kenya smallholders demonstrate that livelihood improvements can be pursued through better food production. This is in line with other studies (FAO, 2012; FAO, CTA, \& IFAD, 2014; Miruka et al., 2012) that reveal agribusiness among smallholders as key to their economic empowerment and livelihood improvement. The economic development of smallholders, mainly through increased agricultural 
productivity, has been recognized as a model to reduce poverty levels especially in rural areas (Birner \& Resnick, 2010). In turn, this affects how smallholders engage with urban populations (Djurfeldt, 2015). For instance, in pursuit of economic stability, studies in India show that selfemployment and entrepreneurship are preferred 'quick routes' out of poverty among farmers (Harris \& Orr, 2014). This trend is achievable in other regions.

In Kenya, entrepreneurship based on agricultural produce is referred to as kilimo biashara (agribusiness) - a term that was commonly used by farmers practicing agribusiness in the study area. This concept of farming-as-a-business was formally stipulated in the Agricultural Sector Development Strategy (ASDS) under the umbrella of Kenya's Vision 2030 (FAO, 2014). Agribusiness is a more lucrative approach for younger farmers (FAO, 2014; FAO, CTA, \& IFAD, 2014) who are eager to have steady cash flows. Agribusiness offers a platform through which other services can be integrated e.g. the use of ICTs, mainly via the mobile phone in Kenya. Some farm management applications such as MFarm ${ }^{17}$ have taken root in Kenya (FAO, CTA, \& IFAD, 2014) riding on the deep penetration of mobile phone usage and wide network coverage. However, agribusiness-oriented smallholders face several challenges based on the informality of their business and their lack of participation in economies of scale (FAO, 2012). These challenges may require strong institutional linkages that integrate them better into value chains and markets.

Smallholders are motivated to engage in non-farm activities and generate additional income due to the seasonality and year-to-year variability in agriculture (Burke \& Lobell, 2010a). The income

\footnotetext{
17 MFarm offers a mobile phone-based trading platform that links subscribed farmers and buyers of agricultural produce. Their online site offers updates on prevailing produce prices as well as information on best farm practices. See www.mfarm.co.ke.
} 
helps in supplementing their food as well as livelihood needs. In his paper on rural livelihoods, Ellis (1998) identifies five main categories from which non-farm income is drawn: (i) employment for wages, (ii) self-employment, (iii) income from properties, (iv) remittances from within the country, and (v) remittances from international sources. Among Mt. Kenya smallhol ders, only the first two, wage- and self-employment, were dominant. On-farm wage labour is more sensitive to seasonality as incomes are affected by level of agricultural output and productivity (Wiggins \& Keats, 2013). This was supported by similar observations among Mt. Kenya smallholders.

\subsubsection{Pre-production processes key to food security}

As a commercial and subsistence crop, maize is considered one of Kenya's most important grains (Brooks, 2014) and forms the staple diets of many Kenyan ethnic communities. Unsurprisingly, all participants in the study planted maize. Kenya has documented success in the adoption of hybrid maize varieties with recorded increases in incomes among the farmers who switch from traditional ones (Mathenge, Smale, \& Olwande, 2014). As with fertilizer, there was a surge in the adoption of improved seed varieties following the launch of the National Accelerated Agricultural Inputs Access Program (NAAIAP) in 2007 (Sheahan, Black, \& Jayne, 2013). At the farm level, the decision to switch to newer or improved seed varieties from traditional types is often hampered by ignorance, costs or perceived risks (Burke \& Lobell, 2010b). In many instances, the costs of improved seeds are a significant expense, with higher prices occurring when demand for the seeds rises (Rao et al., 2014). Due to their popularity in Kenya, some traditional seeds (e.g. of vegetables) have made their way into commercial seed companies such as Kenya Seed who then produce and supply them as certified seeds (Muthoni \& Nyamongo, 2010). Although not yet 
widespread, the commercial production of traditional seeds is contrary to what some scholars (Challinor et al., 2007) had deemed possible in the African context.

The decline in soil fertility expressed by farmers has been recorded in other parts of Africa (Amekawa et al., 2010) necessitating the use of manure and mineral fertilizers. On the basis of quantity applied per unit farmed, African farmers lag behind in their use of fertilizer in comparison to those in developed countries (Mapfumo et al., 2013; Wiggins \& Keats, 2013). In Kenya, an increased demand from smallholders coupled with better access to commercial fertilizer saw its usage double nation-wide in the period between 1990/1991 and 2007/2008 (Sheahan, Black, \& Jayne, 2013). The concerns raised by smallholders on the ever increasing costs of fertilizer have been linked to higher fuel prices (Hanjra \& Qureshi, 2010). As a result, farmers cut down on fertilizer usage which consequently depresses crop productivity (Ariga \& Jayne, 2011; Chamberlin \& Jayne, 2013).

The Kenya Seed Company recommends fertilizer application rates of 185 kilograms per hectare ( $\mathrm{kg} / \mathrm{ha}$ ) of diammonium phosphate (D.A.P. $18: 46: 0)$ and $370 \mathrm{~kg} / \mathrm{ha}$ for Nitrogen, Phosphorous, Potash (N.P.K. 23:23:0) during planting (Kenya Seed Company, 2015b). The average application rate reported by Mt. Kenya smallholders of $124 \mathrm{~kg} / \mathrm{ha}$ falls below the recommended rates. However, their fertilizer use is more than ten times the reported average in sub-Saharan Africa which ranges between 8 and $10 \mathrm{~kg}$ per hectare (FAO, 2008b; Mapfumo et al., 2013). Of concern is whether the smallholders are using the correct type of fertilizer given their claims that high costs prevent them from taking soil samples for testing.

Claims by smallholder farmers in the study that availability of irrigation water offers significant advantages have also been made elsewhere (see Burke \& Lobell 2010b). Many view the lack of 
reliable farming water supply as the greatest constraint to their productivity. This finding was reported in Machakos, a region bordering the drier south eastern part of Embu county (Brooks, 2014). Unsurprisingly, there is a high number of small-scale irrigation projects in the region, which now face challenges of overuse. This is in part driven by goodwill and the sense of community reported earlier where farmers seek to maximize mutual benefits. In the future, it is expected that increased water scarcity rather than decreased availability of arable land will pose a greater challenge to food production globally (Hanjra \& Qureshi, 2010). Regular water assessments are therefore necessary to inform availability and act as a basis for water allocation and management (Kang, Khan, \& Ma, 2009).

\subsubsection{Agricultural productivity and bridging the yield gap}

Over the last half century, global food production has increased to levels that are adequate to meet calorie needs of the current population (Burke \& Lobell, 2010a). The most notable contribution towards this growth emanates from technologies adopted during the Green Revolution (Amekawa et al., 2010; Granoff et al., 2014). However, food production increase is uneven across different global regions and within different farming communities in these regions. In Africa, net productivity has increased but growing populations have led to a reduction in per capita food production (Bennett \& Franzel, 2013). Low productivity in sub-Saharan Africa has often been blamed on soil degradation from nutrient depletion and erosion (Giller et al., 2009) as well as on the poor uptake of new technologies that would be more beneficial vis-à-vis traditional methods (Eidt, Hickey, \& Curtis, 2012). In scholarly literature, the gap between actual and potential yields is referred to as the 'yield gap' (Burke \& Lobell, 2010a). For sub-Saharan 
Africa (SSA), this gap is noted to be as high as $76 \%$, implying that farmers' produce only a quarter of their maximum potential (Wibberley, 2014).

The two maize varieties mentioned earlier are ideal for the study region's altitude.

Table 4.2: Expected maize yield projections by seed companies

\begin{tabular}{llllll}
\hline Variety & $\begin{array}{l}\text { Release } \\
\text { date }\end{array}$ & Produced by & $\begin{array}{l}\text { Production zone } \\
\text { (m.a.s.I.) }\end{array}$ & $\begin{array}{l}\text { Maturity } \\
\text { (days) }\end{array}$ & $\begin{array}{l}\text { Expected yield } \\
\text { (kg/ha) }\end{array}$ \\
\hline $\begin{array}{l}\text { Hybrid 614 } \\
\text { (H614D) }\end{array}$ & 1986 & Kenya Seed Co & $1500-2100$ & $160-190$ & 8,450 \\
\hline SC Duma 43 & 2004 & Agri SeedCo Ltd. & $800-1800$ & $120-150$ & 6,500
\end{tabular}

(SC 407) (SeedCo Kenya)

Note: Hybrid 614 data drawn from Africa Seed Trade Association (2013) and Duma 43 data from Kenya Seed Company, (2015a)

As shown in Table 4.2, the varieties Hybrid 614 and Duma 43 are ideal for an altitude range of 800-2100 meters above sea level (m.a.s.l). The smallholders farmed in areas that were between 1240-1770 m.a.s.I. As indicated in section 4.2.2., the average estimates from maize yields realized by smallholder farmers in the region were $2,000 \mathrm{~kg} / \mathrm{ha}$. When compared to projected yields given by seed companies for the two varieties as in Table 4.2 above, a yield gap of between $69 \%$ and $76 \%$ is reflected. This estimate corroborates the $76 \%$ yield gap across SSA reported earlier.

Studies in high potential areas of Kenya indicate that higher yields are realized from the use of hybrid seeds versus ordinary ones irrespective of fertilizer use (Ariga \& Jayne, 2011; FAO, IFAD, \& WFP, 2015; Mather, Boughton, \& Jayne, 2013). Higher yields mean better incomes and lower poverty levels as was corroborated by a study from analysis of 2000-2010 data by Mathenge et al. (2014). However, in the absence of instruction on proper use, some farmers who opt to recycle hybrid maize seeds have observed increased incidence of the Maize Streak Virus (Gichuru, 2013) thereby eroding any potential gains that would have otherwise been realized. Similarly, lower rates of return on improved seed varieties occur when insufficient water is available for farming 
(Headey \& Jayne, 2014) or inappropriate dosage and type of fertilizer is used (Mather, Boughton, \& Jayne, 2013). Interactions with smallholders in Mt. Kenya could have been further explored to include details of crop spacing, dosage and water availability in order to identify practical ways that these groups of farmers can improve their productivity.

Closing the yield gap is best achieved through better management practices (FAO, 2015) such as improvements on sub-optimal weeding (FAO, ISD, \& TWN, 2011). In Kenya, agricultural productivity is said to be on the decline (Amaru \& Chhetri, 2013) and, inherently, crop productivity is sensitive to climate variability (Challinor et al., 2007; Meijer et al., 2014; Ziervogel \& Calder, 2003). As a response to the decline, in its Vision 2030, Kenya formulated policies that would boost agricultural productivity through seeds, pesticides and fertilizer use as well as investments in agricultural research (FAO, 2014; Miruka et al., 2012). These government initiatives increased the number of players who engage with smallholders and added levels of bureaucracy that smallholders must navigate as they seek to maximize their farming efforts and generate maximum yields. The benefits of these initiatives are yet to be fully realized by Mt. Kenya smallholder farmers.

Upon harvest, smallholder farmers are often faced with management challenges. They expressed their efforts to keep drier foods such as maize and beans to last them from one harvest season to the next. Humidity-induced aflatoxin, theft and attacks by pests often hamper these efforts. The post-harvest losses reported among the smallholders in the study are a snapshot of the $30 \%$ losses in harvested maize registered by farmers across Kenya (Speca, 2013). Other studies among maize farmers in Kenya indicate that most can only keep the grain for two months as urgent cash needs compel them to sell $(F A O, 2014)$ often at lower prices. Some smallholders added that their 
harvests are also directly exchanged for school fees thus eliminating the necessity of cash to meet such needs.

Scholarship from extensive surveys conducted among farmers, including those in Kenya, reveals that the ratio of what a smallholder sells or keeps for their own consumption is constantly in a state of flux. Several factors such as seasonality, market prices and household needs are cited as reasons why a smallholder may at one point be a net buyer while at another time be a net seller (Barrett, 2002; FAO, 2011, 2014; Sheahan, Black, \& Jayne, 2013; Stephens et al., 2012). The definitions of net buyer and net seller are dependent on comparisons of how much a household consumes versus how much of their consumption is from their own farm production. Smallholders in the study demonstrated that they balance between these two states by diversifying into income-generating activities on-farm (e.g. rearing chickens for meat and eggs) as well as off-farm (e.g. seeking employment). Access to food at household levels must therefore be assessed by examining incomes and expenses as well as existing policies (European Commission (EC) \& FAO, 2008). Since the buyer and seller meet at the market, integration from local to regional levels plays a significant part in the prices and revenues that a smallholder can fetch from their produce (Burke \& Lobell, 2010a).

In section 3.1.3, there was a brief discussion on the complexity and interactions across scale. The empirical findings of this research position the smallholder farmer amid complex global, regional and local scales. On a local scale, smallholders are faced with dynamic conditions under which they produce their food. Key among these are shrinking land sizes, water scarcity, and high costs of inputs. Smallholders' post-production processes involve the interaction at regional levels with various markets. With increased globalization, power balances between farmers and retailers 
have shifted to the latter group (Gregory, Ingram, \& Brklacich, 2005), thereby undermining the ability of smallholders' activities to be economically viable. This is supported by claims from smallholders dealing with coffee and tea who have to sell their produce to international markets but through brokers such as factories or co-operatives. These farmers complained that, in comparison, the brokers made more revenues from the transactions yet the farmers undertook the production.

\subsubsection{Utilization and stability remain elusive among smallholders}

Mt. Kenya smallholder farmers did not have much to say regarding the utilization dimension of food security. Their contributions on nutrition and food choices at the household level however reveal that dietary adaptation trends, which are common in urban areas where lifestyles are more fast-paced (FAO, 2004), are now observable in rural areas. Smallholders are primarily concerned with feeding their households by growing produce on their farms or purchasing from local markets. The nutritional quality of the food or the nutritional outcomes they hope to gain from its consumption are of lesser concern. Further, the experience of food security stability among the farmers was largely absent. The environment where farmers negotiate their livelihoods is prone to shocks and interruptions that interfere with their efforts to sustain food security. Smallholder farmers from Mt. Kenya highlight a weakness in the determination of food security status through the four dimensions - they are not of equal weight. The many concerns raised by farmers rest on availability and access and until they have successfully been able to guarantee these, smallholders will not be keen on the utilization and stability dimensions. 


\subsubsection{Related concerns among smallholders}

Discussions with smallholder farmers on matters related to food security revealed several concerns that transcend the production and consumption of food. These issues broaden the scope through which global food security concerns among smallholder farmers should be assessed. Primary among these was the future of smallholder farming, the rural-urban relationship, and increase in disease burdens.

\section{Intergenerational farming}

For the kids to tell them to return to farming they hear like that is a dream. You see? The sons want that when you divide for them some land, they sell and go into the matatu [minibus] business. That is the fight we have here between the children and parents. "You give me the portion you would have allocated to me so I can sell and get into the road"...It is because they want money that is quick to get. They do not want to get tired. That's why you see many young men have gone into the miraa [khat] and bhangi [marijuana] business. I say that when I am alive, I never want to see miraa in my place. True it is quick money but if you look at a miraa farmer, what have they built? How has he developed where he is? He will not tell you. Eventually he sells and goes towards liquor. That's how things are. The youth are not thinking about farming. They want something that brings money quickly if you give them a chance. They do not think about tomorrow.

The smallholders in the study expressed concern on the future of their children and smallholder

farming. First, given the small land sizes that they were presently cultivating, the farmers were unable to utilize their grown children's labour. Consequently, their children must find meaningful work themselves and the parents can only hope that they will secure decent income. Secondly, the smallholders purported that the current generation of youth were unwilling to toil and labour for hours on farms. They instead prefer to work on tasks that require lower investments in time and physical energy but offer higher and faster rewards. The case in point being the business of harvesting the stimulant known as khat (Catha edulis) also locally called miraa, which is grown in the neighbouring districts. Youth who harvest khat are able to work for four hours early in the 
morning and earn a wage that would be equivalent or even more than full-day wages from other on-farm work. Resultantly, the youth are then able to have more free time - allowing for engagement in other uses of their time, which their parents often view as non-constructive. Thirdly, the high levels of unemployment among the youth give rise to idleness and consequently, there is an increase in incidences of unbecoming behaviours such as engaging in petty theft and patronizing local liquor dens.

\section{Complexity of rural-urban relationships}

The rural poor face more hunger than their urban counterparts (Burke \& Lobell, 2010a). In part, this arises from documented urban biases exhibited by government policies that favour these areas over their rural counterparts (Djurfeldt, 2015). Smallholders added a different perspective to this - one where the relationship between them and their urban kin is not mutually beneficial.

Farmer 1: When you people who live in Nairobi come to the village, you do not count that your eating is an expense, bathing is an expense and cooking is also an expense [Group chatters]... When that child of yours comes you give them some of the maize you harvested to carry back with them.

Farmer 2: And at times you may find that they want you to also pay for their ticket back

Farmer 3: They see that in that compound, there are goats, chickens and they say you should slaughter one for them. And then they keep reminding you "I will return to the city on Monday" so that you prepare some beans, maize, bananas and potatoes.

Facilitator: And they are not buying these from you? [Group affirms]

Farmer 4: So they had better remain where they are

The smallholders expressed sentiments that their urban kin took advantage of them. In one such case during a discussion group, farmers expressed the unsustainable expectations of their urban relatives who visit and anticipate returning to their homes loaded with harvests from the smallholders. The urbanites seem detached from the livelihood struggles of rural smallholder farmers. One striking absence from the interaction with smallholders was the existence of 
remittances from their relatives in urban areas. In their experience, the provisions they make to accommodate their urban relatives' demands are inadequately reciprocated. This insight from Mt. Kenya's smallholders supports the proposition that the "balance between producing for growing African urban populations and the livelihood strategies of rural people must be negotiated" (Flora, 2010, p. 126).

\section{Increase in disease burden}

"Cancer has been on the increase in every family."

As earlier mentioned, smallholders are aware that dietary patterns and preferences have been changing as reflected by the foods consumed in their households. They recognize that such changes come at a cost and more so, can be detrimental to their health. They cited the rising cases of diabetes and high blood pressure - diseases that are often observed among elite urbanites who are more prone to have sedentary lifestyles in contrast to the active farm life of smallholders. Whereas they did not offer comments on how these affects the ir productivity, it is clear that the management of these diseases poses a bigger challenge given their limited financial resources.

\subsection{Chapter synthesis}

The aim of this chapter was to present research findings related to food security concerns among smallholder farmers. The chapter began by offering insights into smallholders' livelihoods and revealing a trend of shifting from conventional farming to agribusiness. A key finding is that among smallholders, food security and livelihood security are inextricably linked. This is because from their farm produce, smallholders expect to meet livelihood needs. Further, smallholders 
demonstrated that they engage in income-generating activities to meet their livelihood and food security needs. For example, from wages earned from on- or off-farm work, a farmer may use part of it to pay their child's school fees and the remainder to buy seeds for the next planting season. Table 4.3 contains a summary of concerns related to food security among Mt. Kenya smallholder farmers.

Table 4.3: Summary of smallholders' concerns related to food security

\begin{tabular}{|c|c|}
\hline Input/Resource & Smallholders' concerns \\
\hline Seeds & $\begin{array}{l}\text { - The shift from traditional (poor performing) to improved (high yielding) seeds is often } \\
\text { hampered by high costs } \\
\text { - Weak quality control, checks and balances resulting to an increase in counterfeits } \\
\text { - Knowledge gap on ideal seeds (by climate or soil) can be brokered by agrodealers who are } \\
\text { key informants }\end{array}$ \\
\hline $\begin{array}{l}\text { Fertilizer \& } \\
\text { Manure }\end{array}$ & $\begin{array}{l}\text { - Gatekeepers such as the NCPB and related bureaucracies can be a great hindrance limiting } \\
\text { access } \\
\text { - Evidence of improper application in both type and timing } \\
\text { - Cost is the biggest inhibitor }\end{array}$ \\
\hline Water & $\begin{array}{l}\text { - Guaranteed water supply is seen as an anchor to increased food availability } \\
\text { - Governance concerns on the management and regulation of irrigation schemes } \\
\text { - Food crops for daily consumption e.g. green leafy vegetables require high water supply }\end{array}$ \\
\hline Treatments & $\begin{array}{l}\text { - There has been an increase in the need to use treatments } \\
\text { - High costs raise the greatest concern } \\
\text { - Increased cases of pest resistance } \\
\text { - Lack of knowledge leading to improper usage both in quantity and timing }\end{array}$ \\
\hline Livestock Feeds & $\begin{array}{l}\text { - Competing demands e.g. using crop residues for manure or for livestock feeds } \\
\text { - High costs both in terms of transport and purchase price }\end{array}$ \\
\hline Labour & $\begin{array}{l}\text { - For those employing, wage spikes during peak demand periods } \\
\text { - Shortage of farmhands either due to competing labour needs or outmigration }\end{array}$ \\
\hline Land & $\begin{array}{l}\text { - Shrinking farm land sizes due to population growth and subdivisions for inheritance } \\
\text { - Intergenerational concerns on who will take over their farming when they no longer can }\end{array}$ \\
\hline
\end{tabular}

A majority of the concerns arise before the smallholder undertakes food production. The literature makes mention of some of the challenges echoed by the smallholders. However, it does not emphasize the importance of addressing the issues collectively in order for the farmer to start the production process. The existing definition of food security as bounded by the availability dimension does not offer sufficient focus on the background processes that a farmer needs to accomplish prior to making food available. 
Key lessons are summarized in Table 4.4. In the 'advancing scholarship' column, italicized points

build on existing scholarship while points in regular font offer support for what is already

established.

Table 4.4: Summary lessons from Mt. Kenya smallholders and advancing scholarship

\begin{tabular}{|c|c|c|}
\hline Attr & Learning from Mt. Kenya smallholders & Advancing food security scholarship \\
\hline Live & $\begin{array}{l}\text { - Food and livelihood security are } \\
\text { inextricably linked } \\
\text { - Social support is sought when food and } \\
\text { livelihood needs are not met at household } \\
\text { level }\end{array}$ & $\begin{array}{l}\text { - Additional support to livelihoods among } \\
\text { smallholder farmers } \\
\text { - More emphasis on the need to examine symbiotic } \\
\text { relationship between livelihood and food security }\end{array}$ \\
\hline Avai & $\begin{array}{l}\text { - Pre-production processes and inputs are } \\
\text { key } \\
\text { - Compromises on pre-production processes } \\
\text { limit food availability }\end{array}$ & $\begin{array}{l}\text { - Additional support for food production among } \\
\text { smallholder farmers } \\
\text { - A more nuanced view of the availability dimension } \\
\text { is needed to highlight importance of pre-harvest } \\
\text { processes }\end{array}$ \\
\hline Access & $\begin{array}{l}\text { - Cost of farming, incomes and purchasing } \\
\text { power determine food access at the } \\
\text { household level } \\
\text { - Timing of produce sales, market integration } \\
\text { and regulations are important }\end{array}$ & $\begin{array}{l}\text { - Additional support for physical and economic } \\
\text { access dimensions of food security }\end{array}$ \\
\hline Utiliz & $\begin{array}{l}\text { - Given that availability and access continue } \\
\text { to be persistent concerns, utilization is not } \\
\text { central to food security issues among Mt. } \\
\text { Kenya smallholders }\end{array}$ & $\begin{array}{l}\text { - Experiences from Mt. Kenya smallholders suggests } \\
\text { that the four food security dimensions are not equal } \\
\text { and there is a need to understand dynamics across } \\
\text { all dimension }\end{array}$ \\
\hline Stability & $\begin{array}{l}\text { - This concept is largely absent from the } \\
\text { experiences of the smallholders due to the } \\
\text { numerous uncertainties they face. } \\
\text { - Smallholders use seasonal timeframes } \\
\text { demarcated from one harvest to the next } \\
\text { rather than an uninterrupted food security } \\
\text { state }\end{array}$ & $\begin{array}{l}\text { - Adds on to the many causes of instability and } \\
\text { uncertainty already established in food security } \\
\text { scholarship } \\
\text { - There is a need to reconcile the temporal scale used } \\
\text { by smallholders with that given in the food security } \\
\text { definition of this dimension }\end{array}$ \\
\hline $\begin{array}{l}\text { Other } \\
\text { concerns }\end{array}$ & $\begin{array}{l}\text { - Shrinking farmlands and the lack of interest } \\
\text { in younger generations to take over farming } \\
\text { from the older one raise concern among Mt. } \\
\text { Kenya smallholders } \\
\text { - The relationship between the smallholders } \\
\text { and their urban kin is often not reciprocal. }\end{array}$ & $\begin{array}{l}\text { - The future of farming among smallholders is } \\
\text { already a concern at the grassroots level. There is a } \\
\text { need to have an engaging conversation at broader } \\
\text { levels to seek for lasting solutions to posterity's food } \\
\text { security } \\
\text { - Offers additional support for calls to re-examine } \\
\text { rural-urban balance }\end{array}$ \\
\hline
\end{tabular}




\section{Chapter 5. Smallholders and Institutions}

Smallholders acknowledge self-sufficiency is routinely beyond their grasp and they seek external support from formal and informal institutions to bridge this gap. Smallholders' food and livelihood security are linked. At the household level, smallholders do not differentiate between resources to meet food requirements and those for broader livelihood needs. This chapter examines how smallholders utilize institutions to meet both their livelihood and food security needs when their individual or household capacity is limited.

This chapter presents discussions on the institutional arrangements outside the household level among smallholders in the Mt. Kenya region. The first section discusses how the smallholders engage different institutions, both as individuals and as households. The second section highlights some of the crosscutting concerns emanating from these institutional arrangements. In the third section, the discussion was broadened to incorporate insights from existing scholarship. Lastly, the chapter offers a synthesis of the findings and key messages.

\subsection{Arenas of institutional engagement}

This section explores the arenas of engagement between smallholders and institutions. Responses from the smallholders revealed four areas related to inputs, farm produce, financing and information where interactions with institutions were most prominent. The first subsection concerns the acquisition of inputs and is directlylinked to the pre-production processes discussed in Chapter 4. Marketing, sales and financing in the next two sections are tied to the access dimension and post-harvest management discussed in Chapter 4. The last subsection on information and training discusses ways through which smallholders seek to fill their knowledge gaps through institutional arrangements. 


\subsubsection{Acquisition of inputs and farm or household resources}

That cow that I milk, I got it from group financing. We contributed for a long time and we pondered on how to use the money and when we saw that the money is a substantial amount, the chairman asked us what we would like to do with it. If it stayed in the bank we are just being charged. We told him to go withdraw it and we can utilize it. And now since the group is ours and the money is also ours, we were each given Shs. 5,000. And we were told to each go buy a cow. Do you know that at this time there are no cows costing Shs. 5,000 ?

As discussed in Chapter 4, the purchase and acquisition of inputs prior to the start of the planting season is a primary concern among smallholders. In recent times, they claim that prices of inputs have escalated and some have resorted to buying the inputs jointly in order to maximize on economies of scale. For example, a smallholder farmer in her 30 s shared that her informal group had pooled together and purchased onion seeds, which they planted to germinate in a common nursery prior to sharing the seedlings and transplanting into their individual farms or plots. According to the farmer, it would have been impossible to set up the onion farm on her own since the price of the seeds were prohibitive.

Smallholders utilize existing groups to achieve several objectives. For example, an existing group of farmers belonging to a small scale irrigation scheme set a target that each member would plant at least twenty high-yielding banana stems of the Fhia $17^{18}$ variety. The group made bulk purchases of the banana tubers from the Kenya Agricultural Research Institute (KARI), thus benefiting from wholesale discount pricing. Initiatives to improve food security among smallholders can successfully be achieved through complementary activities.

\footnotetext{
18 This is a high yielding and fast maturing variety. With expected yields of up to 100 kilograms per stem, farmers expect to fetch good prices once they sell their bananas.
} 
Although most farmers purchase fertilizer directly from agrodealers and farm inputs stockists, a few had a fair amount of experience acquiring the government-subsidized fertilizer distributed through the National Cereals and Produce Board (NCPB). Conversations with an agrodealer revealed that some government subsidies for farm inputs are passed on to farmers through agrodealers. An example of this is the Kilimo Biashara (farming as a business) program that offered coupons to registered agrodealers who sell certified inputs (seeds, fertilizers, and treatments) fertilizers from the NCPB, as will be discussed in Section 5.2.

Responses from the smallholders displayed important agriculture-related roles played by religious groups in the region. Most prominent were local dioceses of the Catholic Church, which had introduced livestock rearing projects (chickens, cows and dairy goats), as well as chamomile farming. According to one of the respondents, the Catholic Church had installed a solar power kit in her house that provided lighting in at least three rooms as well as a charging station for her mobile phone. The immediate benefits were a reduction in the expenses she previously incurred by buying candles or kerosene for her lamps. Bundling of such interventions at the household level yields benefits in overall quality of life.

Smallholders demonstrated an ability to acquire water resources as a group through small-scale irrigation schemes. Some of these irrigation initiatives are farmer-led where they get together as a group, formulate a project proposal and seek funding to implement it. In one such example, some participants shared that they had been successful in securing funding from Plan International, a nongovernmental organization working in the region. The smallholders are required to contribute through labour inputs while the funding goes to cover materials and 
equipment. The involvement of smallholders aims to cultivate local ownership of the project and improve its sustainability as they remain committed to the successful functioning of the project. An interview with a smallholder in the lower and drier regions of the study area however revealed that widespread success of such farmer-initiated projects is elusive. The farmer described that their attempts to find a donor had been unsuccessful so far. He also made it clear that it was impossible for them to implement the project on their own without external support. Although the irrigation water would mainly be for farm use, the smallholder added that the situation would have been worse if parts of the area did not have supply connections to the Embu Water Supply Company (EWASCO) network. It is apparent that small-scale irrigation projects are expensive relative to the ability of smallholders in raising the capital. Whereas the smallholders can contribute towards labour and the costs of piping on-farm, the greater challenge is meeting the infrastructure costs from the water source to the farm. Thus lies the potential of further engagement between organizations and smallholder farmers in implementing capital-intensive projects.

\subsubsection{Marketing and sales}

As a response to the notoriously low farm-gate prices offered by buyers, smallholders occasionally resort to selling as a group in order to fetch better pricing. However, this strategy only works if they are able to produce both sufficient quantities and the right quality of the

produce that the buyers are seeking. For instance, some smallholders use their groups to collectively sell their bananas where the price is set per kilogram. By utilizing group sales, they are able to cut down on costs such as transporting to the market since the buyers come to the farms, thus allowing farmers to retain more profits from their sales. A good example comes from 
the irrigation scheme cited above that set targets for each of its members to plant 20 stems of the Fhia 17 banana variety. The farmers look for buyers who need to purchase bananas in bulk since they can raise a good supply of the produce among them. Of equal importance, the group is able to select a buyer with whom they would negotiate a fair price for the produce.

The other marketing model through which smallholders utilize organizations is via contractual agreements with factories, cooperative societies, private companies, and other institutional or large clients. Farmers in the study made use of factories to sell their coffee and tea, cooperative societies to deliver their milk, and some had arrangements with private companies to supply horticultural products such as French beans. For the latter, such contractual arrangements between the company and the smallholder entail the entire production process. This means that the company supplies the farmer with all the necessary seeds and inputs and, at harvest time, they purchase the produce from them making payments after deducting their costs of inputs.

\subsubsection{Financing}

You see you cannot tell somebody to go to a [conventional] financier because you will be told to give your title deed and maybe you don't have one. Perhaps you don't have that much to do with it [the loan] on the farm unless somebody wants a development loan. Then you have to also take care of how you will pay back. Another big problem is because people do not depend too much on farming that can be able to pay back a loan. So they feel unsafe to take a farming loan.

The main problem is funding so our farming is not successful because our pockets are not in good shape. If we have funding, we could have food in surplus.

Financial services providers are crucial to the farming practices among smallholders and three main types of financing institutional arrangements were described by the farmers. These include

formal financial institutions (conventional financing), factories or co-operatives, and financing from informal groups. 


\section{Conventional financiers}

In the study region, farmers shared their limited financial arrangement experiences with formal banks and micro lenders. Whereas these types of institutions were less popular sources of financing for individual smallholders, they are commonly used for group lending. For instance, smallholders who have formally registered groups can benefit from government infinitives such as the Women Empowerment Fund (WEF) and the Uwezo Fund (for women, youth and persons with disabilities). Individual smallholders shy away from such organizations due to the high interest rates, risks of payment defaults, and qualification barriers such as collateral requirements.

\section{Factories and cooperatives}

Smallholders farming coffee and tea shared their experiences on financial arrangements with the cooperatives and factories with which they are registered. In a typical arrangement, if the farmer seeks to obtain some credit, they approach the finance or accounts office and submit a request. The most common reason for seeking financing from these organizations is to meet school fees and related requirements for their children. One smallholder farmer who cultivated both coffee and tea delivered the produce to different factories. She went on to elaborate that the credit approved by the factories is only a portion of the expected income that can be earned from the payout of their deliveries. The approval is based on the farmer's past delivery and loan repayment records.

Financing from tea or coffee factories and co-operatives is however not as easily accessible as smallholders would wish. The smallholders take farm inputs such as pesticides and fertilizers on credit against their anticipated income from produce sales. Therefore, if they are to borrow 
money for school fees, the accounts manager must also assess other outstanding debt that the farmer is likely to accrue. There are instances when the farmer is able to secure a school fees loan but their projected earnings limits access to farm inputs on credit. Farmers also shared instances when they have a negative balance at the end of the pay period. This they elaborated occurs when they borrow more than their projected earnings could cover. Their debt is carried forward and deducted in the next pay period. It is clear that obtaining financing from such organizations comes with trade-offs and the smallholder must prioritize both their livelihood needs and necessities of farming.

\section{'Chamas' - Informal groups}

In this last category lauded as the safest form of financial capital, farmers shared their experience with operating and benefiting from informal groups. Since they live in communities and have familial and neighbourly relations, smallholders often come together and form a group through which they can save money and support each other. These groups are locally known as Chamas and often run under the Rotating Savings and Credit Association (ROSCA) model. The common operating principles across these groups are defined by characteristics such as frequent meetings, table banking, social support and governing members e.g. chair, secretary and treasurer. Members of informal groups who pool their financial resources as savings come up

with a mechanism to have each of them benefit from the funds. Individual smallholders divulged that they benefit financially from these informal groups via table banking in three ways: rotatory slot, borrowing from group contributions and interest at year-end. The schematic in Figure 5.1 below shows how such financial arrangements work. 


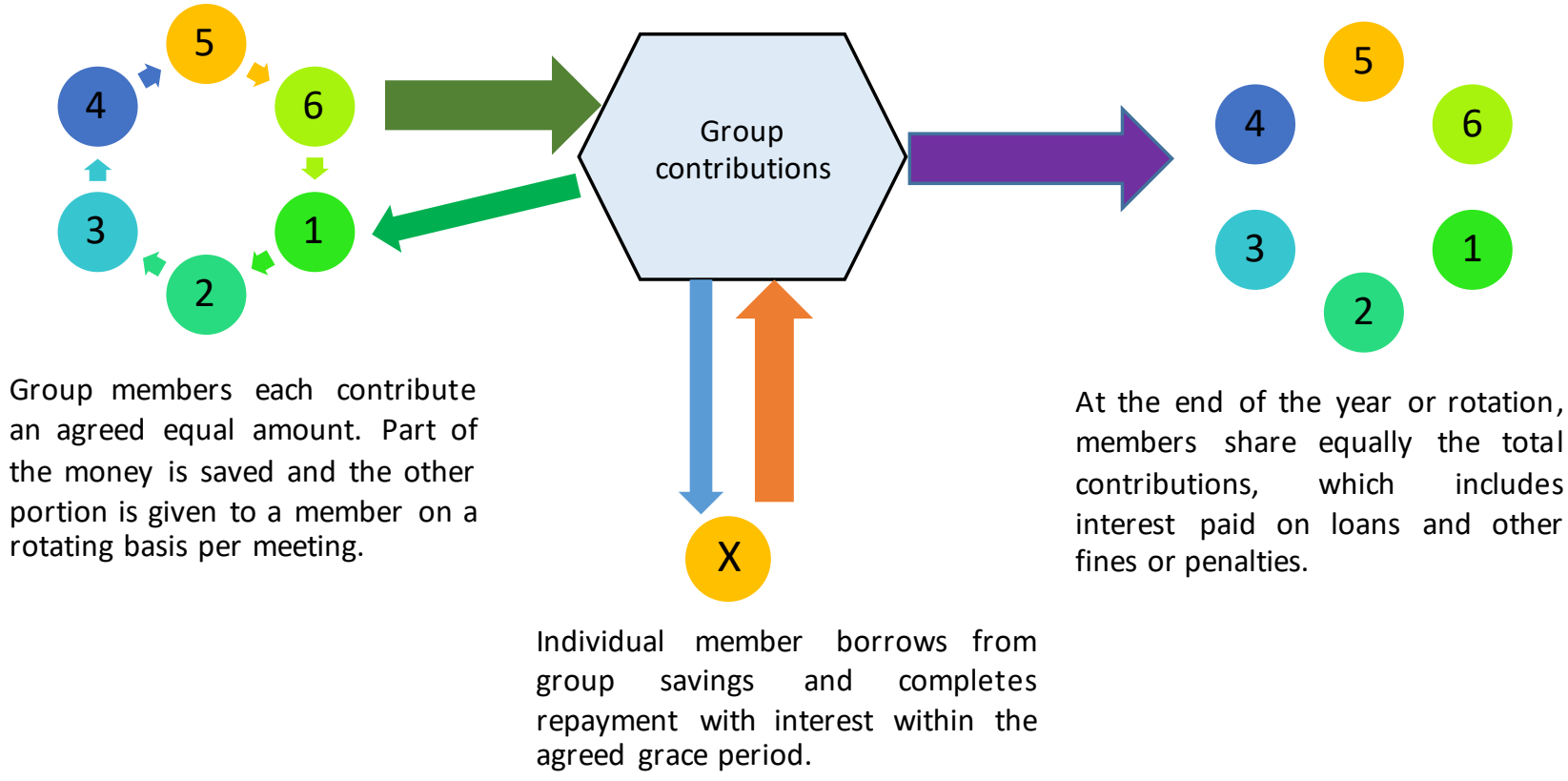

Figure 5.1: Common financial arrangements among most 'Chamas' (informal groups)

At the end of the cycle, which could be the calendar year or when all members have received the rotating funds, the group decides to reorder the rotation often through ballots where they pick numbers. The group can also decide to add the value of mandatory contributions, review the amounts set for penalties, or start saving for a new project in the new cycle or coming year.

\subsubsection{Information \& training}

We were recently trained during a Farmer Field School by KTDA [Kenya Tea Development Agency]. The theme was on sustainable agriculture and we were taught well.

Smallholders engage agents in different institutional arrangements to gain knowledge or new information that would potentially benefit their agricultural practices. Most of the smallholders reported interactions with formal institutions and had received training on agriculture. These trainings and information sessions involving groups of farmers are often delivered through church-initiated projects or those run by development agencies and private organizations. 
Group learning also occurs through home visits. Members of the informal groups that have regular meetings, hold their meetings in different (rotating) venues - usually the homestead of the beneficiary for that particular meeting. During these visits, the farmers stated that they have opportunities to see what the host is doing on the farm and learn from that. The informal groups also organize and invite a trainer to offer them training on certain aspects of agriculture or income-generating activities.

Smallholders expressed the need for training and learning through interactions with different organizations. This need was expressed as urgent in light of changes that the farmers have experienced over time. One farmer gave an example that when her first son was born in 1986, her farming practices entailed mixed cropping of maize and beans and she would not get good yields. She purports that new knowledge and training encouraged her to plant single crops in separate sections of the farm, resulting in better yields. As a beneficiary of several training programs, the farmer is able to point out that new knowledge garnered from institutional interactions has improved her agricultural productivity. However, the smallholders also pointed out information and knowledge needs that require greater attention such as the proper storage and drying of grains (especially maize), preservation of perishable food harvests and the valueaddition of produce.

\subsection{Dynamics of institutional arrangements}

The examples cited above in Sections 5.1.1 through 5.1.4 lay the foundation for a broader discussion on the dynamics of institutional arrangements among Mt. Kenya smallholders. They demonstrate that smallholders, either individually or collectively, have ways of negotiating interactions between them and formal or informal institutions. Their interactions allow them to 
meet various livelihood and food security needs that would otherwise lie beyond their individual or collective capacity. This provides additional evidence on how smallholders' food and livelihood security are inextricably linked. It also demonstrates ways through which smallholders address their household's vulnerability and limited capacity by seeking external support through various institutional arrangements.

Table 5.1 below showcases some of the interplays from the examples cited in Sections 5.1.1 through 5.1.4 identifying the arena of engagement and direction of interplay between formal and informal institutions.

Table 5.1: Examples of interplay between institutions for livelihood and food security

\begin{tabular}{|c|c|c|c|}
\hline $\begin{array}{c}\text { Arena of } \\
\text { engagement }\end{array}$ & Informal institutions & $\begin{array}{l}\text { Interplay } \\
\text { direction }\end{array}$ & Formal institutions \\
\hline \multirow{3}{*}{$\begin{array}{l}\text { Resource } \\
\text { acquisition }\end{array}$} & $\begin{array}{l}\text { Group of women buying onion seeds } \\
\text { for joint nursery germination prior to } \\
\text { transplanting in individual firms. }\end{array}$ & & An agrodealer sells seeds to the group. \\
\hline & $\begin{array}{l}\text { Group saves for purchase of pesticides } \\
\text { or fertilizer prior to season onset. }\end{array}$ & & $\begin{array}{l}\text { Registered agrodealer or NCPB sells } \\
\text { subsidized inputs to individual farmers } \\
\text { in the group. }\end{array}$ \\
\hline & $\begin{array}{l}\text { Group of smallholders develop a } \\
\text { proposal that identifies their collective } \\
\text { need seeking a partner to fund an } \\
\text { irrigation project. Group contributes } \\
\text { "sweat equity" for setting up and } \\
\text { maintaining the project. }\end{array}$ & & $\begin{array}{l}\text { External funder provides financial } \\
\text { capital and technical support to } \\
\text { establish the project. }\end{array}$ \\
\hline $\begin{array}{l}\text { Marketing \& } \\
\text { sales }\end{array}$ & $\begin{array}{l}\text { Group of banana farmers formed by } \\
\text { members of an irrigation scheme seek } \\
\text { a wholesale buyer for their produce. }\end{array}$ & & $\begin{array}{l}\text { Irrigation scheme management } \\
\text { sensitize members encouraging them } \\
\text { to venture into market-oriented } \\
\text { banana farming }\end{array}$ \\
\hline Financing & $\begin{array}{l}\text { Group saves collectively, deposits } \\
\text { money in a bank account. Charged for } \\
\text { account maintenance. }\end{array}$ & & $\begin{array}{l}\text { Bank keeps safe custody of group } \\
\text { savings. Possible to earn interest. }\end{array}$ \\
\hline $\begin{array}{l}\text { Information \& } \\
\text { training }\end{array}$ & $\begin{array}{l}\text { Group identifies knowledge/skill gap } \\
\text { and requests for training. }\end{array}$ & & $\begin{array}{l}\text { Officer/agent from NGO, private or } \\
\text { government agency delivers training. }\end{array}$ \\
\hline
\end{tabular}


Although the initial focus was on individual farmers' interactions with either formal or informal institutions, it emerged that smallholders have devised several innovative models that engage both types of institutions. In some instances, informal institutions act as intermediarie s between farmers and formal institutions. It is therefore possible to build synergies and capitalize on interplays between both types of institutions.

While reflecting on the role of social capital and identity, as discussed in Chapter 3 , it emerges that smallholders' innovative arrangements are driven by their understanding of scale, bargaining power and the dynamic roles that their informal arrangements can play. Smallholders illustrate their understanding of scale by coming together as a group since the sum of their individual resources and capacities is greater collectively. Additionally, they combine scale and bargaining power when they negotiate good prices for produce they have generated in bulk. Finally, it is clear that their informal groups are fashioned in a manner that is customizable to the common needs of the group. This means that the group's purpose and existence is constantly realigned to meet the members' needs. In this manner, smallholders are not confined to the operating mechanisms that are characteristic of formal institutions. Their agility is demonstrated where, in some cases, they take the lead in initiating projects in partnership with external agencies.

\subsection{Smallholders' concerns with institutional arrangements}

Previous sections have discussed in detail how smallholders utilize their informal groups as well as engage formal institutions to make improvements to their livelihoods. Whereas these discussions reveal the agency and agility possessed by smallholders in navigating institutional arrangements, the farmers raised many concerns. These mainly stem from issues of governance, 
power differentials and knowledge gaps that leaves them at a disadvantage in current institutional arrangements.

\subsubsection{Governance, management and quality control}

The study region has many organizations working within the farming communities with different initiatives. The surge of players in this arena causes a challenge in the coordination efforts among the agencies as most initiate independent projects. This gives room to duplication of projects e.g., both the Catholic Church and a local African Christian Churches and Schools (ACC\&S) church were implementing different agricultural initiatives in the same general area. The duplication of projects may limit the scope of greater benefits realized through joint implementation of projects. Additionally, lack of coordination between projects poses a risk of excluding potential beneficiaries.

Among the various pre-production processes discussed in Chapter 4, smallholders are most concerned about the acquisition of fertilizer. Key concerns include high costs, the tedious acquisition process (for subsidized fertilizer), and rising cases of compromised quality. Cases of impropriety were rampant in the operations of the NCPB as reported by the smallholders. In part, the farmers purported that they receive inequitable treatment since they have small farms and thus only require few bags.

This fertilizer that came here to the Cereals Board is meant for the whole Eastern Region. So even people from Kirinyaga come here. So when it arrives here, you can queue for one week and the process is also long.

There is also a problem because there is no limit to the amount you can buy. Because I go there to get my two bags and there is someone who has come with a truck to fill up a load of bags. Now you see that one has taken a lot even though it may be on behalf of other farmers. So there is a distribution problem with the Cereals Board. 
Smallholders raised concerns that distribution centres for subsidized fertilizer were too few to adequately meet the needs of all farmers in the catchment area. Additionally, there lacked a mechanism to protect the needs of 'small' farmers and ensure equitable access. 'Bigger' farmers were regarded as those with high financial capital or those who were closely connected to officers working in fertilizer distribution centres.

Another concern on the subsidized fertilizer reported by farmers was the significantly high level of fraud among the NCPB officers. During a focus group discussion, a smallholder narrated how once they had contributed money as a group with the intention of purchasing subsidized fertilizer from NCPB. When they arrived at the depot however, the officer on duty arbitrarily asked for a bribe of Shs. 100 per bag purchased, which they declined to give. Discussions with farmers also indicate that the subsidized fertilizer shortages might be artificially induced by fraudulent practices. Farmers purported having witnessed NCPB officials colluding with unscrupulous shop owners who buy the subsidized fertilizer in bulk and repackage it in branded bags for sale at a higher cost in their shops. A search through Kenyan news reports online indicates that these fraud cases are not unique to the NCPB depot in the region. In a March, 2016 news article, twenty-two NCPB officers were reportedly interdicted due to fertilizer theft. ${ }^{19}$

Some smallholders in a discussion group discussed 'false starts' and failures in management of irrigation scheme projects. One extreme example was shared by farmers who had been contributing to a proposed irrigation scheme project since 1997 but were yet to benefit from it. As discussed in Chapter 4, several smallholders complained that their schemes often expand to

19 https://citizentv.co.ke/news/ncpb-interdicts-22-senior-staff-over-fertiliser-th eft-127127/. Last accessed $4^{\text {th }}$ August, 2016 
include more members than can neither be sustained by the current levels of water supply nor by the existing irrigation infrastructure. Additionally, the regulation of water usage on individual smallholder farms is not standardized. The current regulation practice relies on limiting the size of the pipe, either $1 / 2$ or $3 / 4$ inch in diameter, which smallholders use on-farm to connect to the main irrigation system. However, there is no restriction in the volume extracted, which can either be regulated by limiting the area of the farm that is irrigated or the duration of water usage. Due to this gap in regulation, some farmers are able to extract more water e.g. by farming larger portions or by watering their crops at night when there are less users and thus higher water pressure. This disproportionately affects other members in the irrigation scheme.

\subsubsection{Smallholder vulnerabilities and power differentials}

I have not been involved in any because for them they take big farmers who are in irrigation. Mostly irrigation. They do not allow people who are 'small timers'. They don't want them.

Evidence of biases against smallholders by organizations working in the region were recorded. Certain types of farmers receive preferential treatment in comparison to others. The statement above points to two issues. First, the farmer self-identifies as a 'small timer' - indicating that even among smallholders, there are tiers that farmers use to classify themselves. This recognition is important and needs to be incorporated across different scales, especially among various formal institutions that work with smallholders. The second point rests on the issue of inclusion. Data analysis revealed that smallholder farmers are marginalized. Project initiators working in this region have specific criteria for selecting farmers to engage. However, it should be the role of government to ensure that, at the very least, public-funded agricultural development projects 
are inclusive of marginalized farmers. If this were the case, then observations of 'feeling left out' expressed in the farmer's quote above would not occur.

In several instances, smallholders expressed disenfranchisement and the lack of a level playing field. For example, whereas the smallholder is the producer of commodities such as tea and coffee, exclusion from post-production processes that lead up to the sale of the produce leaves them disenfranchised. One smallholder who produces both coffee and tea gave this insight on her experience with tea:

You know for tea, there is a company [to which she delivers her produce]. These are people who have come together and then they look for brokers out there. The brokers come together with a third party, EATTA [East African Tea Trade Association], I think they are also a company. And the government is the fourth entity. So that is four people against one who is the farmer.

The farmer goes on to make a case that when the produce is eventually sold, the smallholders end up with the smallest share of the profits.

Based on their experience from dealing with certain types of organizations, smallholders have learnt to counter their vulnerabilities by spreading their risks. Almost all of the farmers who cultivated either coffee or tea were registered with different factories and delivered a part of their produce to each of them. The first justification for this arrangement was so that they could have more places to tap into for financial support, e.g. securing school fees cheques, which are offered on loan against their potential produce deliveries. The second reason points directly to spreading risks since some factories and cooperative societies have been known to collapse, leaving the farmers with huge losses. 
Similarly, in cases where public private partnerships initiate projects to support farmers, some smallholders claimed that public officers engaged in the project tend to benefit the most. This allegation was also raised in cases where relief fertilizer was issued out to the smallholders through agricultural officers. The famers claim some officers hoard the supply and distribute less amounts while keeping some for themselves and their relatives.

The above examples reveal farmers' perceptions on their vulnerability and the power differentials they often encounter when engaging with agents of different organizations. Their reflections were inundated with expressions of how they were 'just ordinary farmers', and how they are vulnerable 'without someone looking after their best interests'. Smallholders allude that current institutional arrangements with formal organizations disfavour or take advantage of them.

\subsubsection{Knowledge gaps and broken links}

The current model of agricultural extension services in Kenya is 'demand-driven' i.e. it is the smallholders' responsibility to seek extension services from government agencies as needs arise. The upside of this model allows the government to maximize on their relatively low number of staff employed for extension services. The downside, however, is that the number of officers is too few and often cover such wide areas thus rendering insufficient support to the many farmers.

The second challenge of the demand-driven approach as expressed by smallholders is that at times they are not aware of the type of support they should seek and when they should demand it. As one farmer lamented, her maize crop had been affected by the fast spreading Maize Lethal Necrosis Disease (MLND) and she had to uproot most of it. She had noticed the crop was not 
doing well and goes on to narrate her experience as well as her opinion on the demand-driven

services offered via agricultural extension officers:

You know when I realized the maize is becoming yellow, I called the agricultural officer. She told me she thought that it was Gikware [maize streak virus] but later told me it was not. So she came and told me it is MLND and advised me to uproot all the ones that have been affected..... These agriculture people are not really helping the farmers very much.....So I told her, you are saying your services are demand-driven. If someone doesn't know they have this disease, how do you expect me to come and ask you? It's not helping me.... If she sees it is there, she is supposed to tell people around that 'your maize is sick, yours is like this and like that'. At least you help farmers to identify what is wrong. You don't have to wait until when we meet in a meeting and then show a picture that this is a maize disease. You are telling somebody when it is already too late.... They say their services are demand-driven, why demand something I am not aware of? You see?

The above quote points to a third problem of curbing the spread of airborne or fast-acting diseases in the agricultural sector. The current demand-driven arrangements miss out on the opportunity to reduce or prevent unnecessary losses in agriculture by taking preventative measures in areas that have not yet been affected.

Additionally, the smallholders expressed concern in knowledge gaps that can be addressed by agricultural officers as well as health officials. During a discussion on how smallholders sell their maize produce at the market, the issue of quality checks came up as farmers shared experiences with health inspectors. Random market inspections carried out by these officers entail checking whether the maize is sufficiently dry to reduce chances of aflatoxin cases. The officers scoop a small amount of maize, which they pour back into the bigger pile and deduce the level of dryness by the sound made upon impact. If they are not satisfied, they confiscate the grain and bury it in a designated area to prevent its consumption by both people and livestock. Two issues emerge from this experience. First, the farmers admitted they have insufficient knowledge on the proper 
drying of maize fit for market sales and human consumption. The farmers expressed their willingness to learn proper drying procedures to acceptable levels so as to mitigate against postharvest losses. Secondly, farmers question the checks and balances applied by the officers from agriculture and health departments who enforce regulations. The absence of a verifiable method of assessing the humidity content in the maize (other than the sound it makes while it drops) casts doubt and allows for bias by the officers. One farmer went on to add the dismay of having all the maize be taken away and buried yet it can be fed to cows. However, another farmer in the same discussion group was quick to respond that maize with aflatoxin is equally unfit for livestock consumption.

Broken links and conflicts with regulatory bodies occur when smallholders move from producing to selling their produce. This was most prominent among milk producers whose production levels exceed their household consumption needs but are inadequate to have the farmers enrolled as suppliers to large dairy companies. This group of smallholders resort to selling their milk to neighbours within their catchment area. They however face three major challenges. First, the smallholders complain that in instances where they are able to engage a small dairy to purchase from them, they are often given very low prices. The purchase price is set by the dairy and often does not favour the smallholder. Secondly, since there are many farmers who produce milk and sell in the same neighbourhoods, there are often more sellers than potential buyers. This mismatch between high supply and low demand gives low returns to the farmers. Lastly, when selling within the neighbourhood, there are often limitations and restrictions set up by health officials. If found vending the milk in their neighbourhoods, smallholders are arrested and charged for trading without a license. 
In another example which links the 'false starts' and 'broken links', smallholders shared instances where well-meaning organizations have initiated projects aimed at promoting their livelihoods. However, some agricultural projects do not have well conceptualized 'farm-to-fork' models. One disappointed farmer who had experienced such a setback shared his story on a rabbit-rearing project. He was recruited by an organization with the promise that setting up a rabbit-rearing project would change his fortunes for the better. However, he and other members were left with mature rabbits but with no market for them as the necessary links to existing demand had not been established. This experience adds on to the many concerns that smallholders face in linking their produce to guaranteed markets.

\subsection{Broader scholarship and institutional arrangements among Mt. Kenya smallholders}

Broadly classified, institutional arrangements fall into five main categories: familial, communal, social, collective and state or policy (Amekawa, 2011). Previous sections discussed smallholder farmers' experiences with the latter three arrangements, which encompass the social capital that an individual or household may possess or have access to. Although it is difficult to quantify social capital (Alwang, Siegel, \& Jørgensen, 2001), the important role that it plays in brokering people's access and utilization of assets has been acknowledged (Amekawa, 2011).

In the study, female farmers had deeper engagements and experience with informal groups than their male counterparts. This disputes an earlier claim by the Food and Agricultural Organization stating that women have less access to social capital than men and are therefore disadvantaged (FAO, WFP, \& IFAD, 2012). Other studies have pointed out Kenya's wealth in social capital on the basis of the numerous rural women groups (Gustafson, 2004). However, physical resources such 
as land and housing are mainly owned by men. Since these resources act as collateral when access to formal financial credit is required, women stand disadvantaged.

In times of widespread and severe crises such as prolonged droughts, the role of safety nets is crucial in offering support to people who are food insecure and face acute hunger (FAO, 2009). As Adger (2006) purports, "resources to reduce vulnerability in times of crisis are largely latent in social institutions" (p. 277). Therefore, the role of these safety nets is most visible in times of crises. It however emerged from the study that safety nets are part of the everyday livelihoods of smallholders. The farmers draw and rely upon them to offer support outside their individual or household capacities. This section discusses how the institutional arrangements among Mt. Kenya smallholders broadens existing scholarship.

\subsubsection{Livelihoods are entrenched within social networks}

What we prioritize is someone who has a need for school fees. We cannot allow for a child to stay at home yet we have money. Fees and sickness, those are the ones we cater for first. The other things come after. We don't like hearing that the child of a memberhas left school and yet we have money.

Informal institutions anchor local livelihood security and should therefore be adequately supported (FAO, 2010). As discussed in Chapter 4, for smallholders, food production underpins their livelihood security. The role of informal social networks is activated where the boundaries or limits of a household's ability to meet its livelihood needs occur. Within such networks or groups, the needs among individual members may be diverse. The smallholder quoted above expressly stated that informal groups prioritize addressing different types of needs among their members. 
Smallholders collectively seek to improve their quality of life. It is their belief and practice that livelihood improvements are best enjoyed if everyone is an equal beneficiary. The farmers leverage their strength as members of an informal group. For example, some of the women farmers were proud to share that each member in their group had benefitted from rotatory contributions and all had bought an agreed upon item e.g. water tanks, kitchen utensils, quality blankets, plastic chairs and even livestock. Additional utility can be derived from the items bought by the group. For example, when group members purchase plastic chairs for individual use, they can decide to collectively hire them out during local functions and generate income for their group. Collectively saving and purchasing of livestock demonstrates that a group's priorities can also improve agricultural productivity. All these examples underscore findings in Chapter 4 that demonstrated how smallholders' food and livelihood security are inextricablylinked. Institutional arrangements offer a supporting role in the attainment of both.

\subsubsection{Lessons in governance from informal groups applicable to formal institutions}

Local informal groups are good avenues to propagate knowledge and potential gains can be made from investments by governments and NGOs (Wood et al., 2014). Interactions with smallholders revealed several attributes exhibited in their social groups that offer valuable lessons for improved governance among formal institutions.

\section{Code of conduct}

Informal groups among smallholders have unwritten yet very clear rules that set the boundaries for their code of conduct. Adherence to established rules is strictly and collectively enforced. The smallholders shared how they esteem timekeeping and their commitment to attending scheduled meetings. For example, there are various rules and penalties for being late in making 
contributions, arriving late for meetings, and skipping several meetings without sufficient apologies. Frequent meetings ensure that these penalties are paid instantaneously and without favour to the errant member. Thus, the enforcement of common rules of conduct enhances a feeling of equal treatment and accountability.

Good governance can lead to lower poverty levels and thus higher food security outcomes. It can be measured through indicators such as low corruption levels and high farm productivity and literacy levels (FAO, 2005). Similarly, good governance is a prerequisite if economic growth in national levels should translate to improvements in food security (FAO, WFP, \& IFAD, 2012). It is commendable that the Kenyan government has set mechanisms in place to supply subsidized fertilizer through its National Cereals and Produce Board depots. However, several governance concerns majoring on corruption and unfair treatment of smallholder farmers are detrimental to expected food security outcomes. For smallholders, their view on improved governance entails a less bureaucratic process of accessing the fertilizer, fair and transparent distribution practices, and the elimination of bribery for officers who serve farmers at NCPB depots. Such a scenario would improve the success of the government's policy on boosting economic growth through increased agricultural production among farmers.

\section{Consensus building and distribution of power}

Through their structured and frequent meetings, smallholders have developed ways to build consensus. Whereas they may take a vote for major decisions (e.g. when selecting a chair), other means of agreement may be employed. For instance, they may agree that a certain member is more trustworthy and thus assign them the treasurer's role. Similarly, group members may decide to select a chair who demonstrates the best leadership skills among them. However, 
power imbalances within informal groups cannot be ruled out. For example, one farmer shared that in their group they select some of their literate members to represent them at forums and trainings. In turn, the trained farmers are expected to transmit the new information and knowledge to the larger group. It can be assumed that those who receive the knowledge firsthand might wield more power over the rest. The main point, however, is that members of informal groups build consensus by matching personal traits and abilities to roles that would promote the group's progress.

Informal groups among smallholders are unencumbered by layers of bureaucracy. Statements of financial accounts (savings, loans and fines) are presented and updated during each meeting. It is therefore easy to promote financial accountability and transparency as any questionable transactions or outstanding balances are openly queried. In this manner, each member has agency, which "refers to an actor's ability to have some effect on the social world, altering the rules or the distribution of resources" (Scott, 2001, p. 76).

At the end of the production process and upon entry into markets to sell their produce, the agency enjoyed by smallholders at local levels is often eroded. On the one hand, this is as a result of market forces, driven by supply and demand dynamics that dictate produce pricing. On the other hand, this lower agency occurs due to differentiated power among other market players such as brokers and organized buyers. Often, smallholder farmers hold a subordinate position in market dynamics. (Foran et al., 2014). For instance, farmers who cultivate tea and coffee are excluded from market arrangements as prices for the produce is often set through auctions and international bidding. Consequently, whereas these farmers are the primary producers, they make smaller margins in comparison to other actors in the produce value chain. 


\section{Prioritizing needs while maximizing shared benefits equally}

Smallholders collectively identify individual needs and work out ways of maximizing benefits among them. A demonstration of this is perhaps best represented in the rotatory format of their meetings. Most groups meet in the homestead of the host member. In this manner, smallholders pay social visits to each member and, more importantly, observe how the host conducts their agricultural activities. The rotatory hosting among the members builds a collegial environment within the groups, enabling them to view each other as contemporaries negotiating their livelihoods both individually and collectively. Further, once the group commits to a livelihoods improvement project, e.g. acquiring dairy goats, they ensure that all members have benefitted equitably prior to embarking on saving for the next project, e.g. purchasing water tanks.

The study region has numerous agricultural and livelihoods projects targeting smallholders run by various organizations. The government's withdrawal of some services that were 'pushed' to smallholders in favour of a 'demand-driven' approach has occasioned the rise of nongovernmental agencies operating to fill the gap in agricultural development strategies (Amekawa et al., 2010). It is common for these projects to have overlapping objectives as they are run independently. In this regard, the organizations running the projects have unexplored potential in synergies that can be built by the co-implementation of similar projects. Joint initiatives would ensure a broader reach of target farmers as well as a wider array of agricultural activities. Such projects should however be constituted after prior consultation, at the design phase, with the target beneficiaries. There is a need to improve coordination between the different stakeholders concerned with food security since they are often driven by divergent interests (FAO, IFAD, \& WFP, 2014). 


\subsubsection{Reworking institutional financing and knowledge brokering}

Evidence from Mt. Kenya smallholders supports views by Ellis (1998) indicating that institutional arrangements serve as safety nets and in some instances, allow for households to diversify their income portfolios. The findings however indicate that as compared to formal institutions, informal groups are more tailored towards smallholders' needs. If institutions are well designed, there is significant potential to lower various agricultural production costs faced by smallholders (FAO, 2014; Kassie, Ndiritu, \& Stage, 2014). Improvements in formal institutions may require more adjustments in policy, which may take a longer time to implement. Quick gains can be made by strengthening informal groups at local levels and linking them to formal institutions. In this subsection, two such quick gains are identified - reworking financing mechanisms and knowledge brokering.

\section{Reworking institutional finance}

The lending for the group is better because if you borrow and are unable to pay, you just pay the interest and move for another month. But we [group members] will not come and take away your cow because we are neighbors and live together. But for the bank if you have listed your cow as an asset, they can come and take it away. There is no problem with the group lending and we see it is good.

Evidence on informal financial arrangements among Mt. Kenya smallholders supports findings by (Trærup, 2012) on "the importance of social capital and informal networks in providing credit access to poor households" (p. 256). There are two main reasons why the smallholders' informal financing arrangements need to be linked to formal external sources. First, their experience demonstrates that informal credit is limited to resources they possess. In order to increase their

financial capital, smallholders need to engage external sources, which would include formal 
institutions that offer credit services. Secondly, while informal credit systems among smallholders function well on the surface, in the long run their interest rates are more exorbitant than lending rates offered by formal institutions. For instance, the costs of financing through table banking or informal lending can be very high and counter-productive to the financial needs of the smallholder. The farmers borrow from their group contributions at an interest rate of $10 \%$ per month, often with a repayment period set to three months. For the first two months, a member may opt to only repay the interest and clear the balance of the principal plus final interest in the third month. In this case, the total interest repaid by the member amounts to $30 \%$, which is well above the lending rates offered by formal institutions. However, smallholders prefer informal lending to formal credit for the three main reasons:

a) Borrowing from social groups poses lower risks to other assets they own. As evidenced in the quote above, a member of an informal does not lose their assets if they are late in repaying their loan at the end of the grace period. Rather, they work out a new arrangement with their group to repay the loan. Such flexibility and leniency may not be possible to negotiate if a smallholder had borrowed from a formal lending institution.

b) Lack of collateral or loan guarantee. The collateral to borrow from a social group may be based on a member's contribution and good standing in the group. However, smallholders can only access formal credit by surrendering ownership documents to a key asset such as title to a land parcel or the logbook of a vehicle. Many smallholders, especially women, may not own such vital documents.

c) Payment plans not aligned to farming calendars. Conventional payment plans by formal lenders may not be synchronized to seasonal calendars used by farmers. Smallholders 
have peak seasons when they expect improved cash flow after the sale of their harvests. These seasons do not overlap with payment arrangements, e.g. monthly, set by formal institutions.

Informal groups of smallholder farmers can be linked to formal institutions through vertical bridging (Trærup, 2012). This linkage would capitalize on the functional system of accountability evident in the informal groups. For instance, records of regular contributions to an informal group by a member can act as a baseline for a formal institution to offer credit. The collective savings of the group can also act as collateral against credit that would be advanced to a member. Since members are committed to the functional running of their groups, they would work to repay the loans with formal institutions at lower interest rates than those offered through their informal groups. Another practical example of a vertical bridge as discussed by Trærup (2012) is between an insurance provider (formal institution) and an informal network of farmers. The insurance provider offers a cover for covariate shocks that would be beyond the capability of the informal network.

\section{Knowledge brokering}

Social learning processes are significantly supported by the existence of informal networks (PahlWostl, 2009). As shared by the Mt. Kenya smallholders, they learn and experiment good farming practices which they observe in each other's farms. They however expressed a need to learn new skills and be equipped with additional information that would, for example, increase incomes from the sale of their produce or reduce postharvest losses. Potentially, great gains can be made by utilizing informal group meetings to offer trainings from agricultural experts to farmers. Such arrangements must however accommodate the heuristic knowledge held by the farmers. With 
the reduction of supply-driven agricultural extension services, group meetings provide a forum for wider dissemination of new information and technology. In such forums, the collective practices of the farmers' group can be discussed to reveal knowledge and skills gaps. These gaps can then be addressed systematically by an agricultural officer. Additionally, since group meetings happen in the homesteads of members, there is potential to incorporate practical onfarm demonstrations.

\subsection{Chapter synthesis}

Institutions must not be rigid to changes. While it has been shown that they do change to accommodate heterogeneity among the beneficiaries (Ericksen, 2008), institutions must also remain flexible and consider changing environments. The findings in this chapter re-emphasize that informal groups among smallholders contain untapped potential and greater flexibility that can be harnessed to make gains in food and livelihood security.

In summary, this chapter presents seven main lessons that broaden the understanding of institutional arrangements among smallholder farmers in the Mt. Kenya region. These are:

a) Social capital is well established among smallholders and is utilized for both livelihood and food security.

b) Smallholders prioritize needs that are supported by social capital especially, school fees and costs of medical care.

c) Additional evidence is provided in support of findings discussed in Chapter 4 that food and livelihood security among smallholders are inextricably linked.

d) Smallholders' individual agency at local levels and within their informal groups is eroded once their interactions expand to formal institutions. 
e) Smallholders have developed innovative approaches of utilizing informal institutions as intermediaries to access support from formal institutions, thereby demonstrating collective agency and agility.

f) Equitable access, transparency, accountability and good governance are key attributes of informal institutional arrangements among smallholders that can be applied in formal institutional arrangements.

g) Formal institutions need to build synergies and capitalize on informal institutions to propagate financially inclusive services, broker new knowledge and improve both food and livelihood security outcomes. 


\section{Chapter 6. Climate change: The experience and perceptions of smallholders}

This chapter builds on the 'lives lived' approach among smallholder farmers that has been developed in previous chapters. It interrogates smallholders' experiences and perceptions related to climate change. Specifically, it probes their narratives on recollections of recently observed or perceived changes in the climate as well as the responses they chose as a result. The smallholders' narratives are contextual in both temporal and spatial perspectives. As a result, the findings represent general but crosscutting responses that were common to smallholders engaged in the research.

This chapter is organized in four major sections. First, the smallholders narrate changes in weather and climate, as they perceive them. Second, a discussion of Mt. Kenya smallholders' perspectives and broader scholarship is presented including climatic trends, information, and the integration of local knowledge. The third part attempts to draw lessons from heuristic responses to climate change perceptions. It argues that vulnerability and risk perceptions inform coping mechanism and that climate change does not occur in a vacuum. Lastly, the chapter offers a synthesis on Mt. Kenya smallholders and climate change.

\subsection{Smallholders' chronicles on weather and climate}

The following section offers room for smallholders in the region to express their everyday engagements with the weather and give views on climate change and its effects on their livelihoods. In an effort to understand this, the first sub-section gives the smallholders narratives. Next is a discussion on how these narratives are shaped. Third, an exploration of the perceived effects of weather and climate change at the farm level as well as subsequent responses chosen by the smallholders is offered. 


\subsection{1. "A long time ago.....but now....."}

Within the study, the smallholders recalled with nostalgic undertones how the weather patterns have changed while making explicit claims that the changes have been for the worse. For instance, as an indicator of how weather patterns had changed, farmers cited the disappearance of seasonal rains locally known as 'gathano' that fell in July/August and 'mbicera nyeki' or 'mahoria matongi' that occurred in February. As a result, the farmers no longer planted some crops such as finger and bulrush millets, which relied on these rains.

Smallholders also narrated how changes in the weather have had negative effects on soil fertility and subsequently productivity of the land. One farmer in his 60 s recalled that when his family was resettled by the colonial government in the study region in 1958, the rains fell adequately, the land was fertile and the population was low. It was therefore customary to farm in one area and when the land became less productive, they would move to another parcel. He attributes the current decline in rainfall quantity and consistency due to the cutting down of trees that took place as virgin land was cleared for cultivation and settlement.

Other changes in the climate as observed by the farmers pertain to aspects of their everyday life and exposure to the weather. Most notably, smallholders offered narratives citing effects that would be considered subjective. For example, participants in one of the focus group discussions on this topic made the following statements:

This sun that is shining I don't know where it came from. When you look at someone's headscarf or even their clothes, there are signs of fading.

Now the sun is too hot. When we were children, we would go to school without shoes but now children cannot. Because the soil is too hot.

And then when it gets cold, you cannot step on a cement floor. 
In fact, it is not just those physical changes. It is also affecting mentally. When the sun is hot, you cannot even think normally. You find that making a decision takes more time. And it makes you feel drowsy.

But honestly, you feel like you are sick. And you want to take medicine because you are feeling ill.

The above quotes from individual smallholders raise two points. First, smallholders experience and interpret evidence of climate change effects uniquely. While one farmer may observe that increase in heat causes clothes to fade, the other may note that it results in the soil being too hot. Secondly, the quotes highlight that there are various non-standard ways of deducing climate change at local and individual levels.

Initial discussions with smallholders revealed some challenges in aligning their narratives to equivalent terms used in scientific literature. Given this, a disclaimer on two fronts is necessary; the first is on timescales and the second on contextual meanings. While considering timescales, the farmers were asked to state how long they had been farming in the region. This allowed for a comparative assessment of changes that have been experienced over 20-30 years, a period that aligns closely to conventional timescales used to deduce climate change in scientific literature.

The second front on context required probing farmers' responses a little further. For instance, many would say 'kulikuwa na jua kali sana', which literally translates to 'there was a lot of hot sun'. Similarly, others would say 'wakati wa kiangazi', which literally translates to 'during the hot and dry season'. Looking at the two statements, one would assume that the smallholders are describing a similar situation. However, it was necessary to probe contextual meanings since both phrases could mean that there was either a period of drought or one of famine. The smallholders appear removed from their actions, which may have led to them experiencing kiangazi or feeling 
jua kali. The farmers do not view their actions as contributing to anthropogenic climate change. Rather, they position themselves as victims of changes in the weather and climate. This observation emerged from how they shaped their narratives.

\subsubsection{The story shapers: God, fate and luck}

The shared experiences of smallholders do not exhibit high risks of or exposure to natural disasters such as floods, typhoons and earthquakes. Rather, the respondents expressed their lack of control and influence over conducive climate for their agricultural practices, as well as a high level of uncertainty on what the seasonal patterns might look like. Interactions with the smallholders revealed various aspects of their livelihoods that they related to 'God', 'fate' or 'luck'. As an indicator of importance to this attribution, a search through the interviews and discussion group transcripts on the word "God" yielded over 80 results. A screenshot of the word tree around the word "God" from a query run on the transcripts in NVivo is shown in Figure 6.1. As most of the farmers were practicing Christians, the God they referred to was a singular Supreme Being who is all-knowing in accordance with their faith. The identification of God as a weather and climate controller was by far the most common among the smallholder farmers, which points to two key observations. The first is an observable disconnect between how farmers view their impact on local weather patterns and the powerlessness they express as victims of the weather. The second observation stems from an obvious gap in the knowledge on the prevailing or expected weather patterns. These observations illuminate two themes of uncertainty and seeking external intervention or support that are core to the findings of this research. 


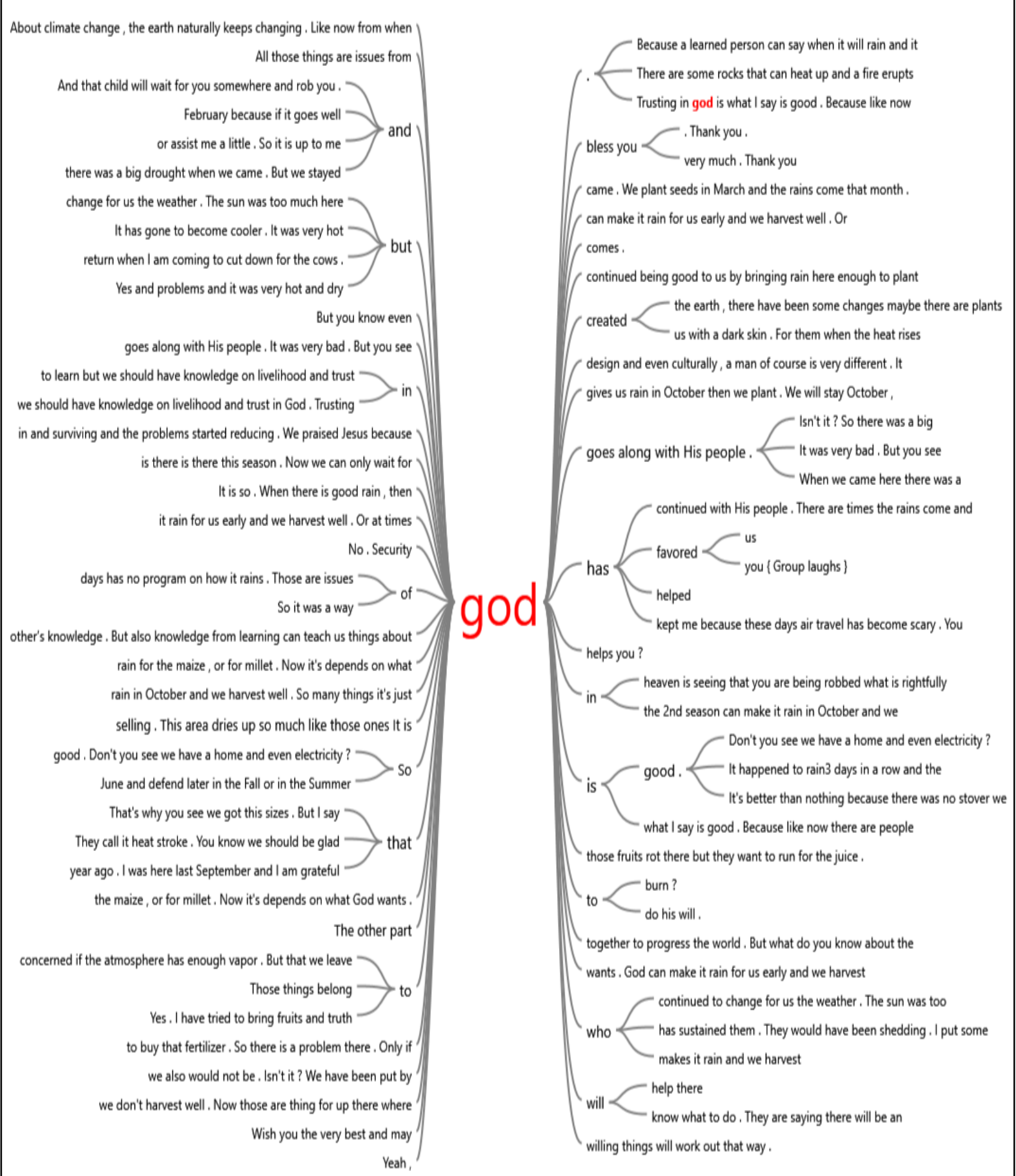

Figure 6.1: A word tree created with a text search query in NVivo on references to "God" from interview transcripts of smallholder farmers. 
As summarized in Table 6.1 below, smallholders made additional references to God highlighting several attributes. These attributes or roles of God are presented in order of decreasing mention or occurrence. The "programmer/in control" conveys that smallholders are at the mercy of God where weather patterns are concerned. The "provider", "sustainer", "assistant" and "companion" build on the element of seeking external support as discussed in Chapter 5. God as a "witness" reveals that the disenfranchisement encountered by the smallholders does not go unnoticed. Finally, God as a "matchmaker" and "designer" demonstrates the uniqueness of each gender and how their roles should be complementary.

Table 6.1: The different ways farmers relate to and describe God in their everyday life

\begin{tabular}{ll}
\hline Role of God & Example of contexts \\
\hline Programmer/In Control & Plans the seasons and the rains - when and how they will fall \\
Provider & Gives good harvests \\
Sustainer & Keeps the crops growing even in bad weather \\
Assistant & Is the only support that farmers can rely on for help \\
Companion & Goes along with his people \\
Witness & An observer of how farmers are oppressed by others \\
Matchmaker & Has put men and women together to develop the world \\
Designer & Bestowed uniqueness in men and women so equality is elusive \\
\hline
\end{tabular}

A summary of the weather and climate narratives given by the smallholders offers six major points:

a) The smallholders purport that the surface temperatures (evidenced by 'hot soil') have increased over time.

b) The increase in surface (hot soil) and atmospheric (too much heat/sun) temperatures has affected their wellbeing.

c) Farming seasons, marked by both the onset and duration of rainfall, are now more difficult to determine. 
d) The rainfall quantities have declined and patterns are inconsistent with their previous experiences.

e) Farmers feel disempowered to controlling weather patterns and conclude that the elements are either at the behest of God, fate or luck.

f) While they feel disempowered to control the temperature and rainfall, they find it easier to adjust to changes in rainfall.

Given these points, the farmers went on to describe what possible effects the weather and climate changes had on their farming and how they chose to respond.

\subsubsection{Perceived effects of and related responses to weather and climate change}

The findings reveal that perceived changes in the weather and climate had effects on the farmers' livelihoods and agricultural productivity. In response, most smallholdersmade changes either onfarm or at the household level while a minority chose to maintain the same practices even though they acknowledge changes in climate. Table 6.2 captures the most common effect(s)-response(s) pairings.

Table 6.2: Smallholders' perceived effects of and related (on-farm) responses to changes in weather and climate

\begin{tabular}{|l|c|l|l|c|c|}
\cline { 2 - 6 } \multicolumn{1}{c|}{} & \multicolumn{5}{c|}{ Responses } \\
\hline \multicolumn{1}{c|}{ Effects } & $\begin{array}{l}\text { Set up } \\
\text { irrigation }\end{array}$ & $\begin{array}{l}\text { Switch or } \\
\text { stagger } \\
\text { planting } \\
\text { dates }\end{array}$ & $\begin{array}{l}\text { Switch to } \\
\text { new crops } \\
\text { \& seed } \\
\text { varieties }\end{array}$ & $\begin{array}{l}\text { Increase } \\
\text { use of plant } \\
\text { treatments }\end{array}$ & $\begin{array}{l}\text { Take up } \\
\text { insurance }\end{array}$ \\
\hline Low or poor quality crop yields & $\mathrm{X}$ & $\mathrm{X}$ & $\mathrm{X}$ & $\mathrm{X}$ & $\mathrm{X}$ \\
\hline Total crop failure & $\mathrm{X}$ & $\mathrm{X}$ & $\mathrm{X}$ & $\mathrm{X}$ & $\mathrm{X}$ \\
\hline Increase in diseases and pests & & $\mathrm{X}$ & $\mathrm{X}$ & \\
\hline $\begin{array}{l}\text { Low water levels in local streams } \\
\text { \& rivers }\end{array}$ & $\mathrm{X}$ & $\mathrm{X}$ & & \\
\hline
\end{tabular}

Setting up an irrigation scheme is determined by the availability of such arrangements e.g. water sources and infrastructure in the farmer's region. The decision to switch or stagger planting dates 
is made at the household level, relying on experience from the previous season. This decision is also based on the current information a smallholder has at hand regarding the expected weather patterns. The smallholders' response to switch to new seed varieties or apply plant treatments, e.g. pesticides, is often preceded by consultations with an agricultural officer or agrodealer in the region. Smallholders take insurance based on new information on its availability and the financial resources to cover premiums. Less common pairings of effect(s)-response(s) included; crop is diseased - uproot entire crop (e.g. banana or coffee), and crop is diseased (maize) - plant an alternative crop to treat the soil (arrowroots).

\section{Irrigation}

There was wide consensus that unpredictable rainfall caused the biggest dilemma to farmers who practice rain-fed agriculture. The leading response to solving this problem was an effort to link the farm to a reliable source of water. While the exact number of farmers accessing irrigation water was not established, it was clear that a majority did not have this service. At the time of the field study, several farmers had contributed towards proposed irrigation water projects and were awaiting installation plans to come to fruition. For others, they expressed a desire to enjoin themselves to existing irrigation water supply projects in their areas. The farmers opined that access to irrigation water supply outside of the rainy seasons not only allows them to mainta in their crop production but also offers an opportunity to diversify into other crops such as vegetables, which have greater demand in the local markets. In this regard, irrigation not only helps smallholders navigate through unreliable rainfall periods but also acts as a catalyst that can enhance crop productivity and subsequently improve livelihoods. 
On the contrary, smallholders who had access to irrigation water expressed less concern on prevailing rainfall patterns as they enjoy farming outside the rainfall seasons. Most reported that the onset and cessation of the rains was inconsequential to their farm management and planning especially when to plant. This advantage however is eroded during long dry spells since their water sources cannot be replenished in the prolonged absence of rain. Rather, they discussed a different set of challenges they experience as irrigation-based farmers. Prime among these was the interruption of water supply through rationing programs caused by too many water extractors such that demand exceeds supply, as was discussed in Chapter 4. They additionally attributed interruptions through rationing that are driven by low water levels from the rivers or reservoirs as a consequence of prolonged drought or poor rainfall.

\section{Staggering or changing planting dates}

Farmers reported that the onset of seasonal rains is expected around the second week of March for the long rains and the second week of September for the short rains. Most farmers reported planting as soon as the rains began to fall - indicating that days prior to this, they had prepared the farm (e.g. dug holes for seeds) in readiness for the rains' onset. Farmers reported changing regular planting dates for two main reasons; (i) depending on when the rains fall, and (ii) based on external advice they received from meteorological broadcasts or agricultural officers. Smallholders who are more risk averse have resorted to planting several rounds, staggered days apart, across the period when the rains are expected. This was driven by farmers' observations that at times the rains start as expected but cease a few days into the season and resume a few days later. To counter this, some farmers reported planting as many as three times, spacing out five days in between the second and the third planting. In this manner, they reason that should 
the first seeds be lost due to poor rain onset, the seeds planted later may offer hope against total crop loss.

\section{Switching to new seed varieties and crops}

This option as a response to perceived or observed changes appeared to be the most common among smallholders. Farmers purported they no longer plant millet in some areas since the disappearance of some short rains on which the crops relied. Additionally, some smallholders reported having switched to different crops or seed varieties since the types they previously farmed no longer performed well under existing conditions. There is however a challenge in linking the necessity of switching to new crops or seeds directly to climatic changes without examining the farm management practices employed by the smallholder. For instance, it is difficult to ascertain whether the old seeds they were planting were of good quality and ideal for their soil type and whether they utilized fertilizer and pesticides appropriately. However, more informed smallholders reported switching to low maintenance crops such as drought-tolerant varieties of green grams (mung beans).

\section{Maintaining the same farm practices}

A small number of farmers reported that although they have noted changes in the weather and climate over time, they opt to continue with their farm practices unaltered. The farmers' decisions not to act are driven by two main attributes. In the first, the farmers view farming and good yields as taking a chance - sometimes you are lucky, sometimes you are not. This links to the earlier discussion on God, fate and luck where farmers exhibit a high level of uncertainty. These farmers believe that the risk of loss from making any changes far outweighs potential gains from the same. The second aspect rests on the costs related to making changes. Often, a change 
in farm practices comes with attached costs which smallholders may be either unwilling or unable to meet.

\subsection{Broader scholarship on climate change and relevance to smallholders}

The discussions of smallholder perspectives above offer a platform on which broader scholarship on climate change and smallholders can be assessed. In the first subsection below, climate variability and change in the study region from secondary data will be provided as well as a discussion on the implications for smallholder farming. The second subsection will focus on climate information, discussing both its attributes and dissemination with relevance to smallholder-decision making. Finally, insights on how local and traditional knowledge can be integrated into climate change scholarship will be offered.

\subsubsection{Climate and weather trends in the region}

Within the study region lies the county's administrative headquarters and more importantly a regional agriculture research centre. Under the Ministry of Agriculture's guidelines, this centre has for several decades been producing annual reports on agriculture in Embu region. Currently, it operates as one of the Kenya Agricultural \& Livestock Research Organization's (KALRO) Food Crops Research Institutes, which has maintained a repository of agricultural reports on Embu. It is from this repository that rainfall data from the region over the last three decades was gathered. 

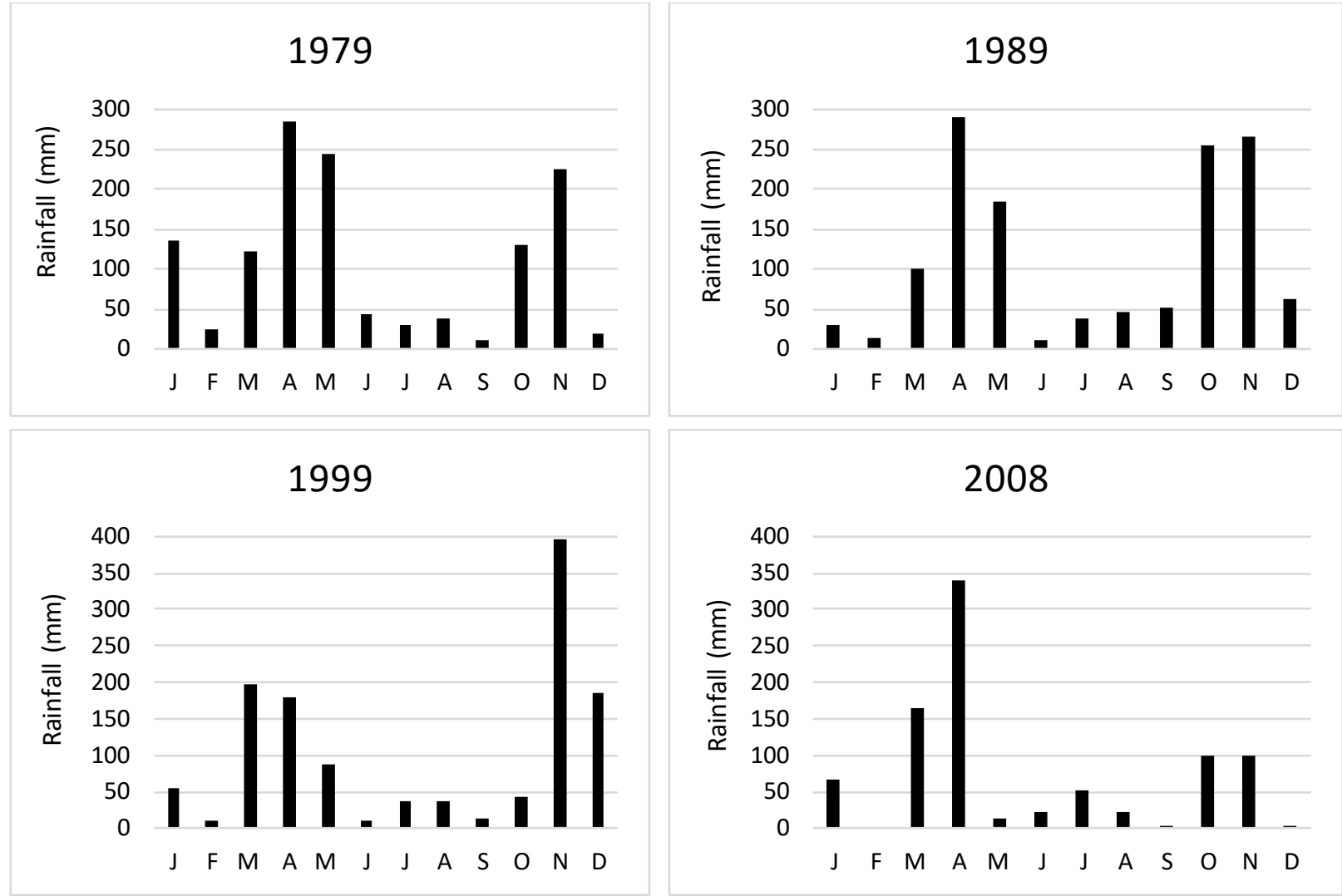

Figure 6.2: Monthly rainfall data at the Embu agricultural research centre for 1979, 1989, 1999 and 2008.

Source: Compiled from various reports from Kenya Agricultural \& Livestock Research Organization www.kalro.org

As evidenced in Figure 6.2 there is a marked difference in the monthly rainfall pattern across the three decades. The data reveals a general trend of declining total annual rainfall - from $1311 \mathrm{~mm}$ in 1979 to $880 \mathrm{~mm}$ in 2008, fewer rainy days (120 in 1997 and 91 in 2008), and a notable decline in Oct to Dec rains. These trends in the precipitation record were of importance for smallholders in the study area, and expressed as concern over greater rainfall variation within the two farming seasons between March to May (MAM) and October to December (OND). Their concerns are additionally supported by rainfall data that shows considerable variation from one year's season to the next. The Kenya Meteorological Department (KMD) compiles and reports weather data by dekads - every ten days - from its weather stations across the country. These reports contain various weather attributes such as rainfall, pan evaporation, temperature and sunshine duration. 
For comparison, data from the MAM season in 2013 and 2014, was compiled from these reports and charted as shown in Figure 6.3.
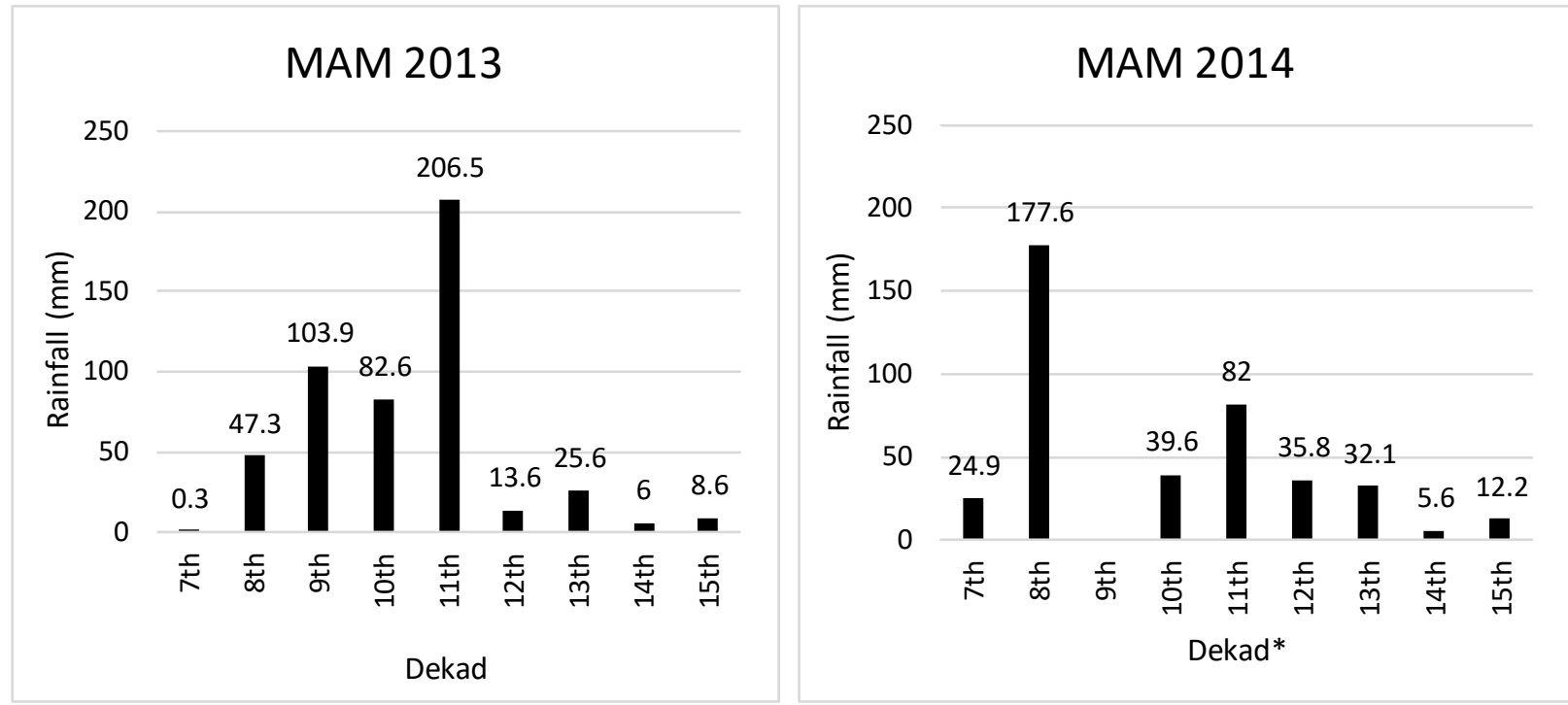

Figure 6.3: Rainfall amounts per dekad in MAM seasons of 2013 and 2014.

Where $7^{\text {th }}$ dekad is $1-10^{\text {th }}$ March and $15^{\text {th }}$ dekad is $21-31^{\text {st }}$ May. *Missing data for $9^{\text {th }}$ dekad in 2014

Source: Kenya Meteorological Department (2016)

It is clear from Figure 6.3 that there is a distinct variation in the MAM season from one year to the next. For smallholders, the rainfall pattern variation has significant impacts to their cropping seasons. Given that this is the season that smallholders rely on the most since the rains are more dependable than in the OND season, this variation can be disruptive. This is especially the case for smallholders who rely on their historical experience from the previous season (MAM 2013) to guide their farming decisions in the next one (MAM 2014).

The climate variability experienced by Mt. Kenya smallholders in the past four decades (as shown in Figure 6.2) and between seasons (as illustrated in Figure 6.3), is likely to continue. Projected climate change will give rise to precipitation fluctuations affecting water resources as well as 
temperature increases leading to more heat waves (Intergovenmental Panel on Climate Change (IPCC), 2014).

\subsubsection{Climate information: attributes and dissemination}

At local levels, smallholders often rely on heuristic approaches. However, there has been an increase in the uptake of downscaled national climate information to aid decision-making at the farm level. Climate information and forecasting are only useful if there is a possibility of pursuing adaptation options as a result (Reilly \& Schimmelpfenning, 2000). Consequently, there is a significant need to build sufficient trust in climate and weather forecasts. This need is essential in moving farmers from hedging (by taking lower risks or making fewer investments) to adaptation to climatic changes through informed decision-making (Coles \& Scott, 2009; Tall et al., 2014). Successful climate information adoption would only be possible if the following prerequisites are met: credibility - perceived technical quality and the authority of information; salience - perceived relevance to user's decisions; and legitimacy - perception that the information seeks to promote the user's best interests (Hansen et al., 2007). To this list of prerequisites, Tall et al. (2014) add that attributes of equity and integration must also be present. Equity would ensure that the climate information offered is sensitive to marginalized populations as well as gender perspectives. Integration implies that the information should leverage synergies offered by other agricultural agencies. As mentioned in Chapter 2, formal institutions have the potential to improve projected climate information disseminated to farmers for better decisionmaking at the farm level.

As per their mandate, the KMD generates weather and climate data and disseminates it to other agencies such as those concerned with civil aviation, water resources and agriculture among 
others. The onus then is on these agencies to customize the information for internal consumption or further dissemination to other end users. Smallholders in the study reported that they mostly receive weather information through radio and television.

An analysis of responses from the smallholders in the research area, together with observations from the field, yielded a set of four climate information attributes that need to overlap and offer a sound platform for relevant decision-making.

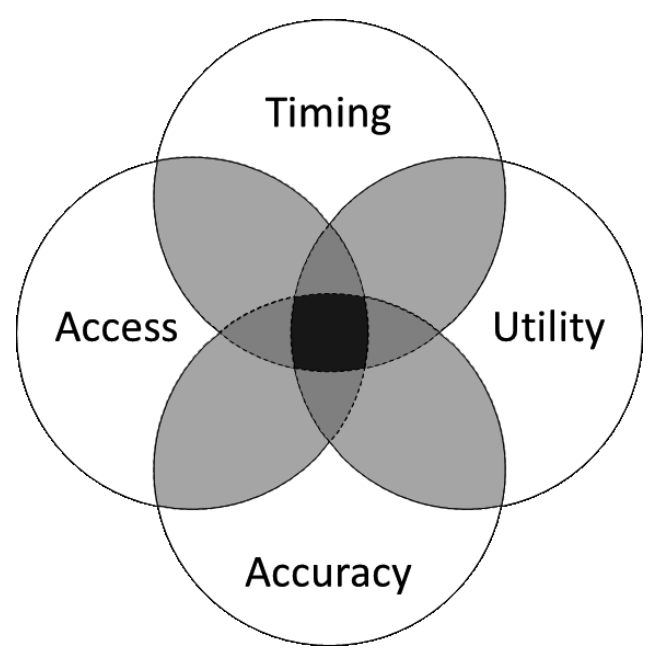

Figure 6.4: Climate information attributes. Darkest shade indicates overlap sought by farmers

As shown in Figure 6.4, meaningful climate information must be (i) accessible, (ii) accurate, (iii) timely, and (iv) useful in order to remain beneficial to the smallholders. Achieving the highlighted central section (with the darkest shade) that has an overlap of the four attributes is crucial if gains are to be made in improving smallholder decision-making based on climate information.

\section{Access}

The main access modes for climate information as reported by the smallholders was through radio and television broadcasts. These two mediums are often used to access news on current affairs and it has been shown that the likelihood of farmers acting on climate information 
increases if it comes via sources they trust (Hansen et al., 2007). Access to weather and climate information via television and radio broadcasts has challenges. First, a farmer seeking weather forecast information through such mediums must be tuned in at the appropriate time. If they fail to do so, they miss the broadcast as recording or replay functions may be unavailable. Secondly, TV and radio broadcasts often focus on daily weather conditions rather than distribution patterns with agroecological contexts and implications, which would be more beneficial for farm-level decision making.

Great potential exists in combining the use of mobile phones to disseminate seasonal and weekly forecasts. All the smallholders in the research study owned a mobile phone. The advantage of mobile phones over TV and radio is the option to provide on-demand information on a short messaging service (SMS) platform. A leading example of such an initiative in Kenya is iShamba ${ }^{20}$ where a non-governmental organization in partnership with a dominant mobile communication company offers information services to farmers. By subscribing at a small cost per text message, farmers are able to request and receive information on weekly weather forecast specific to their location.

\section{Accuracy}

Forecasted weather and climate information contains a level of predictive accuracy. Studies have shown that an increase in accuracy leads to improvements in livelihoods of poorer farming households as they are able to make better farming choices and thus increase their resilience (Bharwani et al., 2005). However, this accuracy must be presented in a transparent format as

\footnotetext{
${ }^{20}$ Shamba is a Kiswahili word for farm. See more on iShamba at: http://www.shambashapeup.com/ishamba
} 
well as in probabilistic contexts (Hansen et al., 2007) that smallholder farmers can understand and act upon. Seasonal weather forecasts issued by the Kenya Meteorological Department (KMD) will often use the terms 'above-normal' and 'below-normal' in reference to expected rainfall quantities. Such a framing should specify a meaningful range of values to which farmers can relate. Whereas the farmers may be informed when the onset of rains will be, they stated that they often do not know how it will be spread across the season. Secondly, above- or belownormal may be relative to particular crops and favor the growing conditions of one crop over the other.

Results from interactions with smallholders revealed mixed opinions on the accuracy of the weather forecasts they receive from the meteorological department via television and radio mediums. However, a majority perceive the forecast to be inaccurate. One example of this perceived inaccuracy that was offered a few times during the field study was related to a prediction that the MAM 2014 would experience El Niño weather depicted by enhanced rainfall. For farmers, this meant that there would be excessive rainfall. However, this was not the case in the study area. As one farmer expressed, had they based their planting decisions on the El Niño forecast, it was likely they would incur huge losses. His example was that a farmer might opt to plant a maize variety that required a lot of rainfall in order to do well only to be disappointed by the occurrence of low rainfall. Accuracy is enhanced by refining downscaled weather data to local levels.

\section{Timing}

As meteorologists strive to provide climate information with predictive accuracy, they need to balance this with timeliness (Ingram, Roncoli, \& Kirshen, 2002). As these authors argue, "a less 
accurate forecast with sufficient lead-time would be more valuable than a highly accurate forecast that arrives after farmers have made irrevocable decisions" (Ingram, Roncoli, \& Kirshen, 2002, p. 339). Specifically, there is a need to improve on the lead-time for provision of climate information to the end-users such as smallholders in order to realize timely interventions (Vermeulen et al., 2012).

As discussed in a previous section, intra-annual and intra-seasonal climate variability is of great concern to smallholders within the study region. Climate information that is accurate and presented a week or two in advance of incidence would significantly improve smallholder decision-making. For instance, it may help curtail the practice of staggered planting dates that smallholders practice to counter uncertainty on the onset of the rainy season. Further, a season's

success is determined by the timing of soil and crop management especially in regions where rainfall patterns are erratic - underscoring the need to increase the utility of climate information by offering additional advisory services (Davidson et al., 2003). An example of crop management given by Ingram et al. (2002) is advise on the best time within the season when insecticide application can be done with minimum risk of being washed away by the rain.

\section{Utility}

Seasonal climate forecasts can be an important tool for farmers in their decision-making. However, the uncertainty attached to these forecasts diminishes their utility especially when combined with the farmers' low tolerance for risks (Coles \& Scott, 2009). Besides uncertainty, another barrier to the utility of climate information is how it is presented. The information must be provided and customized to specific end-users with full cognition of their resources, different education levels (FAO, 2008a), as well as their capacities to act on it. Similarly, climate 
information dissemination and interpretation does not occur in a socio-political vacuum, which has impacts on its utility (Archer, 2003). The utility of such information is activated and complemented by other support services. For instance, knowledge on the onset of the rainy season may only be useful if services such as seed and fertilizer access are also in place in order for the smallholder to take relevant action. Therefore as Coles and Scott (2009) purport, access to climate information does not guarantee that it will be acted on.

The utility of climate information should enable end-users such as farmers to maximize on yields during good seasons (e.g. by investing in more profitable crops) while protecting families and farms or mitigating yield loss during adverse conditions (Hansen et al., 2007; Vermeulen et al., 2013). Further, climate information must be extended to inform possible impacts and management options (Tall et al., 2014) in order to be relevant to the farmers. In this case, smallholders can be assisted in scenario planning that would enable them to envision implications of certain management choices. For example, iShamba provides enhanced utility of climate information as they offer advisory-based services upon request by farmers. They also offer information on market prices for farm produce enabling farmers to get the best prices.

The attributes of access, accuracy, timing and utility identified from the smallholders' responses expand scholarship on climate information identified earlier - credibility, salience, legitimacy, and integration. Smallholders are clear on the types of information related to weather and climate that would be relevant to their decision-making at the farm level. However, some services such as those requiring subscription to weather and agricultural advisory services via mobile phone, may be inaccessible to poorer farmers due to costs involved. A practical example of how these attributes are built into advisory services and distributed in pamphlets to farmers is found 
in Appendix C. It comes from an existing project ${ }^{21}$ in Makueni County that brings together farmers, meteorological officers and agricultural workers to develop seasonal agro-advisories. In the pamphlet, an outlook for the rainfall season is offered together with advisories on the best crops for the season, farm management such as crop spacing, types of pests to be wary of, and recommendations for fertilizer use.

\subsubsection{Integrating local knowledge}

The smallholders traditionally relied on various indicators for information about upcoming rainy seasons but they stated that these were becoming less evident. The presence of dragonflies and the flowering of certain tree species such as the muhuti (Erythrina abyssinica) and jacaranda (Jacaranda mimosifolia) were used as indicators for the onset of rains. The smallholders were quick in acknowledging that human destruction and wanton deforestation have led to the disappearance of such vital trees. Available climate information should be sufficiently detailed to accommodate the heterogeneous needs of various end-users and address any misconceptions. For instance some end-users may view traditional weather-forecasting methods as credible while others may disregard these opting to rely only on scientifically-derived data (FAO, 2008a).

Smallholders can be supported in refining climate information that was previously gained from traditional observations by integrating relevant climate information. In a study done by Ziervogel and Calder (2003) among smallholders in Lesotho, crop farmers ranked the top five types of climate information they deemed most important (in descending order) as follows:

\footnotetext{
21 The project is funded by the Consultative Group for International Agricultural Research' (CGIAR) program on Climate Change, Agriculture and Food Security (CCAFS). As one of their project sites, CCAFS has developed an extensive database on Makueni. See https://amkn.org/ccafs-sites/makueni/? embedded $=1$. Last accessed $4^{\text {th }}$ August, 2016.
} 

a) Distribution of rain throughout the season
b) Start of the rainy season
c) Maximum rainfall in one month
d) Minimum temperatures
e) Maximum temperatures

A list similar to the one above was also suggested by farmers in Burkina Faso in a study conducted by Ingram et al. (2002). Based on concerns raised by the smallholder farmers in the Mt. Kenya region, there is a clear similarity to the list above. The distribution of rain in the cropping season was the primary concern - many asserted that the rains started as they had been forecast but they did not know how they would be spread out. Using traditional methods, some are still able to reliably predict when the rainy season would start but not how the rains would spread out or what temperatures can be expected.

Colder temperatures in the cropping season also seemed to have more adverse effects than higher temperatures. For instance, the farmers lamented that the season may start well and favour horticultural crops such as cabbages and tomatoes, but midway through, the temperatures would dip below an expected minimum level. This would in turn affect their crops leading to poor yields. In such a case, if the farmers were aware of the likelihood of this occurring beforehand, they would have prepared to undertake appropriate management strategies (such as application of crop treatments) or opted for more tolerant crops.

Local knowledge on climate variability and change was demonstrated by smallholders' narratives on the physiological effects they experienced. The evidence provided by smallholders of 'clothes fading', 'soil too hot to walk barefoot' or 'heat making them feel sick' are all valid although they 
have not been studied scientifically in the region. Previous and extensive work carried out in developed countries has seen scholars study heat illnesses and thermoregulatory behaviour. An example of this was from research carried out by Wolf et al. (2009) in the United Kingdom among the elderly. Their findings suggest that the most vulnerable, e.g. the elderly and children, are likely to be more prone to the effects of high heat relative to the duration of exposure. Climate change and variability can thus be measured in different ways.

\subsection{Climate change adaptation and lessons from heuristic approaches}

The research findings concur with Rufino et al. (2013) who called for more elucidation on the livelihood changes that are driven by climate change vis-á-vis other drivers among rural households. Smallholders in East Africa are making changes to their agriculturally-derived livelihood practices and climate change is only but one of the drivers (Kristjanson et al., 2012). This section teases out the adaptation lessons learnt from the smallholders relative to the question of climate change and its impacts on their food security and livelihoods. The lessons are bounded on one front by vulnerability and risk perceptions held by the smallholders and on the other side by the coping and compensation mechanisms they opt for.

\subsubsection{Vulnerability and risk perceptions inform coping mechanism}

Climate change risk is constructed in multiple ways and experienced differently (Granderson, 2014) within a community. Within the study's participants, a poorer-than-expected rainy season poses relatively lower risks to farmers who practice irrigation or who have alternative water sources. Similarly, a farmer who has livestock such as chickens and dairy cows may have different risks in comparison to one who only farms maize and beans. These examples highlight the 
importance of ownership or access to diverse resources that smallholders need in order to lower risks posed by climate change and variability.

Once an understanding of vulnerabilities to and risks from climate change has been reached, the next steps would involve an assessment of what it takes to mitigate or address them. Simply put, the adaptive capacity of smallholders comes to the fore. Where the adaptive capacity is found deficient, a logical step would be to build it up. As Granderson (2014) asserts, building the adaptive capacity of smallholders can be a challenge if they view the risks either as negligible on one end or as overwhelming on the other.

In areas that are prone to natural disasters such as coastlines, floodplains and seismic zones, residents are more aware of the hazards (Cutter et al., 2008). However, the capacity to respond to and cope with such possible hazards is often determined by various entitlements and capitals that the residents possess or have access to. For example, case studies of small island nations demonstrate that the low capacity of responses by households to disasters positions them to believe in higher forces. In a study on the island Republic of Kiribati, scholars reported that "adopting avoidant behaviour such as faith in God may enable respondents to alleviate feelings of hopelessness and fears of the threat" (Kuruppu \& Liverman, 2011, p. 666). Similarly, in the Pacific Island of Tuvalu, residents hold on to a biblical promise that God will never again flood the earth (Lata \& Nunn, 2012). Other studies have further explored these concepts on the 'Will of God' in Mozambique (Artur \& Hilhorst, 2012) and 'Acts of God' in Bangladesh (Grothmann \& Patt, 2005). In these examples, the relationship between the levels of vulnerability to natural disasters and the capacity to respond is clear. The seminal work by Wijkman and Timberlake (1984) published in their book 'Natural Disasters: Acts of God, or Acts of Man?' sheds more light on this 
relationship. The view of a Supreme Being who is in control of the weather is widespread in Africa and other developing regions. Examples of these beliefs are provided by several scholars drawing from case studies in South Africa, Ghana and Mexico (Kolawole, 2013; Saldaña-Zorrilla, 2008; Tschakert \& Dietrich, 2010). They point towards a Being who provides conducive environments for agricultural productivity as well as offering protection from losses.

In cases where loss occurs, other remedial measures such as compensation from insurance can occur. However, in developing countries such as Kenya and more so in sectors such as agriculture that are dominated by small-scale producers, insurance providers are yet to make significant inroads. There is however a cautious increase of micro-insurers who would be more favoured by smallholders due to their attractive small premiums (FAO, 2008a). A case in point is the indexbased insurance model which can be applied in prevailing drought conditions (FAO, WFP, \& IFAD, 2012) as has been piloted in parts of semi-arid Kenya among cattle keepers.

Only one smallholder in the research had experience with weather-based index insurance after paying premiums while she was purchasing her inputs at a local agrodealer. During that particular season, the projected versus actual weather conditions fell within acceptable range thus eliminating the need for compensation. As a result, this smallholder viewed the extra cost of the insurance premium as an unnecessary expense. Come the next season, she opted to forgo the insurance but as 'fate' would have it, her crop performed poorly. In her assessment, the poor performance was weather-related but she no longer had the option to seek compensation. This farmer's experience points to a broader gap in knowledge among the smallholders on the relationship between risk, insurance and probability dynamics. Formal institutions can play a role 
of educating smallholders on benefits of insurance compensation mechanisms relative to cost of premiums, as well as communicating what probability means in insurance arrangements.

\subsubsection{Climate change does not occur in a vacuum}

Terry (2009) asserts that climate change in developing countries does not occur in a vacuum. Smallholders voiced other environmental issues related to weather that had affected their farm productivity. Notably, the role of trees in influencing microclimates was often mentioned. Additionally, the cutting down of indigenous trees, with or without replacement with foreign species, was also a concern. The farmers related that as the tree cover continues to decline in the region due to deforestation, the following effects were evident:

- Lower water retention capacity of the soil

- Increased incidence of drought

- More attacks on grain stalks (e.g. millet) since 'birds no longer have trees to perch on'

- Replacement with foreign tree species does not simulate the preferred effects generated by the indigenous varieties

- Increased exposure to wind and direct heat from the sun that can damage the crops

The smallholders demonstrated their knowledge on the important role of trees and benefits to their farms and some have planted fruit trees such as mangoes, oranges and avocadoes for the triple benefits of yields, shade and fruits. However, the small farm sizes place a constraint due to the high demand for space on which to grow food crops to feed the household. In two of the discussion groups, some farmers brought up the term 'climate-friendly' trees in the context of species that are not heavy on water usage. One farmer lamented that he shared a boundary with another farmer who had a plantation of Eucalyptus trees that had rendered part of his farm 
unusable since the species drains water from his side of the fence. His dilemma points to a broader issue of agricultural governance through zoning and land-use restrictions which are largely unenforced in Kenya.

A decline in the amounts of annual rainfall received has been recorded. In some areas, this has occasioned the cessation of growing certain crops such as millet. However, the smallholders presented other climate-unrelated reasons as to why some crops are no longer grown. One female farmer in her mid-forties gave an example of a type of millet that was no longer grown in their region. When they were children, it was their role to go and look after the millet - mainly by chasing away birds that pestered the grain just before harvest time. Currently, school enrollment is at an all-time high therefore reducing the available farm labour to keep away birds from the millet. This example demonstrates that food security is affected by both changing climates as well as social factors. It is also clear that climate change perspectives vary and although some changes in farming practices are attributed to changes in the weather, this might not always be accurate.

In the face of various uncertainties or risks, and often as a last resort, some smallholders exercise 'distressed liquidation', opting to do away with farming or dispose of vital assets that are crucial to their agricultural-based livelihoods. The term 'distressed liquidation' is defined by Burke and Lobell (2010b) as perverse temporal trade-offs often made by farmers in developing countries in order to meet urgent needs. They add that these measures, though temporal, undermine the capacity of smallholders to adapt to future climate change.

Examples of these trade-offs were several among the smallholders in Mt. Kenya region. They not only underscored how smallholders' can reduce their future capacity to adapt, but also highlight 
that there are additional stressors besides climate change that are more impactful and pertinent to smallholders' livelihood and food security. Table 6.3 shows examples of these trade-offs and instances of distressed liquidation that emerged from interactions with smallholder farmers.

Table 6.3: Examples of trade-offs or distressed liquidation with reasons given by select smallholders.

\begin{tabular}{ll}
\hline Smallholder's action & Reason given for smallholder's action \\
\hline Got rid of cows & Lacked energy to go foraging for their fodder due to her old age \\
Uprooted coffee stems & Most were infected by disease \\
Reduced number of cows & The levels were unmanageable (financially and labour-wise) \\
Sold off milk-producing cow & To pay the daughter's school fees \\
Reduced the number of goats & Lost some fingers in an accident with fodder threshing machine. \\
Sold off chickens and goats & Meet fees for her sons \\
Sold off cows & Feeds were too expensive \\
Sold off chickens layers & To meet his late wife's medical bills \\
Uprooted tea stems & Due to mismanagement of tea factories \\
Sold off pigs & Was unable to meet cost of feeds \\
Sold off farm & Unproductive since neighbour planted trees that drain water from his soil \\
\hline
\end{tabular}

From the above examples there are four main categories of reasons given by smallholders on why they deem temporal trade-offs necessary. These are: (i) inability to meet costs and expenses e.g. for feeds and labour; (ii) in order to meet pressing livelihood expenses such as medical costs and school fees; (iii) diseases affecting crops and livestock; and (iv) external factors such as mismanagement of factories.

\subsection{Chapter synthesis}

In summary, smallholders provided sufficient evidence pointing to changing climatic conditions that have had significant influences to their food security. Smallholders view themselves as victims of climate dynamics and favourable conditions are at the behest of God, fate or luck. Their narratives from what happened in their past to the present day offered contrasting conditions that they have had to make adjustments to as they negotiate their livelihoods. However, not all changes have been induced by climate as human activities and changing socio-economic dynamics have also been at play. 
Based on their individual and household capacities, smallholders choose different responses to perceived climatic changes. As rainfall variability poses the greatest concern and disruption to their crop productivity, most smallholders resort to joining small-scale irrigation schemes where such an option is available. Switching to new crops or improved seeds, staggering or changing planting dates and taking up insurance were additional options pursued by the smallholders.

There are gaps in climate information that incapacitate smallholders' ability to make informed decisions related to their farm management. The four attributes teased out from the smallholders' responses necessary for quality climate information rest on access, accuracy, timing, and utility. However, there lies potential in disseminating climate information on platforms such as mobile phones and radio - the two communication mediums that have the highest coverage in Kenya.

Lata and Nunn (2012) state that the failure to distinguish climate variability from climate change can be a barrier to adaptation. As the authors elaborate, variability often leads to short-term planning and solutions. As earlier demonstrated, rainfall variability within a season can significantly differ from one year to the next. If the farmer makes a farm-level cropping decision, e.g. when to plant and whether to stagger the planting based on the rainfall pattern of one season, it is highly likely that they need to review that decision the following season. Smallholder decision-making at the farm-level is often in a state of flux requiring a level of flexibility and possible options for the farmer to pursue. The empirical findings call for a more nuanced approach to accessing relevant climate information that offers smallholders a practical platform for decision-making with greater confidence at the start of the season. 
The theoretical concepts of trade-offs, risks, vulnerability, cross-scale (spatial and temporal) interactions and complexity appear to emerge in smallholders' perceptions and experiences of climate dynamics. In response to changes, smallholders have been adapting their practices demonstrating both diversity (more activities) and dynamism (constantly changing activities). These changes are partially driven by climate dynamics and smallholder responses may alter their vulnerability, both positively and negatively to longer-term changes in climate and other factors. Therefore, there is a greater need to engage formal institutions in offering decision-support over longer time frames, a better understanding of uncertainty and risk, as well as provide a bouquet of information and options to meet the heterogeneous priorities of smallholder farmers. 


\section{Chapter 7. Re-imagining food security: Lessons from Mt. Kenya smallholders}

Using the understanding of food security dimensions and climate change concepts, this research lent itself to learning from the narratives of smallholder farmers. As discussed in the previous three chapters, the research probed the experiences and perceptions of smallholder farmers on food security, institutional arrangements and climate change. This chapter is divided into three main parts offering a synthesis of the research findings and reflecting on broader implications. The first part begins by revisiting key lessons from the three research sub-questions. The second section uses these lessons to respond to the overarching research question related to the fit of institutional arrangements. In the final section, conclusions are offered including the contributions of this research and suggestions for future directions.

\subsection{Lessons from empirical findings}

In Chapters 4 through 6, an in-depth analysis of the empirical findings was conducted while identifying their contributions to existing scholarship. In this section, some of the key lessons that contribute to the overarching question will be presented. This will be done while linking to the thematic areas identified in Chapters 2 and 3.

\subsubsection{Dynamics and dimensions of food security among Mt. Kenya smallholders}

Notable gains have been made in addressing food insecurity globally. The most commendable initiatives with greatest gains are traced to the Green Revolution that saw many developing countries in Asia improve food security outcomes for their citizens. However, much needs to be done to realize similar successes in sub-Saharan Africa (SSA). At the center of food security concerns lie smallholder farmers who are both food producers and consumers. Evidence from Mt. Kenya smallholder farmers indicates a maize yield gap of up to $76 \%$, which is in line with 
studies in other SSA regions. It is in smallholder farming communities that gains can be made in food security as they support many agricultural-based SSA economies.

Among smallholder farmers, food production is not only driven by dietary demands but also by livelihood needs. However, existing scholarship does not place adequate emphasis on the inextricable link between food and livelihood security among smallholder farmers. Examples from the field research indicated that other livelihood needs such as school fees can often subsume dietary needs at the household level. Smallholders view the bridge between subsistence farming and agribusiness as key to increasing their agricultural productivity and income thus improving their quality of life. A subsistence farmer mainly produces food to meet dietary needs and sells the surplus while the agribusiness-oriented farmer produces food with the aim of market sales. This research showed that more farmers are moving towards agribusiness as this allows them to better cater for other livelihood needs that require monetary transactions. However, since agribusiness is more capital intensive, bridging this gap is dependent on the resources at hand at the household level or that can be accessed from external sources. Many farmers would wish to install a small-scale irrigation system in their farms. Such an undertaking would require access to a steady source of water plus sufficient financial capital to cater for the necessary infrastructure.

Smallholders' livelihoods are negotiated in dynamic conditions, primarily through producing food. Since a steady state (equilibrium) is not possible, smallholder farmers must make decisions in environments that are in constant flux. Some of the dynamics include those that emanate from: changing climatic conditions, fluctuating market prices, unclear or changing regulations, and political instability. These dynamic environments necessitate a level of flexibility among the 
smallholders in making farm and household level decisions. Their decision-making ability is empowered by their understanding of risk and the resources they can access. As such, smallholders either make anticipatory or reactionary decisions.

As stated in Section 3.1.3, matters related to food security span both spatial and temporal scales. The spatial effects of phenomena such as globalization, market trends and food distribution have been studied at length in existing scholarship. However, recognition of the temporal scale across smallholder farming dynamics receives less attention. Smallholders plan and make decisions around timeframes defined by farming seasons that are marked on one end by the onset of rainfall and by the harvest of primary food crops on the other end. In the study region, two farming seasons exist - the first season is between March and May while the second season lies between October and December. The harvest realized at the end of each season are expected to sustain the dietary and livelihood needs of the smallholder's household until the end of the next season. In the current farming conditions of the study region, smallholders reported that they oscillate in between states of food security. Therefore, the temporal perspective implied by "at all times" in the widely accepted definition of food security does not apply.

The four food security dimensions in existing scholarship of availability, access, utilization and stability do not receive equal attention among smallholder farming practices. Evidence from Mt. Kenya smallholder farmers reveals that the food security dimensions of availability and access are well understood but those of utility and stability receive less recognition among smallholders. Further, smallholders extend the dimensions of availability and access and apply them beyond food security. As producers, smallholders understand that in order to have sufficient food to feed their families and meet other livelihood needs, availability and access to key production 
resources is a prerequisite. These resources include: crop inputs (seeds, pesticides and fertilizers); animal feeds and treatments; water and irrigation infrastructure; storage, markets and transportation; and financial services. The two dimensions should therefore be considered in pre-production processes rather than only after the production of food, which current scholarship places more emphasis on.

The utilization dimension appears to be the domain of mothers as most nutrition-related information is conveyed to them through maternal-child health clinics. As a result, female smallholder farmers were more informed on what constitutes balanced diets and the foods that would be more nutritious for their families especially children. This knowledge does not however appear to influence the decision on the types of food to grow - economic reasons such a as costs and produce prices are more influential in this decision. Additionally, the choice to have more nutritious diets is determined by monetary resources that would enable their purchase as well as dietary preferences. Smallholders reported changing preferences of certain types of food, mainly processed, which is in line with global dietary convergence patterns.

Although smallholders pay less attention to the stability dimension, the findings indicate that they often oscillate between periods when their access to food is guaranteed and other periods when food access remains uncertain. For them to realize this state, two main aspects need to be considered. First, if farming is their core activity, the food they produce must meet the bulk of their livelihood needs including food, school fees and other expenses. Often, unforeseen or unexpected events (such as illnesses that necessitate medical expenses) challenge their resources. Second, a different time scale needs to be considered. As pointed out earlier, smallholders plan in seasons. Their stability therefore is experienced seasonally with 
interruptions in between. This instability points towards limitations in their capacity to meet their needs at the household level.

\subsubsection{Institutional arrangements and food security dimensions}

Where the individual or household capacity to meet the above requirements is exceeded, smallholders tap into their social capital by utilizing various formal and informal institutional arrangements to augment their livelihoods. As discussed with examples in Chapter 5, these arrangements allow them to bridge that gap between their individual or collective capacities and their food or other livelihood needs. Such arrangements are either with other farmers in their community (informal institutions) or with various organizations dealing with farmers in their region (formal institutions). The most common support sought among the farmers from both sets of institutional arrangements lies in the acquisition of resources. This is directly linked to the aforementioned pre-production processes that have to be satisfied prior to food production. Informal arrangements offer additional social support, e.g. catering for medical costs, funeral expenses, and other needs as they arise.

Smallholders perceive higher levels of trust, balance of power, accountability and transparency among their arrangements in informal groups than those with formal institutions. However, the informal groups are limited in their capacity to offer support, especially when covariate shocks are experienced. Evidence from Mt. Kenya smallholders indicates that smallholders have greater agency when dealing with formal institutions as part of a group rather than as individuals. As presented in Section 5.2, various interplays exist between formal and informal institutional arrangements as smallholders utilize both to acquire resources, market their produce as well as to access financing and information. 
Smallholders utilize institutional arrangements, both formal and informal, to address the availability and access dimensions of the conventional food security definition. Many initiatives by formal and informal institutions in the region were focused on promoting both food and livelihood security. For example, projects introducing farmers to a high-yielding banana variety, poultry and dairy goat keeping are all aimed at increasing agricultural productivity, diversity and quality of food produced. This potentially leads to higher incomes at the household level and improvements in quality of life. Collaborations between formal and informal institutions have also increased physical and economic access to resources. For instance, partnerships have seen the establishment of small-scale irrigation schemes where the formal institution fronts the financial and technical capital while the informal group of smallholders provide the 'sweat equity' by building and maintaining the infrastructure. This joint ownership of such projects aims at curbing a culture of dependency on donor aid (Devereux et al., 2008). Institutions also contribute to the access dimension by mediating market arrangements between traders, consumers and the smallholders. These arrangements include: contract farming (e.g. of French beans); selling through a co-operative (e.g. for coffee and tea); or a group of smallholders collectively selling to a wholesale buyer.

Findings from Mt. Kenya indicate that institutional arrangements have not been sufficiently activated to address utilization and stability dimensions of food security. According to the smallholders, there are two main nutrition-based avenues of knowledge on food utilization. The first and most common is through maternal and childcare clinics where expectant or young mothers receive information on nutrition and proper diets for their households. The second is through a doctor's office when a farmer falls ill and upon visiting a health facility is offered advice 
on changes in diet that would improve their wellbeing. Both of these channels lie outside the day-to-day interactions that smallholders have with institutions related to farming. Similarly, the stability dimension of food security merits greater attention from institutions as it encompasses exposure to risks faced by smallholders. As earlier presented in Table 2.1, the vulnerability of smallholders as well as shocks they face act as indicators of the stability dimension. Some of the indicators include food price volatility and political instability. Formal institutions, especially government agencies, can play a significant role in tackling these in addition to addressing graft - all of which bear negative impacts on smallholders' food and livelihood security.

\subsubsection{Climate change realities more nuanced than everyday uncertainties}

The experiences shared by Mt. Kenya smallholders are replete with examples of responses they have made as a result of changes in their environments. While some of the changes are based on shifting weather patterns, a majority of the smallholder responses are however attributable to and driven by livelihood needs that they expect to meet. Nevertheless, smallholders offered examples of climate variability in the region and gave hints of climate change patters they have noted. Their observed climate variability was corroborated by rainfall data from local we ather stations as discussed in Section 6.2.1. It was however difficult to attribute some of their observed effects to climate change as other socio-economic factors have also shifted. For example, some farmers claimed they no longer planted millet due to its poor performance as a result of changing weather patterns. Others however stated that they no longer planted it since their children were school-going and hence there was no labour to chase away birds.

Given the temporal decision-making approach used by smallholders, climate variability has greater and immediate impact on their season-to-season food and livelihood security. Climate 
variability and change do not occur in a vacuum as other dynamics such as fluctuating costs of inputs and interrupted access to primary productivity resources are at play. As discussed in Chapter 6 these dynamics that raise uncertainty levels and increase risks to livelihoods are only exacerbated by climate change. Given the examples provided on 'distressed liquidation', there are many drivers of farm- and household-level changes adopted by smallholder farmers.

That empirical findings indicate climate change uncertainties are often subsumed by everyday uncertainties should not imply that its effects among smallholders in the region are of less

concern. Existing climate unrelated uncertainties cause smallholders to pay attention to them with immediacy at the cost of taking measure to build their adaptive capacity to climate change. As discussed in Section 2.3, climate change poses a great risk to smallholder farmers in SSA. Indeed, climate change challenges the smallholder's individual and household capacity to cope. However, as demonstrated in Chapter 5, smallholders have greater agency through informal institutions. The reality of climate change calls for a re-imagination of institutional arrangements among smallholder farmers.

\subsection{Leveraging institutional arrangements for gains in smallholders' food security}

This research was guided by the following overarching research question: Are the current institutional arrangements among smallholder farmers sufficient to bolster their food security in view of climate variability and climate change threats? Empirical findings from Mt. Kenya smallholders submit a response more complex than a simple "yes" or "no" that warrants further discussion. From the onset, interactions with smallholders conveyed that informal institutional arrangements were dominant than those with formal institutions. As a result, they shared more intricate details on their informal arrangements but also offered insights as to why the latent 
potential from engagements with formal institutions had not been realized. Further, smallholders acknowledged that the support gained from their informal groups was limited, especially in the context of dealing with covariate shocks as well as learning new skills. It is on this vein that proposals for leveraging institutional arrangements are made below.

This research adds to calls made in existing scholarship for more vertical bridging - where informal groups of farmers are linked to formal institutions. Section 5.4.2 explored the better qualities of informal institutions that offer lessons in governance for formal institutions. However, these lessons need not be one-way since a symbiotic relationship between informal and formal institution is feasible. Some of the positive attributes that can be capitalized upon from each group are shown in Table 7.1 below and have the potential to improve on the examples of interplays presented earlier in Table 5.1.

Table 7.1: Potential attributes of informal and formal institutions to be leveraged in vertical bridging

\begin{tabular}{l|l}
\hline Informal institutions among farmers & Formal institutions (organizations) \\
\hline - Trust \& accountability & $\begin{array}{l}\text { Professionalism, e.g. proper record keeping } \\
\text { - Mutual and equal benefits }\end{array}$ \\
$\begin{array}{l}\text { - Technical know-how, e.g. understanding of risks and } \\
\text { - Prioritization of needs }\end{array}$ & $\begin{array}{l}\text { - Non-local perspectives, e.g. global trends } \\
\text { - Mechanisms for resource mobilization }\end{array}$ \\
\hline
\end{tabular}

The social identities of individual smallholders are entrenched in the membership of their informal groups. These memberships shape their perceptions of farming and other livelihood activities, which in turn influence their decision-making.

Power dynamics from global to regional scales are well documented in literature. The existence of knowledge gaps and distances that extend commodity chains have been shown to influence the distribution of power in food governance (Clapp, 2014a). However, evidence from Mt. Kenya suggests that the local power differentials and dynamics at play are more dominant for 
smallholders (with exception of internationally traded commodities such as tea and coffee). Relatives or close friends to those in power, e.g. fertilizer distribution officers, are said to enjoy more benefits than others. Cartels comprising of unscrupulous traders and corrupt officials wield great influence on smallholders' access to resources, e.g. subsidized fertilizers.

Smallholders need to build trust and be confident that formal institutions are vested in their priorities and are interested in their success. This confidence is largely absent as many barriers such as power imbalances, bureaucratic systems and corruption impede smallholders' agency. If addressed, the institutional arrangements with organizations stand a better chance of offering solid support to smallholders.

Whereas institutional arrangements have the capacity to enhance the agency of smallholders and improve food security outcomes, evidence from Mt. Kenya reveals that the four dimensions of food security do not receive equal attention. Climate change however impacts all four dimensions. Further, climate change poses covariate shocks, potentially affecting all households in a locality, thus more difficult to tackle through informal networks as would be the case with idiosyncratic shocks (Trærup, 2012). As Alwang et al. (2001) expound, "because of the limited strength of informal risk pools, covariate risk is not well managed using informal mechanisms" (p. 19). Although informal institutions are the first level of support outside the household, their support may be limited by effects induced by climate variability and change. As discussed in Chapter 5, smallholders in the study demonstrated several models where they use their informal groups as intermediaries in engagements with formal institutions. There lies the potential to build synergies and improve on the adaptive capacity of households. Institutional arrangements 
against a backdrop of climate change can be addressed through two main areas: (i) information, knowledge and learning; and (ii) dealing with uncertainties, risks and trade-offs.

\subsubsection{Information, knowledge and learning}

"Informal social interactions and institutions play a central role in building trust and interpersonal relationships, which in turn increase the speed and frequency of knowle dge, resource, and other input sharing". (Juma, 2011, p. 63)

Engagements with smallholder farmers during the field research illuminated several areas where information deficiencies had limited their working knowledge for on-farm improvements. These included information gaps on expected weather patterns, disease trends in both crops and livestock, and market dynamics such as regulations, demand and prices. The bulk of this information lies in the custody of formal institutions. Mechanisms to convey relevant and timely information to smallholder farmers has been found wanting. In Section 6.2.2, an in-depth discussion was presented on the attributes of climate information and its dissemination that would be relevant to smallholder farmers. The utility of such information is however elusive if it is not complemented with relevant information such as the appropriate seeds for the season coupled with advisories on farm management. An example of this is offered in Appendix C, which contains an agro-climatic advisory pamphlet from Makueni. The advisories are generated collaboratively in forums where smallholders, agricultural extension officers, climate scientists and veterinary officers are in attendance. The pamphlet is also produced in the local language, Kamba, and information to illiterate farmers is passed on from those in attendance of the forums as well as agricultural officers. Through such a collective effort, it is possible to build consensus 
from the ground upwards in order to ensure that the heterogeneous priorities of each stakeholder are addressed (Sultana \& Thompson, 2004).

At the local level, initiatives by small scale farmers demonstrate the stimulation of self-uptake (Munang \& Nkem, 2011) especially in developing countries where there is often a breakdown in top-down communication (Lata \& Nunn, 2012). There was evidence of this given by smallholders who shared that their group meetings offer opportunities to visit each other's farms and learn in the process. New knowledge and improved technologies can only be introduced from interactions that are external to the informal group setting.

Most smallholders live on the same land on which they carry out their farming activities and are thus able to closely observe prevailing farming conditions and related outcomes. Their experience in one season is likely to influence the decisions they take in the next. It is therefore important that their experiences and observations are coupled with relevant scientific-based evidence and gain knowledge that would improve scenario planning. This is critically important since, as discussed in previous chapters, projected changes in climate may outpace the historical heuristic knowledge that smallholders often rely on. Further, responses to short-term weather events have the potential to disrupt longer-term adaptation to climate change.

Climate information dissemination in the region appears to be limited with radio and television dominating mass communication of information relevant to smallholders. However, there lies great potential in developing a dynamic agro-climatic information network that engages both smallholders and other actors who work and interact closely with farmers. A good example is on the close contact that smallholders have with agrodealers, often at the point where the former comes to buy farm inputs from the latter. During such transactions, smallholders often ask for 
advice from the agrodealers e.g. on a pest they have noticed affecting their crops and what the best treatment would be. Thus, these engagements involve the transaction of both information and goods. The government can take advantage of the close proximity of agrodealers to farmers and use them as an avenue to distribute the aforementioned pamphlets. At the same time, they should incentivize the agrodealers to stock appropriate farm inputs in advance of planting seasons.

There are additional ways of utilizing agrodealers in gathering information that would offer a sense of the prevailing farming conditions. Since agrodealers serve many customers who patronize their shops, they are positioned uniquely as gatekeepers of knowledge. While playing a positive role as gatekeepers, this knowledge can be harnessed to inform actions that would improve farming outcomes among smallholder farmers. For instance, if there is an increase in the number of smallholders who report negative changes in a particular crop or livestock, the agrodealer can alert and consult an agricultural extension worker. Relevant advice can then be relayed back to the smallholder farmer through the agrodealer. Conversely, as custodians of vital knowledge from smallholders, agrodealers can also contribute to negative farming outcomes. For example, they may receive incentives from input manufacturers to promote certain products for purchase by smallholders through the agrodealers' outlets. However, similar products from a competing manufacturer may be better suited to the prevailing farming conditions.

The utility of agrodealers in information exchange may not be suitable in other cases. Take for example the farmer in Chapter 5 whose maize crop was affected by the Maize Lethal Necrosis Disease (MLND). In her case, she was unaware about the fast-spreading disease and would have benefitted from prior information that it had reached her region so that she could pre-treat and 
thus protect her crops. Her critique of the 'demand-driven' approach where farmers seek extension services underscores the point that this model only works if a farmer identifies a gap in their knowledge. As information brokers, agricultural agents have a role to play in passing on relevant knowledge to smallholders in a timely and actionable manner.

The smallholders in the study region demonstrated the use of group meetings as learning forums. A study in Kenya by Eidt et al. (2012) concluded that farmers benefitted more from demanddriven extension services if they organized into common interest groups ( $\mathrm{CIGs})$ and summoned an agricultural extension officer (AEO). The informal groups formed by smallholders in the study region are $\mathrm{CIGs}$ since most are formed with the objective of improving both their farming as well as addressing welfare needs common among them. Some of the arrangements concur with the findings of these authors as the informal groups occasionally invite an expert to come and provide some training.

In a different learning model, smallholders in an informal group select their literate or more educated members to attend training sessions conducted by formal institutions. Inherent in the selected participants are power dynamics since they are in turn required to return to the group and share their lessons. The question on the quality of information transmitted to the larger group also comes to the fore. Where this model exists, it is the recommendation of this research that such trainings of select participants have in-built mechanisms to control for quality and evaluate the same.

\subsubsection{Understanding risks and dealing with uncertainties}

Empirical findings from Mt. Kenya highlight that smallholders make decisions in an environment that is in a constant state of flux. As such, there are instances where their decisions are made in 
contexts where various uncertainties occur. The smallholders also offered examples pointing towards evident effects of climate variability and change. However, there are more sources of instability e.g. the fluctuations in input prices that smallholders have to constantly negotiate. As stated earlier, livelihood needs have greatinfluence on the choices made by smallholder farmers. For instance, a farmer is more likely to pay emergent medical bills from funds set aside than buy hybrid seeds for the upcoming planting season. This choice has an obvious consequence to the yields the farmer expects to realize if they are not able to secure replacement funds to buy proper seeds in time. This example provides four interrelated areas in which institutional arrangements can be of further support to the smallholder: (i) long-term planning, (ii) scenario-building, (iii) financial support, and (iv) sequencing dilemma.

As was demonstrated in Chapter 4, smallholders plan season-to-season often demarcated by the start of the planting period and the end of the harvest session. This short-term planning is often as a result of uncertainties caused by both limited resources and information. Formal institutions have a role to play in supporting farmers to and plan think longer-term. Convincing smallholders of benefits of longer-term investments should not be a difficult task since evidence exists that they already do so in some arrangements. An example of this is derived from the informal savings and credit groups. The practical example given in Section 5.1.3 on Chamas indicates that smallholders have the capacity to self-organize and work together for one year until all have had a share of the mutual funds. Longer-term planning is key if gains in building their adaptive capacity and resilience to climate change are to be recorded.

In scenario-building, there is a need for farm management training that would maximize on the agricultural activities undertaken by smallholder farmers. Smallholder farmers can be trained by 
formal institutions on how to create better synergies in the farm and reduce wastage while making progress towards self-reliance. For example, more smallholders should adopt kitchen gardens and use livestock manure to grow common vegetables, which are part of the staple diet thus reducing costs incurred in buying the same. Similarly, more farmers should take on water harvesting through the use of gutters on their roof structures that drain rainwater into storage tanks.

However it is recognized that some of the scenarios described above come at a cost that the smallholder can neither afford as an individual, nor receive financing of the same from their informal group. Hence the suggested reworking of finance mechanisms in Section 5.4.3 where formal institutions work with informal groups of farmers to provide financially inclusive and affordable services.

In what they describe as a 'sequencing dilemma', Huntjens et al. (2012) state that adaptation actions are based on whether to act early or to postpone. The broader question here is whether smallholders are equipped with adequate information and capacities that would propel them to act $a$ priori to anticipated changes. These changes need not be driven by weather or climate variability. As discussed earlier in this chapter many reasons for distressed liquidation are driven by various livelihood needs. While appreciating that smallholders understand the inherent risks they face and choose trade-offs based on their livelihood priorities, formal institutions can offer support in addressing sequencing dilemmas. These dilemmas can be tackled by either providing more and better information as described in the previous section or by offering options such as insurance as a back-up in case risks are realized. These would allow for smallholders to make decisions in greater confidence that any losses they incur as a result are manageable. As a result, 
there is at least the potential to increase their adaptive capacity and at best, build their resilience to climate shocks.

\subsection{Reflections from the field}

The field work carried out in 2013 - 2014 among Mt. Kenya smallholders led to several points of reflection, some of which were highlighted in Chapter 3 under Section 3.3.1 on 'operating principles and ethical considerations'. In this subsection, I use my voice to expand on areas that gave me pause and reflect on how else this study might have been carried out.

\subsubsection{Debunking my assumptions}

While crafting the proposal for this research, I had held on to various assumptions based on existing literature as well as my limited understanding of smallholder farming in Kenya. Here, I discuss in brief some of these assumptions and how they have changed post-fieldwork.

a) Smallholders are vulnerable and in dire need of external support - They know what works and what does not. Their ability to self-organize and rely on social support systems among themselves is remarkable. I was challenged by their forward-thinking "saving culture" - no amount is too small to set aside - as demonstrated by their groups and the commitment to seeing each other succeed. Smallholders are already adapting. They may need support that lays outside their current informal arrangements but they have a lot more agency than is captured in existing literature

b) Climate change is the greatest threat that smallholders face - In the longer-term, this may be true. However, smallholders have to negotiate many other uncertainties before they can focus on strengthening themselves against imminent threats of climate change. Their focus of handling these uncertainties in the shorter-term may leave them more 
vulnerable to future effects of climate change. If climate change is to receive the warranted attention from smallholder farmers, it must be addressed in tandem with other existing uncertainties.

c) I had sufficient background information on the study area - Most of the knowledge is undocumented. The fieldwork was the most engaging classroom I have ever attended. The wealth of knowledge demonstrated by smallholders made me realize how their expertise is hardly applauded. I was further humbled by the manner in which they were willing to share their experiences and welcome me into their farms and lives. It was a pleasure to learn from them and have an opportunity to make a small contribution to questions they asked whose answers I held. For example, what climate change was and insights about my life in Canada.

\subsubsection{If I was to do this again....}

Here, I reflect on what I would have done differently if I was to re-write my proposal and return to the field to probe the overarching research question. As well, I highlight some areas where my findings would have been enriched if it were possible to construct a more extensive study.

From the onset, I had determined that my research work will try to the best of my ability to convey the voices of the farmers. The findings in Chapters 4 through 6 are a reflection of this as I presented smallholders' perceptions of and experiences with food security, institutional arrangements and climate change. In order to gather in-depth responses, I chose to work with a group of forty farmers engaging them through interviews and focus group discussions. Initially, I

had proposed to triangulate my analysis - from the smallholder farmers' responses, to those of agents representing various organizations working with smallholders in the region, while 
comparing with broader scholarship. However, after analysing my first focus group discussion transcripts, it emerged that the interaction between smallholders and formal institutions was much lower than I had assumed. Rather, they revealed the diverse nature in which they utilize informal groups to supplement their food and livelihood security activities. As a result, very few agents working with smallholders in the region were engaged. If this study was to be repeated, I would find a way to engage more of them and if possible, gather the official perspectives of organizations working with farmers in the region. Of interest would be to assess how the priorities of major institutions working in the region align with those of smallholder farmers. The third arm of the triangulation - on broader scholarship - was however accomplished and is presented in Chapters 4 through 6 after the discussions on empirical findings.

In working with a comparatively small group of farmers, the collection of quantitative data that would be representative of the general population was not feasible. If it were possible, a larger survey involving hundreds of farmers would have been conducted to gain insight into attributes such as dominant practices, levels of capacity as defined by capitals such as physical assets and education, mix of livelihood activities, as well as gender dynamics such as distinct roles of men and women. It would then be possible to adequately determine if the smallholders who participated in my study are fully representative of others in the region.

This study would have been enriched by mapping out the various organizations working in the region, their roles, coverage and operating mandates. Such a mapping process would showcase what has been done well by organizations in the region and where vulnerabilities may exist due to lack of support services. It would also be possible to point out overlaps - where organizations offer similar services to farmers in the same region - in order to suggest collaboration. 
Lastly, as was mentioned in Chapter 3, the study took place shortly after a newly constituted administrative system had been effected in Kenya. The provincial administration was in the process of being replaced by a devolved system of county governance. Some key sectors such as agriculture are now being run by counties. At the time of the field study, the transition to this system was nascent as reflected by the presence of both former provincial agricultural officers and newly appointed county officers at the duty station. Surprisingly, the governance transition period was not of concern to smallholder farmers. This may indicate the low contact level smallholders have with administrative officers. However, some farmers mentioned that they were still in contact with agricultural extension officers who had served their areas for several years and continued to do so under the new administration. It is my expectation that the elapsed time between the present and when the fieldwork was conducted has been adequate in redefining the administrative roles of agricultural officers. As such, it might be of interest to engage these new officers in the research process and understand if they are implementing different county-driven initiatives in comparison to the former nationally- and provincially-driven programs.

\subsection{Conclusion and suggestions for future directions}

This research sought to better understand food security dynamics among smallholder farmers. Existing literature identifies this group as vulnerable yet one that holds great potential in addressing global food insecurity challenges. Against emerging threats of climate change, the research sought to establish the potential and suitability of various institutional arrangements in supporting smallholder farmers' food security. While learning from the experience of farmers, the research findings were analyzed through a framework guided by political ecology on themes 
of social identities, risk perceptions, uncertainty and elements of scale. A case study was designed engaging farmers from Embu, Mt. Kenya region through in-depth interviews and focus group discussions. Reviews of the literature were also conducted to set the background information as well as understand how empirical findings contribute to broader scholarship. The research submits the following conclusions:

Food (in)security is difficult to measure at all levels. Global and regional measurements rely on food estimates determined from national level surveys. As was demonstrated in Chapter 2 using the 1990-92 (base period) numbers of undernourished populations, each subsequent State of Food Insecurity (SOFI) report from 2001 onwards has revised this base period number upward. This is a result of improved estimates from more data collected at the national level. At household levels, measurement of food security is also challenged by other livelihood dynamics that are at play. For smallholders, this remains pertinent since they grow food to meet their dietary needs as well as for trade or exchange to meet their livelihood needs such as school fees for their children.

The food security dimensions are not equal. Existing scholarship has not underscored this but it was evident from the field research that the availability and access dimensions receive more attention from smallholders than either utilization or stability. It appears that this will remain the case until smallholders can guarantee achieving the first two.

Among smallholders, livelihood security and food security are inextricably linked. This observation that emerged from the empirical findings does not receive the emphasis it merits in existing scholarship. 
The reality of smallholder farming is that farmers are in and out of food security status. This is in part because their livelihoods needs are met by the food they produce and often these needs prevail over dietary requirements. It is also as a result of the season-to-season temporal scale that is used by smallholders. Thus the conventional definition of food security coined during the Wold Food Summit in 1996, especially the section on "at all times", falls short of the realities of smallholder farming.

Smallholders are identified as vulnerable but also have agency. The farmers derive additional identity as members of informal groups through which they enjoy greater agency. These informal groups act as brokers in easing the access to resources and meditators in arrangements with formal institutions.

Food security among smallholders is challenged to a lesser extent by climate variability and change than other unrelated uncertainties. Negotiating these uncertainties is tasking and can be at the cost of putting in place adaptive capacity measures or building resilience towards climate change threats.

If properly leveraged, informal group dynamics offer greater potential of improving smallholders' food security through various institutional arrangements. These relate to financing, knowledge brokering and provision of coping mechanisms such as insurance.

Future directions of smallholder farmers in the study region are guided by several global and continental policies. 2015 marked the expiration of Millennium Development Goals (MDGs). Several of the goals remained unaccomplished including that of halving the population that was food insecure. In revamped efforts to pursue some of the missed goals, the 17 Sustainable Development Goals with 169 associated targets were crafted in 2015 and ratified by over 190 
countries. The second goal aims to end hunger and achieve food security and improved nutrition by 2030 while pursuing sustainable agriculture. One target under this goal seeks to double the productivity of smallholder through improved access to resources and markets.

At regional levels, efforts to address food insecurity have also been developed. For sub-Saharan Africa (SSA), these revamped efforts are found in Agenda 2063, a roadmap document ratified in 2015 by African heads of state at the African Union headquarters in Addis Ababa, Ethiopia. Under Aspiration 1 on inclusive growth and sustainable development, the document commits to increase agricultural productivity and value-addition through modern farming methods that would ultimately lead to prosperous farmers and nations. It specifies that farming by the use of hand-held hoes will be a long-forgotten practice by 2025 as modern farming technologies will then be commonplace. These goals appear idealistic at best. One smallholder during a focus group discussion scoffed at the idea that in future they would be using tractors to farm. Her viewpoint was valid as she highlighted the nature of the small and shrinking farm-sizes. Further, these ambitions by SSA governments need to reflect previous ambitions made through initiatives such as the Maputo Declaration that saw a high non-compliance rate in the set targets for investments in agriculture.

New and ambitious directions have also been taken by individual governments in tackling climate change. Kenya is one of the countries that has ratified the Paris Agreement, which comes into effect in 2020 and has submitted its Intended Nationally Determined Contribution (INDC). In the INDC, Kenya has committed to go beyond adapting to the effects of climate change but also pursue a low carbon and climate-resilient development pathway as form of mitigation. The 
commitments specific to food production call for enhanced resilience as well as climate-smart agriculture.

These policies at global, regional and national levels related to smallholder farmers, food security and climate change offer a great platform on which related projects can be established. However, such initiatives seeking to improve the food and livelihood security of smallholder farmers must as well be informed by dynamics in the target regions. This research has demonstrated how institutional arrangements among smallholder farmers can be leveraged to improve on food and livelihood security. 


\section{References}

Acosta-Michlik, L., \& Espaldon, V. (2008). Assessing vulnerability of selected farming communities in the Philippines based on a behavioural model of agent's adaptation to global environmental change. Global Environmental Change, 18, 554-563. http://oi.org/10.1016/j.gloenvcha.2008.08.006

Adger, N. W. (2006). Vulnerability. Global Environmental Change, 16, 268-281. http://doi.org/10.1016/j.gloenvcha.2006.02.006

Africa Seed Trade Association. (2013). Improved maize (Zea mays) variety list from Kenya, Uganda and Tanzania. Nairobi.

Agrawal, A., Kononen, M., \& Perrin, N. (2009). The role of local institutions in adaptation to climate change (Social Development Working Paper No. 118). Washington, D.C.

Alila, P. O. (1977). Kenyan agricultural policy: The colonial roots of African smallholder agricultural policy and services (Institute of Development Studies, University of Nairobi Working Paper No. 327). Nairobi.

Allen, J., Mohatt, G. V, Markstrom, C. A., Byers, L., \& Novins, D. K. (2012). "Oh no, we are just getting to know you": The relationship in research with children and youth in indige no us communities. Child Development Perspectives, 6(1), 55-60. http://oi.org/10.1111/j.17508606.2011.00199.x

Alwang, J., Siegel, P. B., \& Jørgensen, S. L. (2001). Vulnerability: A view from different disciplines. Social Protection Discussion Paper Series. Washington, D.C.

Amaru, S., \& Chhetri, N. B. (2013). Climate adaptation: Institutional response to environmental constraints, and the need for increased flexibility, participation, and integration of approaches. Applied Geography, 39, 128-139. http://doi.org/10.1016/j.apgeog.2012.12.006

Amekawa, Y. (2011). Agroecology and sustainable livelihoods: Towards an integrated approach to rural development. Journal of Sustainable Agriculture, 35(2), 118-162. http://doi.org/10.1080/10440046.2011.539124

Amekawa, Y., Sseguya, H., Onzere, S., \& Carranza, I. (2010). Delineating the multifunctional role of agroecological practices: Toward sustainable livelihoods for smallholder farmers in developing countries. Journal of Sustainable Agriculture, 34(2), 202-228. http://doi.org/10.1080/10440040903433079

Archer, E. R. M. (2003). Identifying underserved end-user groups in the provision of climate information. American Meteorological Society, (November), 1525-1532. http://doi.org/10.1175/BAMS-84-11-1525

Ariga, J., \& Jayne, T. S. (2011). Fertilizer in Kenya: Factors driving the increase in usage by smallholder farmers. In P. Chuhan-Pole \& M. Angwafo (Eds.), Yes Africa can: Success stories from a dynamic continent (pp. 269-288). Washington, D.C.: The World Bank.

Artur, L., \& Hilhorst, D. (2012). Everyday realities of climate change adaptation in Mozambique. Global Environmental Change, 22(2), 529-536. http://oi.org/10.1016/j.gloenvcha.2011.11.013

Atkinson, A. (1991). Principles of political ecology. John Wiley \& Sons Ltd.

Barrett, C. B. (2002). Food security and food assistance programs. In B. Gardner \& G. Rausser (Eds.), Handbook of Agricultural Economics: Agricultural and Food policy (Vol. 2, pp. 2103-2190). New York. 
Bazeley, P. (2013). Qualitative data analysis: Practical strategies. London: SAGE Publications Ltd.

Bazeley, P., \& Jackson, K. (2013). Qualitative data analysis with NVivo(2nd ed.). London: SAGE Publications Ltd.

Bennett, M., \& Franzel, S. (2013). Can organic and resource-conserving agriculture improve livelihoods? A synthesis. International Journal of Agricultural Sustainability, 11(3), 193215. http://doi.org/10.1080/14735903.2012.724925

Bharwani, S., Bithell, M., Downing, T. E., New, M., Washington, R., \& Ziervogel, G. (2005). Multi-agent modelling of climate outlooks and food security on a community garden scheme in Limpopo, South Africa. Philosophical Transactions of the Royal Society, 360, 2183-2194. http://doi.org/10.1098/rstb.2005.1742

Biermann, F., Betsill, M. M., Gupta, J., Kanie, N., Lebel, L., Liverman, D., .. Siebenhuner, B. (2009). Earth system governance: People, places and the planet. IHDP Report No. 20. Bonn.

Birner, R., \& Resnick, D. (2010). The political economy of policies for smallholder agriculture. World Development, 38(10), 1442-1452. http://doi.org/10.1016/j.worlddev.2010.06.001

Brooks, S. (2014). Enabling adaptation? Lessons from the new "Green Revolution" in Malawi and Kenya. Climatic Change, 122(1-2), 15-26. http//doi.org/10.1007/s10584-013-0992-0

Brown, H. C.P. (2011). Gender, climate change and REDD+ in the Congo Basin forests of Central Africa. International Forestry Review, 13(2), 163-176. http://doi.org/10.1505/146554811797406651

Brown, M. E., \& Funk, C. C. (2008). Food security under climate change. Science, 319, 580-581. http://doi.org/10.1126/science.1154102

Bruinsma, J. (2009). The resource outlook to 2050: By how much do land, water and crop yields need to increase by 2050. In FAO Expert Meeting on How to Feed the World in 2050. Rome.

Bryan, E., Ringler, C., Okoba, B., Roncoli, C., Silvestri, S., \& Herrero, M. (2013). Adapting agriculture to climate change in Kenya: Household strategies and determinants. Journal of Environmental Management, 114, 26-35. http://doi.org/10.1016/j.jenvman.2012.10.036

Bryant, R. L. (2001). Political ecology: A critical agenda for change? In N. Castreee \& B. Braun (Eds.), Social nature: Theory, practice and politics (pp. 151-169). Malden, MA and Oxford: Blackwell Publishers Ltd.

Bryant, R. L., \& Bailey, S. (1997). Third World political ecology. London and New York: Routledge.

Buechler, S. (2009). Gender, water, and climate change in Sonora, Mexico: Implications for policies and programmes on agricultural income-generation. Gender \& Development, 17(1), 51-66. http://doi.org/10.1080/13552070802696912

Burke, M., \& Lobell, D. (2010a). Climate effects on food security: An overview. In D. Lobell \& M. Burke (Eds.), Climate change and food security: Adapting agriculture to a warmer world (1st ed., pp. 13-30). Springer Netherlands. http://doi.org/10.1007/978-90-481-2953-9

Burke, M., \& Lobell, D. (2010b). Food security and adaptation to climate change: What do we know? In D. Lobell \& M. Burke (Eds.), Climate change and food security: Adapting agriculture to a warmer world (1st ed., pp. 133-153). Springer Netherlands. http://doi.org/10.1007/978-90-481-2953-9

Caplan, P. (2009). Who benefits from globalization in Tanzania and India? In D. Inglis \& D. Gimlin (Eds.), The Globalization of Food (pp. 273-290). Oxford, New York: Berg. 
Ceccato, L., Giannini, V., \& Giupponi, C. (2011). Participatory assessment of adaptation strategies to flood risk in the Upper Brahmaputra and Danube river basins. Environmental Science and Policy, 14(8), 1163-1174. http://doi.org/10.1016/j.envsci.2011.05.016

Challinor, A., Wheeler, T., Garforth, C., Craufurd, P., \& Kassam, A. (2007). Assessing the vulnerability of food crop systems in Africa to climate change. Climate Change, 83, 381399. http://doi.org/10.1007/s10584-007-9249-0

Chamberlin, J., \& Jayne, T. S. (2013). Unpacking the meaning of "market access ": Evidence from rural Kenya. World Development, 41, 245-264. http://doi.org/10.1016/j.worlddev.2012.06.004

Clapp, J. (2014a). Financialization, distance, and global food politics. The Journal of Peasant Studies, 41(5), 797-814. http://doi.org/10.1080/03066150.2013.875536

Clapp, J. (2014b). Trade liberalization and food security: Examining the linkages. Geneva: Quaker United Nations Office (QUNO).

Coles, A. R., \& Scott, C. A. (2009). Vulnerability and adaptation to climate change and variability in semi-arid rural southeastern Arizona, USA. Natural Resources Forum, 33, 297-309.

County Assembly of Embu. (2014). First assembly - (Second session): Votes and Proceedings. Wednesday 2nd July, 2014. In J. Omayo (Ed.), Motion: County Assembly petitions the Commission on Administrative and Justice to investigate the violation and secure appropriate redress for the farmers on maize which never germinated (p. 32). Embu.

Cutter, S. L., Barnes, L., Berry, M., Burton, C., Evans, E., Tate, E., \& Webb, J. (2008). A placebased model for understanding community resilience to natural disasters. Global Environmental Change, 18, 598-606. http://oi.org/10.1016/j.gloenvcha.2008.07.013

Darwin, C. P. (1958). Population problems. Bulletin of the Atomic Scientists, 14(8), 322-324.

Davidson, O., Halsnæs, K., Huq, S., Kok, M., Metz, B., Sokona, Y., \& Verhagen, J. (2003). The development and climate nexus: The case of sub-Saharan Africa. Climate Policy 3SI, S97S113. http://doi.org/10.1016/j.clipol.2003.10.007

Davis, M. (1945, March 25). Will freedom from want in world end wars. FAO considers food important as security. The Washington Post.

De Blij, H. J. (1964). A geography of Subsaharan Africa. Rand McNally.

Denton, F. (2002). Climate change vulnerability, impacts, and adaptation: Why does gender matter? Gender \& Development, 10(2), 10-20. http //doi.org/10.1080/13552070215903

Deressa, T. T., Hassan, R. M., Ringler, C., Alemu, T., \& Yesuf, M. (2009). Determinants of farmers' choice of adaptation methods to climate change in the Nile Basin of Ethiopia. Global Environmental Change, 19(2), 248-255. http//doi.org/10.1016/j.gloenvcha.2009.01.002

Devereux, S., Sabates-Wheeler, R., Guenther, B., Dorward, A., Poulton, C., \& Al-Hassan, R. (2008). Linking Social Protection and Support to Small Farmer Developmeny, (April).

Djoudi, H., Brockhaus, M., \& Locatelli, B. (2013). Once there was a lake: Vulnerability to environmental changes in northern Mali. Regional Environmental Change, 13(3), 493-508. http://doi.org/10.1007/s10113-011-0262-5

Djurfeldt, A. A. (2015). Urbanization and linkages to smallholder farming in sub-Saharan Africa: Implications for food security. Global Food Security, 4, 1-7. http://doi.org/10.1016/j.gfs.2014.08.002

Dwyer, P. D., \& Minnegal, M. (2006). The good, the bad and the ugly: Risk, uncertainty and decision-making by Victorian fishers. Journal of Political Ecology, 13, 1-23. 
Eidt, C. M., Hickey, G. M., \& Curtis, M. A. (2012). Knowledge integration and the adoption of new agricultural technologies: Kenyan perspectives. Food Security, 4(3), 355-367. http://doi.org/10.1007/s12571-012-0175-2

Ellis, F. (1998). Household strategies and rural livelihood diversification. Journal of Development Studies, 35(1), 1-38. http://doi.org/10.1080/00220389808422553

Engle, N. L. (2011). Adaptive capacity and its assessment. Global Environmental Change, 21(2), 647-656. http://doi.org/10.1016/j.gloenvcha.2011.01.019

Engle, N. L., \& Lemos, M. C. (2010). Unpacking governance : Building adaptive capacity to climate change of river basins in Brazil. Global Environmental Change, 20, 4-13. http:/doi.org/10.1016/j.gloenvcha.2009.07.001

Ericksen, P. J. (2008). Conceptualizing food systems for global environmental change research. Global Environmental Change, 18, 234-245. http //doi.org/10.1016/j.gloenvcha.2007.09.002

Ericksen, P. J., Ingram, J. S., \& Liverman, D. M. (2009). Food security and global environmental change: Emerging challenges. Global Environmental Change, 12, 373-377. http://doi.org/10.1016/j.envsci.2009.04.007

Ericksen, P., Stewart, B., Dixon, J., Barling, D., Loring, P., Anderson, M., \& Ingram, J. (2010). The value of a food system approach. In J. Ingram, P. Ericksen, \& D. Liverman (Eds.), Food security and global environmental change (pp. 25-45). London \& Washington, D.C.: Earthscan.

Eriksen, S., Aldunce, P., Bahinipati, C. S., Martins, R. D., Molefe, J. I., Nhemachena, C., ... Ulsrud, K. (2011). When not every response to climate change is a good one: Identifying principles for sustainable adaptation. Climate and Development, 3(1), 7-20. http://doi.org/10.3763/cdev.2010.0060

European Commission (EC), \& FAO. (2008). An introduction to the basic concepts offood secutiy. Fankhauser, S., \& Schmidt-Traub, G. (2011). From adaptation to climate-resilient development: The costs of climate-proofing the Millennium Development Goals in Africa. Climate and Development, 3(2), 94-113. http://doi.org/10.1080/17565529.2011.582267

FAO. (1999). The state of food insecurity in the world 1999. Food insecurity: When people must live with hunger and fear starvation.

FAO. (2001). The state of food insecurity in the world 2001. Food insecurity: When people live with hunger and fear starvation.

FAO. (2002). The state of food insecurity in the world 2002. Food insecurity: When people must live with hunger, fear and starvation. Rome: FAO.

FAO. (2003). The state of food insecurity in the world 2003. Monitoring progress towards the World Food Summit and Millennium Development Goals. Rome.

FAO. (2004). The state of food insecurity in the world 2004. Monitoring progress towards the World Food Summit and Millennium Development Goals (p. 43). Rome.

FAO. (2005). The state of food insecurity in the world 2005. Eradicating world hunger - key to achieving the Millennium Development Goals. Rome.

FAO. (2006). The state of food insecurity in the world 2006. Eradicating world hunger - taking stock ten years after the World Food Summit. Rome.

FAO. (2008a). Climate change and food security: A framework document. Rome.

FAO. (2008b). The state offood insecurity in the world 2008. High food prices and food security 
- threats and opportunities. Rome.

FAO. (2009). The state of food insecurity in the world 2009. Economic crises - impacts and lessons learned. Rome.

FAO. (2010). The state of food insecurity in the world 2010. Addressing food insecurity in protracted crises. Rome.

FAO. (2011). The state of food insecurity in the world 2011. How does international price volatility affect domestic economies and food security? Rome.

FAO. (2012). Decent rural employment for food security: A case for action. Rome.

FAO. (2014). Understanding smallholder farmer attitudes to commercialization: The case of maize in Kenya. (A. Woolverton \& D. Neven, Eds.). Rome: Food and Agriculture Organization of the United Nations.

FAO. (2015). Climate change and food systems: Global assessments and implications for food security and trade.

FAO. (2016). Food and agriculture key to achieving 2030 Agenda for Sustainable Development (Vol. 1).

FAO, CTA, \& IFAD. (2014). Youth and agriculture: Key challenges and concrete solutions. FAO.

FAO, IFAD, \& WFP. (2013). The state of food insecurity in the world 2013. The multiple dimensions of food security. Rome.

FAO, IFAD, \& WFP. (2014). The state of food insecurity in the world 2014. Strengthening the enabling environment for food security and nutrition. Rome.

FAO, IFAD, \& WFP. (2015). The state of food insecurity in the world 2015. Meeting the 2015 international hunger targets: Taking stock of uneven progress. Rome.

FAO, ISD, \& TWN. (2011). Climate change and food systems resilience in sub-Saharan Africa. (L. L. Ching, S. Edwards, \& N. E.-H. Scialabba, Eds.). Rome: Food and Agriculture Organization of the United Nations.

FAO, WFP, \& IFAD. (2012). The state of food insecurity in the world 2012. Economic growth is necessary but not sufficient to accelerate reduction in hunger and malnutrition. Rome.

Flora, C. B. (2010). Food security in the context of energy and resource depletion: Sustainable agriculture in developing countries. Renewable Agriculture and Food Systems, 25(2), 118128. http:/doi.org/10.1017/S1742170510000177

Folke, C. (2006). Resilience: The emergence of a perspective for social-ecological systems analyses. Global Environmental Change, 16, 253-267. http://doi.org/10.1016/j.gloenvcha.2006.04.002

Foran, T., Butler, J. R. A., Williams, L. J., Wanjura, W. J., Hall, A., Carter, L., \& Carberry, P. S. (2014). Taking complexity in food systems seriously: An interdisciplinary analys is. World Development, 61, 85-101. http://doi.org/10.1016/j.worlddev.2014.03.023

Forsyth, T. (2003). Critical political ecology. London and New York: Routledge.

Frank, E., Eakin, H., \& López-Carr, D. (2011). Social identity, perception and motivation in adaptation to climate risk in the coffee sector of Chiapas, Mexico. Global Environmental Change, 21(1), 66-76. http://doi.org/10.1016/j.gloenvcha.2010.11.001

Freidberg, S., \& Goldstein, L. (2011). Alternative food in the global south: Reflections on a direct marketing initiative in Kenya. Journal of Rural Studies, 27(1), 24-34. http://doi.org/http://dx.doi.org/10.1016/j.jrurstud.2010.07.003 
Friedmann, H. (1998). A sustainable world food economy. In R. Keil, D. V. J. Bell, P. Penz, \& L. Fawcett (Eds.), Political ecology: Global and local (pp. 85-97). London and New York: Routledge.

Gaiser, T., Judex, M., Igué, M. A., Paeth, H., \& Hiepe, C. (2011). Future productivity of fallow systems in sub-Saharan Africa: Is the effect of demographic pressure and fallow reduction more significant than climate change? Agricultural and Forest Meteorology, 151(8), 11201130. http://doi.org/10.1016/j.agrformet.2011.03.015

Gibson, C. C., Ostrom, E., \& Ahn, T. K. (2000). The concept of scale and the human dimens ions of global change: A survey. Ecological Economics, 32(2), 217-239. http://doi.org/10.1016/S0921-8009(99)00092-0

Gichuru, L. N. (2013). Breeding investigations on utility of maize streak virus resistant germplasm for hybrid development in the tropics. University of KwaZulu-Natal.

Giller, K. E., Witter, E., Corbeels, M., \& Tittonell, P. (2009). Conservation agriculture and smallholder farming in Africa: The heretics' view. Field Crops Research, 114, 23-34. http://doi.org/10.1016/j.fcr.2009.06.017

Githinji, M. W., \& Cullenberg, S. E. (2003). Deconstructing the peasantry: Class and development in rural Kenya. Critical Sociology, 29(1), 67-88. http://doi.org/10.1163/156916303321780564

Gockowski, J., \& van Asten, P. (2012). Agricultural intensification as a climate mitigation and food security strategy for sub-Saharan Africa. In E. Wollenberg, A. Nihart, M.-L. TapioBiström, \& M. Greig-Gran (Eds.), Climate change and mitigation agriculture (pp. 382-390). New York: Routledge.

Granderson, A. A. (2014). Making sense of climate change risks and responses at the community level: A cultural-political lens. Climate Risk Management, 3, 55-64. http://doi.org/10.1016/j.crm.2014.05.003

Granoff, I., Eis, J., Hoy, C., Watson, C., Khan, A., \& Grist, N. (2014). Targeting zero zero: Achieving zero extreme poverty on the path to zero net emissions. London: Overseas Development Institute.

Gregory, P. J., Ingram, J. S. I., \& Brklacich, M. (2005). Climate change and food security. Philosophical Tansactions of the Royal Society, 360, 2139-2148. http://doi.org/10.1098/rstb.2005.1745

Grothmann, T., \& Patt, A. (2005). Adaptive capacity and human cognition: The process of individual adaptation to climate change. Global Environmental Change, 15(3), 199-213. http://doi.org/10.1016/j.gloenvcha.2005.01.002

Gupta, J., Termeer, K., Klostermann, J., Meijerink, S., van den Brink, M., Jong, P., ... Bergsma, E. (2010). The adaptive capacity wheel: A method to assess the inherent characteristics of institutions to enable the adaptive capacity of society. Environmental Science and Policy, 13, 459-471.

Gustafson, D. (2004). Kenya: Supporting the demand for change - Recent project experience with farmer learning grants. In W. Rivera \& G. Alex (Eds.), Vol 3: Demand-driven approaches to agriculture extension. Case studies of international initiatives (pp. 22-30). The World Bank.

Hanjra, M. A., \& Qureshi, E. M. (2010). Global water crisis and future food security in an era of climate change. Food Policy, 35(5), 365-377. http://doi.org/10.1016/j.foodpol.2010.05.006

Hansen, J. W., Baethgen, W., Osgood, D., Ceccato, P., \& Ngugi, R. K. (2007). Innovations in 
climate risk management: Protecting and building rural livelihoods in a variable and Changing Climate. SAT eJournal ICRISAT, 4(1), 1-38.

Harris, D., \& Orr, A. (2014). Is rainfed agriculture really a pathway from poverty? Agricultural Systems, 123, 84-96. http://doi.org/10.1016/j.agsy.2013.09.005

Headey, D. D., \& Jayne, T. S. (2014). Adaptation to land constraints: Is Africa different? Food Policy, 48, 18-33. http//doi.org/10.1016/j. foodpol.2014.05.005

Hodgson, G. M. (2006). What are institutions? Journal of Economic Issues, XL(1), 1-25.

Huntjens, P., Lebel, L., Pahl-Wostl, C., Camkin, J., Schulze, R., \& Kranz, N. (2012). Institutional design propositions for the governance of adaptation to climate change in the water sector. Global Environmental Change, 22(1), 67-81. http://doi.org/10.1016/j.gloenvcha.2011.09.015

Iglesias, A., Quiroga, S., \& Diz, A. (2011). Looking into the future of agriculture in a changing climate. European Review of Agricultural Economics, 38(3), 427-447. http://doi.org/10.1093/erae/jbr037

Ingram, K. T., Roncoli, M. C., \& Kirshen, P. H. (2002). Opportunities and constraints for farmers of west Africa to use seasonal precipitation forecasts with Burkina Faso as a case study. Agricultural Systems, 74, 331-349.

Intergovenmental Panel on Climate Change (IPCC). (2007). Climate Change 2007: Synthesis Report. Contribution of Working Groups I, II and III to the Fourth Assessment Report of the Intergovernmental Panel on Climate Change. (Core Writing Team, R. K. Pachauri, \& A. Reisinger, Eds.). Geneva.

Intergovenmental Panel on Climate Change (IPCC). (2014). Climate Change 2014 Synthesis Report.

Jaetzold, R., Schmidt, H., Hornetz, B., \& Shisanya, C. (2006). Farm management Handbook of Kenya. Natural conditions and farm management information. Part C - East Kenya. Subpart C1 - Eastern Province (2nd ed., Vol. II). Nairobi: Ministry of Agriculture, Kenya. German Agency for Technical Cooperation (GTZ).

Janssen, M. A., \& Ostrom, E. (2006). Resilience, vulnerability, and adaptation: A cross-cutting theme of the International Human Dimensions Programme on Global Environmental Change. Global Environmental Change, 16, 237-239. http //doi.org/10.1016/j.gloenvcha.2006.04.003

Jayne, T. S., \& Muyanga, M. (2012). Land constraints in Kenya's densely populated rural areas: Implications for food policy and institutional reform. Food Security, 4(3), 399-421. http://doi.org/10.1007/s12571-012-0174-3

Juma, C. (2011). The new harvest. Agricultural innovation in Africa. New York, NY: Oxford University Press.

Kang, Y., Khan, S., \& Ma, X. (2009). Climate change impacts on crop yield, crop water productivity and food security - A review. Progress in Natural Science, 19(12), 1665-1674. http://doi.org/10.1016/j.pnsc.2009.08.001

Kassie, M., Ndiritu, S. W., \& Stage, J. (2014). What determines gender inequality in household food security in Kenya? Application of exogenous switching treatment regression. World Development, 56, 153-171. http://doi.org/10.1016/j.worlddev.2013.10.025

Kenya Meteorological Department. (2016). Dekadal agrometeorological bulletin. Retrieved June 5, 2016, from http://www.meteo.go.ke/dekad/

Kenya Seed Company. (2015a). Maize varieties at a glance. Retrieved September 4, 2015, from 
http:/www.kenyaseed.com/index.php?option=com_content\&view=article \&id=243\&Itemid $=220$

Kenya Seed Company. (2015b). "What is the right quantity of fertilizer application?" Retrie ved November 16, 2015, from $\mathrm{http}: / /$ www.kenyaseed.com/index.php?option=com_content\&view $=$ article $\& \mathrm{id}=435 \&$ Itemid $=274$

Kerer, J. (2013). Background paper on the situation of agricultural insurance in Kenya with reference to international best practices. Nairobi.

Kilelu, C. W., Klerkx, L., Leeuwis, C., \& Hall, A. (2011). Beyond knowledge brokering: An exploratory study on innovation intermediaries in an evolving smallholder agricultural system in Kenya. Knowledge Management for Development Journal, 7(1), 84-108. http://doi.org/10.1080/19474199.2011.593859

Kiptot, E., Franzel, S., Hebinck, P., \& Richards, P. (2006). Sharing seed and knowledge: Farmer to farmer dissemination of agroforestry technologies in western Kenya. Agroforestry Systems, 68(3), 167-179. http://doi.org/10.1007/s10457-006-9007-8

Kolawole, O. D. (2013). Soils, science and the politics of knowledge: How African smallholder farmers are framed and situated in the global debates on integrated soil fertility management. Land Use Policy, 30(1), 470-484. http://doi.org/10.1016/j.landusepol.2012.04.006

Kotir, J. H. (2011). Climate change and variability in Sub-Saharan Africa: A review of current and future trends and impacts on agriculture and food security. Environment, Development and Sustainability, 13, 587-605. http://doi.org/10.1007/s10668-010-9278-0

Kristjanson, P., Neufeldt, H., Gassner, A., Mango, J., Kyazze, F. B., Desta, S., .. Coe, R. (2012). Are food insecure smallholder households making changes in their farming practices? Evidence from East Africa. Food Security, 4(3), 381-397. http $/ /$ doi.org/10.1007/s12571 012-0194-z

Krueger, R. A., \& Casey, M. A. (2009). Focus groups: A practical guide for applied research (4th ed.). Thousand Oaks, CA: SAGE Publications, Inc.

Kuruppu, N., \& Liverman, D. (2011). Mental preparation for climate adaptation: The role of cognition and culture in enhancing adaptive capacity of water management in Kiribati. Global Environmental Change, 21(2), 657-669. http://doi.org/10.1016/j.gloenvcha.2010.12.002

Lata, S., \& Nunn, P. (2012). Misperceptions of climate-change risk as barriers to climate-change adaptation: A case study from the Rewa Delta, Fiji. Climate Change, 110, 169-186. http://doi.org/10.1007/s10584-011-0062-4

Laube, W., Schraven, B., \& Awo, M. (2012). Smallholder adaptation to climate change: Dynamics and limits in Northern Ghana. Climate Change, 111, 753-774. http $/ /$ doi.org/10.1007/s10584011-0199-1

Liu, J., Fritz, S., van Wesenbeeck, C. F. A., Fuchs, M., You, L., Obersteiner, M., \& Yang, H. (2008). A spatially explicit assessment of current and future hotspots of hunger in subSaharan Africa in the context of global change. Global and Planetary Change, 64(3-4), 222235. http:/doi.org/10.1016/j.gloplacha.2008.09.007

Lutes, M. W. (1998). Global climatic change. In R. Keil, D. V. J. Bell, P. Penz, \& L. Fawcett (Eds.), Political ecology: Global and local (pp. 157-179). London and New York: Routledge.

Lynam, J. K., \& Twomlow, S. (2014). A 21st-century balancing act: Smallholder farm heterogeneity and cost-effective research. In P. B. R. Hazell \& A. Rahman (Eds.), New 
Directions for Smallholder Agriculture (pp. 324-354). Oxford: Oxford University Press.

Mapfumo, P., Adjei-Nsiah, S., Mtambanengwe, F., Chikowo, R., \& Giller, K. E. (2013). Participatory action research (PAR) as an entry point for supporting climate change adaptation by smallholder farmers in Africa. Environmental Development, 5, 6-22. http://doi.org/10.1016/j.envdev.2012.11.001

Marshall, N. A. (2010). Understanding social resilience to climate variability in primary enterprises and industries. Global Environmental Change, 20, 36-43. http://doi.org/10.1016/j.gloenvcha.2009.10.003

Mathenge, M. K., Smale, M., \& Olwande, J. (2014). The impacts of hybrid maize seed on the welfare of farming households in Kenya. Food Policy, 44, 262-271. http://doi.org/10.1016/j. foodpo1.2013.09.013

Mather, D., Boughton, D., \& Jayne, T. S. (2013). Explaining smallholder maize marketing in southern and eastern Africa: The roles of market access, technology and household resource endowments. Food Policy, 43, 248-266. http://doi.org/10.1016/j. foodpol.2013.09.008

Maxon, R. M., \& Ofcansky, T. P. (2000). Historical dictionary of Kenya (2nd ed.). Scarecrow Press.

Mayne, R. (2006). Causing hunger: An overview of the food crisis in Africa. Briefing Paper, July 2006.

Meijer, S. S., Catacutan, D., Ajayi, O. C., Sileshi, G. W., \& Nieuwenhuis, M. (2014). The role of knowledge, attitudes and perceptions in the uptake of agricultural and agroforestry innovations among smallholder farmers in sub-Saharan Africa. International Journal of Agricultural Sustainability, 13(1), 40-54. http:/doi.org/10.1080/14735903.2014.912493

Miruka, M. K., Okello, J. J., Kirigua, V. O., \& Murithi, F. M. (2012). The role of the Kenya Agricultural Research Institute (KARI) in the attainment of household food security in Kenya: A policy and organizational review. Food Security, 4(3), 341-354. http://doi.org/10.1007/s12571-012-0197-9

Misselhorn, A., Aggarwal, P., Ericksen, P., Gregory, P., Horn-Phathanothai, L., Ingram, J., \& Wiebe, K. (2012). A vision for attaining food security. Current Opinion in Environmental Sustainability, 4(1), 7-17. http://doi.org/10.1016/j.cosust.2012.01.008

Mitchell, T., \& Tanner, T. (2008). Defining a future research agenda on pro-poor adaptation(IDS Bulletin) (Vol. 39).

Molua, E. L. (2011). Farm income, gender differentials and climate risk in Cameroon: Typology of male and female adaptation options across agroecologies. Sustainability Science, 6, 21-35. http://doi.org/10.1007/s11625-010-0123-z

Morton, J. F. (2007). The impact of climate change on smallholder and subsistence agriculture. Proceedings of the National Academy of Sciences of the United States of America, 104(50), 19680-19685.

Moser, S. C., \& Ekstrom, J. A. (2010). A framework to diagnose barriers to climate change adaptation. Proceedings of the National Academy of Sciences of the United States of America, 107(51), 22026-22031. http://doi.org/10.1073/pnas.1007887107

Munang, R., \& Nkem, J. N. (2011). Using small-scale adaptation actions to address the food cris is in the Horn of Africa: Going beyond food aid and cash transfers. Sustainability, 3(9), 15101516. http://doi.org/10.3390/su3091510

Muthoni, J., \& Nyamongo, D. O. (2010). Traditional food crops and their role in food and 
nutritional security in Kenya. Journal of Agricultural \& Food Information, 11(1), 36-50. http://doi.org/10.1080/10496500903466745

Nelson, V., \& Stathers, T. (2009). Resilience, power, culture, and climate: A case study from semiarid Tanzania, and new research directions, 17(1), 81-95. http://doi.org/10.1080/13552070802696946

NEPAD. (2013). African agriculture, transformation and outlook.

Neumann, R. P. (2005). Making political ecology. New York: Routledge.

Never, B. (2011). Who drives change? Comparing the evolution of domestic climate governance in India and South Africa. Journal of Environment and Development, 21(3), 362-387.

Ogutu, Z. A. (1993). Responding to population pressure in the rural Kenya. GeoJournal, 30(4), 409-419. http://doi.org/10.1007/BF00807222

Osbahr, H., Twyman, C., Adger, N. W., \& Thomas, D. S. G. (2008). Effective livelihood adaptation to climate change disturbance: Scale dimensions of practice in Mozambique. Geoforum, 39(6), 1951-1964. http://doi.org/10.1016/j.geo forum.2008.07.010

Pahl-Wostl, C. (2007). The implications of complexity for integrated resources management. Environmental Modelling \& Software, 22(5), 561-569. http://doi.org/10.1016/j.envsoft.2005.12.024

Pahl-Wostl, C. (2009). A conceptual framework for analysing adaptive capacity and multi-level learning processes in resource governance regimes. Global Environmental Change, 19(3), 354-365. http://doi.org/10.1016/j.gloenvcha.2009.06.001

Patt, A. G., \& Schröter, D. (2008). Perceptions of climate risk in Mozambique: Implications for the success of adaptation strategies. Global Environmental Change, 18, 458-467. http://doi.org/10.1016/j.gloenvcha.2008.04.002

Pelling, M., High, C., Dearing, J., \& Smith, D. (2008). Shadow spaces for social learning: A relational understanding of adaptive capacity to climate change within organisations. Environment and Planning A, 40(4), 867-884. http://doi.org/10.1068/a39148

Pielke, R. A., Adegoke, J. O., Chase, T. N., Marshall, C. H., Matsui, T., \& Niyogi, D. (2007). A new paradigm for assessing the role of agriculture in the climate system and in climate change. Agricultural and Forest Meteorology, 142, 234-254. http://doi.org/10.1016/j.agrformet.2006.06.012

Pinstrup-Andersen, P., \& Watson II, D. D. (2011). Food policy for developing countries: The role of government in global, national, and local food systems. book, Ithaca, N.Y.: Cornell University Press.

Population Reference Bureau. (2015). 2015 World population data sheet. Washington, D.C.

Rao, K. P. C., Sridhar, G., Mulwa, R. M., Kilavi, M. N., Esilaba, A., Athanasiadis, I. N., \& Valdivia, R. O. (2014). Impacts of climate variability and change on agricultural systems in East Africa. In Handbook of Climate Change and Agroecosystems (Vol. Volume 3, pp. 75124). Imperial College Press. http://doi.org/doi:10.1142/9781783265640_0015

Reilly, J., \& Schimmelpfenning, D. (2000). Irreversibility, uncertainty and learning: portraits of adaptation to long-term climate change. Climate Change, 45, 253-278.

Ribot, J. (2011). Vulnerability before adaptation: Toward transformative climate action. Global Environmental Change, 21, 1160-1162. http://doi.org/10.1016/j.gloenvcha.2011.07.008

Robinson, L. W., \& Berkes, F. (2011). Multi-level participation for building adaptive capacity: Formal agency-community interactions in northern Kenya. Global Environmental Change, 
21(4), 1185-1194. http://doi.org/10.1016/j.gloenvcha.2011.07.012

Rodima-Taylor, D., Olwig, M. F., \& Chhetri, N. (2012). Adaptation as innovation, innovation as adaptation: An institutional approach to climate change. Applied Geography, 33, 107-111. http:/doi.org/10.1016/j. ap geog.2011.10.011

Rufino, M. C., Thornton, P. K., Ng'ang'a, S. K., Mutie, I., Jones, P. G., van Wijk, M. T., \& Herrero, M. (2013). Transitions in agro-pastoralist systems of East Africa: Impacts on food security and poverty. Agriculture, Ecosystems and Environment, 179, 215-230. http:/doi.org/10.1016/j. agee.2013.08.019

Saldaña-Zorrilla, S. O. (2008). Stakeholders' views in reducing rural vulnerability to natural disasters in Southern Mexico: Hazard exposure and coping and adaptive capacity. Global Environmental Change, 18, 583-597. http:/doi.org/10.1016/j.gloenvcha.2008.09.004

Schmidhuber, J., \& Tubiello, F. N. (2007). Global food security under climate change. Proceedings of the National Academy of Sciences of the United States of America, 104(50), 19703-19708.

Scott, R. W. (2001). Institutions and organizations (2nd ed.). Thousand Oaks, CA: SAGE Publications, Inc.

Sheahan, M., Black, R., \& Jayne, T. S. (2013). Are Kenyan farmers under-utilizing fertilizer? Implications for input intensification strategies and research. Food Policy, 41, 39-52. http://doi.org/10.1016/j. foodpol.2013.04.008

Sietz, D., Lüdeke, M. K. B., \& Walther, C. (2011). Categorisation of typical vulnerability patterns in global drylands. Global Environmental Change, 21, 431-440. http://oi.org/10.1016/j.gloenvcha.2010.11.005

Sigel, K., Klauer, B., \& Pahl-Wostl, C. (2010). Conceptualising uncertainty in environmental decision-making: The example of the EU water framework directive. Ecological Economics, 69(3), 502-510. http://doi.org/10.1016/j.ecolecon.2009.11.012

Slater, D. (1973). Geography and underdevelopment - 1. Antipode, 5(3), 21-32. article. http://doi.org/10.1111/j.1467-8330.1973.tb00568.x

Smit, B., \& Wandel, J. (2006). Adaptation, adaptive capacity and vulnerability. Global Environmental Change, 16, 282-292. http//doi.org/10.1016/j.gloenvcha.2006.03.008

Soja, E. W. (1968). The geography of modernization in Kenya: A spatial analysis of social, economic, and political change. Syracuse, N.Y.: Syracuse University Press.

Speca, A. (2013). Kenya food security brief. United States Agency for International Development Famine Early Warning Systems Network (FEWS NET).

Stephens, E. C., Nicholson, C. F., Brown, D. R., Parsons, D., Barrett, C. B., Lehmann, J., ... Riha, S. J. (2012). Modeling the impact of natural resource-based poverty traps on food security in Kenya: The Crops, Livestock and Soils in Smallholder Economic Systems (CLASSES) model. Food Security, 4, 423-439. http://doi.org/10.1007/s12571-012-0176-1

Sultana, P., \& Thompson, P. (2004). Methods of consensus building for community-based fisheries management in Bangladesh and the Mekong Delta. Agricultural Systems, 82, 327353. http://doi.org/10.1016/j.agsy.2004.07.007

Tall, A., Hansen, J., Jay, A., Campbell, B., Kinyangi, J., Aggarwal, P. K., \& Zougmoré, R. (2014). Scaling up climate services for farmers: Mission possible. Learning from good practice in Africa and South Asia. Copenhagen: CGIAR Reserach Program on Climate Change, Agriculture and Food Security (CCAFS). 
Tanumihardjo, S. A., Anderson, C., Kaufer-Horwitz, M., Bode, L., Emenaker, N. J., Haqq, A. M., ... Stadler, D. D. (2007). Poverty, obesity, and malnutrition: An international perspective recognizing the paradox. Journal of the American Dietetic Association, 107(11), 1966-1972. Journal Article, Research Support, N.I.H., Extramural, Research Support, Non-U.S. Gov't, Research Support, U.S. Gov't, Non-P.H.S., Review. http://doi.org/10.1016/j.jada.2007.08.007

Terry, G. (2009). No climate justice without gender justice: An overview of the issues. Gender \& Development, 17(1), 5-18. http://doi.org/10.1080/13552070802696839

Thornton, P. K., Jones, P. G., Ericksen, P. J., \& Challinor, A. J. (2011). Agriculture and food systems in sub-Saharan Africa in a $4^{\circ} \mathrm{C}+$ world. Philosophical Tansactions of the Royal Society A, 369, 117-136. http//doi.org/10.1098/rsta.2010.0246

Thurston, A. F. (1987). Smallholder agriculture in colonial Kenya: The official mind and the Swynnerton Plan (Cambridge African Monographs No. 8). African Studies Centre.

Tirado, M. C., Cohen, M. J., Aberman, N., Meerman, J., \& Thompson, B. (2010). Addressing the challenges of climate change and biofuel production for food and nutrition security. Food Research International, 43(7), 1729-1744. http://doi.org/10.1016/j.foodres.2010.03.010

Trærup, S. L. M. (2012). Informal networks and resilience to climate change impacts: A collective approach to index insurance. Global Environmental Change, 22(1), 255-267. http://doi.org/10.1016/j.gloenvcha.2011.09.017

Tschakert, P. (2013). From impacts to embodied experiences: Tracing political ecology in climate change research. Danish Journal of Geography, 112(2), 144-158.

Tschakert, P., \& Dietrich, K. A. (2010). Anticipatory learning for climate change adaptation and resilience. Ecology and Society, 15(2), 11.

UNCTAD. (2009). Food security in Africa: Learning lessons from the food crisis.

United Nations Population Division. (1998). World population prospects: The 1998 revision.

Vermeulen, S. J., Aggarwal, P. K., Ainslie, A., Angelone, C., Campbell, B. M., Challinor, A. J., ... Wollenberg, E. (2012). Options for support to agriculture and food security under climate change. Environmental Science and Policy, 15(1), 136-144. http://doi.org/10.1016/j.envsci.2011.09.003

Vermeulen, S. J., Challinor, A. J., Thornton, P. K., Campbell, B. M., Eriyagama, N., Vervoort, J. M., ... Smith, D. R. (2013). Addressing uncertainty in adaptation planning for agriculture. Proceedings of the National Academy of Sciences of the United States of America, 110(21), 8357-62. http://doi.org/10.1073/pnas.1219441110

Viviroli, D., \& Weingartner, R. (2008). "Water Towers"' - A global view of the hydrological importance of mountains. In E. Wiegandt (Ed.), Mountains: Sources of water, sources of snowledge (pp. 15-20). inbook, Dordrecht: Springer Netherlands. http://doi.org/10.1007/9781-4020-6748-8_2

Watts, M. J. (1989). The agrarian question in Africa: debating the crisis. Progress in Human Geography, 13(1), 1-41.

Watts, M. J. (1989). The agrarian question in Africa: debating the crisis. Progress in Human Geography, 13, 1-41. http:/doi.org/10.1177/030913258901300101

Wibberley, J. (2014). Family farms at the heart of tropical agro-ecology for ecosystem security. Agriculture for Development: Special Issue on Climate Change and Agriculture, 42-44.

Wiggins, S., \& Keats, S. (2013). Leaping \& learning: Linking smallholders to markets in Africa. 
London: Agriculture for Impact, Imperial College London and Overseas Development Institute.

Wijkman, A., \& Timberlake, L. (1984). Natural Disasters: Acts of God, or Acts of Man? London: International Institute for Environment and Development, Earthscan.

Wolf, J., Lorenzoni, I., Few, R., Abrahamson, V., \& Raine, R. (2009). Conceptual and practical barriers to adaptation: Vulnerabilities and responses to heat waves in the UK. In N. W. Adger, I. Lorenzoni, \& K. L. O’Brien (Eds.), Adapting to climate change: Thresholds, values governance (p. 514). Cambridge University Press.

Wood, S. A., Jina, A. S., Jain, M., Kristjanson, P., \& DeFries, R. S. (2014). Smallholder farmer cropping decisions related to climate variability across multiple regions. Global Environmental Change, 25, 163-172. http:/doi.org/10.1016/j.gloenvcha.2013.12.011

Young, O. R. (2010). Institutional dynamics: Resilience, vulnerability and adaptation in environmental and resource regimes. Global Environmental Change, 20(3), 378-385. http://oi.org/10.1016/j.gloenvcha.2009.10.001

Ziervogel, G., \& Calder, R. (2003). Climate variability and rural livelihoods: Assessing the impact of seasonal climate forecasts in Lesotho. Area, 35(4), 403-417.

Ziervogel, G., \& Cartwright, A. (2011). The use of climate science in agricultural adaptation in Africa. In R. Fujikura \& M. Kawanishi (Eds.), Climate change adaptation and international development: Making development cooperation more effective (pp. 109-128). London/Washington, D.C.: Earthscan. 


\section{Appendices}

\section{Appendix A. Sample questions for smallholder farmers and non-farmer informants}

\section{A.1. Sample questions for focus group discussions}

\section{General questions}

1. What is your age group: $20-30,30-40,40-50,50-60$, over 60

2. How long have you been living/farming in this region?

3. What types of livelihood activities do you engage in?

4. Generally, how would you describe life in this a rea?

\section{Food security}

5. What is your understanding of food security?

6. Overall, how would you describe the food security status of this area?

7. What are the main challenges in the region that undermine food security?

\section{Institutional arrangements}

8. Do you belong to any chamas ${ }^{22}$ (informal institutions)? What are the purposes of the groups?

9. How have the chamas affected your livelihoods

10. What are the main challenges with chamas?

11. What are the most important types of services you seek from formal institutions?

12. How have these services affected your livelihoods?

13. Are you satisfied with the services delivered? Why?

14. What would an ideal scenario of institutional support look like?

\section{Climate change}

15. What is your understanding of climate change?

16. Is there evidence of climate change in the region?

17. Has this affected your livelihood strategies and outcomes? How?

18. What changes have you made to respond to these effects?

\section{A.2. Sample questions for one-on-one interviews}

\section{Household Dynamics}

1. What is your household composition: \# of - adults, children (5-18yrs; <5yrs)

2. What is your highest level of formal education completed: none, primary, secondary, postsecondary

3. How many years have you lived in this area: $<5,6-10,>10$

4. What types of livelihood activities does your household engage in?

5. What are your household's livelihood priorities?

${ }^{22}$ A chama (chamas - plural) is the Kiswahili name for informal associations/groups among locals 


\section{Food security}

6. What is your understanding of food security?

7. Do you think that your household is food secure? If not, what have you done about it?

8. If your present status remains unchanged, will your household be food secure in 5 , or in 10 years to come?

9. What external factors influence the food security of your household

10. How do you receive information on agricultural services?

\section{Climate change}

11. What is your understanding of climate change?

12. Have you witnessed it? If so, please describe giving evidence.

13. How has this affected your livelihood/food security if at all?

14. What changes have you made in response to this?

\section{Institutional arrangements}

15. Are you or any adults in the household members of a chama (informal group)?

16. If yes,

a. How many and for what purposes?

b. What are the most important chamas to you?

c. For each of these chamas,

i. How is membership obtained and is it single or mixed gender?

ii. How often do you meet?

iii. How has membership in this chama supported your livelihood?

iv. Would you consider withdrawing your membership? Why?

17. Are you or any adults in the household receiving services from any formal institution?

a. How many and for what purposes?

b. What are the two most important services to you?

c. For each of these two formal institutions,

i. How did you get to hear about their services?

ii. How often do you use their services?

iii. In what way have their services improved your livelihood, if at all?

iv. Are you satisfied with the services offered? Why?

v. Do you provide feedback to the institution e.g. verbally or via their suggestions box?

\section{A.3. Sample questions for non-farmer informants}

1. What types of services does the institution offer to farmers in the region?

2. What informs the types of services offered?

3. How does the institution target service delivery to the farmers?

4. Do you receive feedback from or conduct information-sharing sessions with the farmers?

5. What are the major challenges in service delivery to farmers in the region? 
6. How would you describe the attitudes of the farmers towards the agency and services rendered?

7. How would you describe food security in the region?

8. What is your knowledge of climate change in the region and how does this affect smallholders?

9. Are you aware of specific programs carried out by your institution that address food security and climate change issues in the region?

10. How does the institution build the capacity of smallholders to ensure continuity beyond project life? 


\title{
Appendix B. Informed consent and recruitment script
}

\section{B.1. Script for recruiting farmers for group discussions and interviews}

\author{
Carleton \\ U N I V E R S I T Y \\ Canada's Capital University
}

\author{
Carleton University \\ 1125 Colonel By Drive \\ Ottawa, Ontario, K1S5B6 \\ Canada
}

(A Kiswahili version will be available)

Title of research project: Institutional responses to climate change: strengthening food security among Mount Kenya's smallholders

Date of ethics clearance: $28^{\text {th }}$ June, 2013

Ethics Clearance for the Collection of Data (Project \#13260 14-0163): Expires 31st May, 2016

Hello. My name is Beth Mburu and I am a full-time PhD student at Carleton University in Canada. My studies focus on climate change adaptation and under the supervision of Prof. Michael Brklacich at the Department of Geography and Environmental Studies, my research interests expand to include the food security of smallholder farmers. As part of my research, I would like to learn about the smallholder farmers in Mt. Kenya region. Of particular interest is their food security and the level of institutional support they receive towards achieving it while minimizing negative effects of climate change.

\section{For focus group discussion participants}

This is the reason why I am reaching out to you to participate in a discussion with other farmers. More specifically, I would like to learn about yourviews on food security, climate change and the type of support you receive from various institutions. The discussions will be less than 2 hours and you will be in a group with 5 to 7 other farmers.

\section{For participants in in-depth interviews}

It is on this basis that I invite you to participate in an in-depth interview, which will take less than two hours. This will be on a one-on-one session preferably at your farm where I will seek your views on food security, climate change and the benefits of group membership in various institutions.

I would appreciate if you could be a part of my research. If you wish to participate, we can agree on a convenient date and time to set up the discussion group/interview.

If No: thank you for your time and have a good day.

If Yes: thank you for indicating your interest in the research. If you have the time now, I could describe the research a little bit more and we can set up a time to meet.

[Read the informed consent form and/or set up a time for the in-depth interview or obtain an indication of availability for focus group discussions] 


\section{B.2. Script for recruiting non-farmers via phone or email}

Carleton

Canada's Capital University
Carleton University

1125 Colonel By Drive Ottawa, Ontario, K1S5B6

Canada

Title of research project: Institutional responses to climate change: strengthening food security among Mount Kenya's smallholders

Date of ethics clearance: $28^{\text {th }}$ June, 2013

Ethics Clearance for the Collection of Data (Project \#13260 14-0163): Expires 31 ${ }^{\text {st }}$ May, 2016

Hello. My name is Beth Mburu and I am a full-time PhD candidate at Carleton University in Canada. My studies focus on climate change adaptation and under the supervision of Prof. Michael Brklacich at the Department of Geography and Environmental Studies, my research interests expand to include the food security of smallholder farmers. As part of my research, I would like to learn about the smallholder farmers in Mt. Kenya region. Of particular interest is their food security and the level of institutional support they receive towards achieving it while minimizing negative effects of climate change.

A major part of my research involves engaging with institutions that deal with farmers in the region. You have been identified as a key resource person who is both knowledgeable in the operations of your institution and has working experience with smallholder farmers in the region. I would like to invite you to participate in an interview that will take less than two hours of your time where you can share these experiences. More specifically, I would wish to learn more on your institution's approach to food security, climate change and the support you give to smallholder farmers in the region. I would highly appreciate your support by participating in the research.

If No: thank you for your time and have a good day.

If Yes: thank you for indicating your interest in the research. Shortly, I will send you a brief description of the research and a consent form for you to sign and email back to me. In your response, please indicate a convenient time and date within the next two weeks when we can have the interview.

[Confirm the email address I have on file and email the consent form] 


\section{B.3. Informed consent from farmers}

\section{Carleton \\ U N I VER S I T Y \\ Canada's Capital University}

\section{Carleton University \\ 1125 Colonel By Drive Ottawa, Ontario, K1S5B6 \\ Canada}

(A Kiswahili version will be available)

Title of research project: Institutional responses to climate change: strengthening food security among Mount Kenya's smallholders

Date of ethics clearance: $28^{\text {th }}$ June, 2013

Ethics Clearance for the Collection of Data (Project \#13260 14-0163): Expires 31 ${ }^{\text {st }}$ May, 2016

Dear Farmer,

Hello. Thank you for agreeing to participate in this research. As I had mentioned earlier, my name is Beth Mburu a PhD candidate at Carleton University in Canada. Under the supervision of Prof. Michael Brklacich at the Department of Geography and Environmental Studies, I will be conducting research on the food security of smallholder farmers in Mt. Kenya. This will be with special focus on institutional support received in order to overcome the challenge of climate change. The purpose will be to determine how institutions can improve their support to farmers and thus strengthen their food security.

The research will be carried out over the next three months. During your participation, I will seek your viewpoints on food security, climate change, informal group membership and the institutional support you receive. In order to capture your responses as accurate as possible, I will audio record them with a digital device and take notes as well. I might also take photographs to help me document the research process. I will not identify you by your full names either during the discussions or on digital records. All the information you provide will be kept safely and I will not share it with anyone. Should you wish to withdraw your participation at any point within three months of the data collection date, you are free to let me know via phone or in person. Any data you will have provided will not be included in my research and will later be destroyed.

This research has been approved by the Ethics Committee at Carleton University. Should you have any further questions, please do not hesitate to contact me at the phone number provided below. Thank you for your time and I look forward to learning from you.

Beth Mburu

+254722553160

$\underline{\text { Informed consent for farmer }}$
Date: (dd/mm/yyyy) 
By signing this form, I agree to participate in the research study conducted by Beth Mburua PhDcandidate at Carleton University. I have fully read or been read to the purpose of the study and I voluntarily agree to participate.

I am aware and agree to the audio recording, notes and photograph taking during my engagement with the researcher. Any information that I provide will be held in confidence and the researcher will not identify me at any point and in any format after the completion of the session. I am also aware that at any point during the study, I am free to withdraw my participation and the data that I have provided will be not be used and will be later destroyed.

At any stage during and after the research process, I can contact the researcher or her supervisor for matters related to the research study. Should I have any concerns, I am aware that I can contact the Ethics Committee at Carleton University using the address provided in this letterhead.

Participant's Signature

Date: $(d d / m m /$ yyy)

\section{B.4. Informed consent from non-farmers}

Carleton

Canada's Capital University
Carleton University

1125 Colonel By Drive

Ottawa, Ontario, K1S 5B6

Canada

Title of research project: Institutional responses to climate change: strengthening food security among Mount Kenya's smallholders

Date of ethics clearance: $28^{\text {th }}$ June, 2013

Ethics Clearance for the Collection of Data (Project \#13260 14-0163): Expires 31 ${ }^{\text {st }}$ May, 2016

Dear participant,

Hello. Thank you for agreeing to participate in this research. As I had mentioned earlier, my name is Beth Mburu a PhD candidate at Carleton University in Canada. Under the supervision of Prof. Michael Brklacich at the Department of Geography and Environmental Studies, I will be conducting research on the food security of smallholder farmers in Mt. Kenya. This will be with special focus on institutional support received in order to overcome the challenge of climate change. The purpose will be to determine how institutions can improve their support to farmers and thus strengthen their food security.

I have identified several organizations working with farmers in the region and your institution is among them. Further, you have been identified as a key resource person with the relevant knowledge on your 
institution and farmers in the region. Through a recorded interview, I would like to solicit your responses on issues related to food security, climate change and your institution's approach in program delivery. During the interview, you will be free to let me know which sections you would like to provide as the institution's perspectives and others that you may wish to comment on as your 'personal opinion'. At any point within three months of the data collection, you are free withdraw from the study. Any responses collected from you will not be used in the research and will later be destroyed.

This research has the approval of Carleton University Ethics committee. Should you wish to clarify this, feel free to write to them or my supervisor Prof. Michael Brklacich at the address provided in the above letterhead. Additionally, you are welcome to contact me with concerns or questions about this research on my email address and through my mobile phone below. Kindly read the consent statement below, sign and send it back to me via email. Please indicate your availability to meet for an interview within the next two weeks.

Beth Mburu

Date: (dd/mm/yyyy)

+254722553160

\section{Informed consent for non-farmer}

By signing this form, I agree to participate in the research study conducted by Beth Mburua PhD candidate at Carleton University. I have fully read the purpose of the study and I voluntarily agree to participate. Based on my experience in the topic matter and/or the region, I have agreed to be interviewed as an expert consultant.

I have been informed that the researcher will be seeking an institutional perspective from my responses. It is clear to me that I can choose to state that some of my responses are personal and do not represent the perspective my institution. I consent to note-taking and audio recording of my interview. I am aware that at any point during the research period and within three months of the interview date I can choose to withdraw from the study. Any response I might have given will be invalid and the data will be destroyed. I have the assurances of the researcher that confidentiality will be maintained and anonymity will be observed as requested.

I am aware that the research has the approval of Carleton University's Ethics Committee and I am free to contact them or the researcher's supervisor Dr. Michael Brklacich at the address provided.

Participant's Signature

Date: $(d d / m m /$ yyy) 


\section{Appendix C. Example of agro-climatic advisory pamphlet for seasonal forecast}
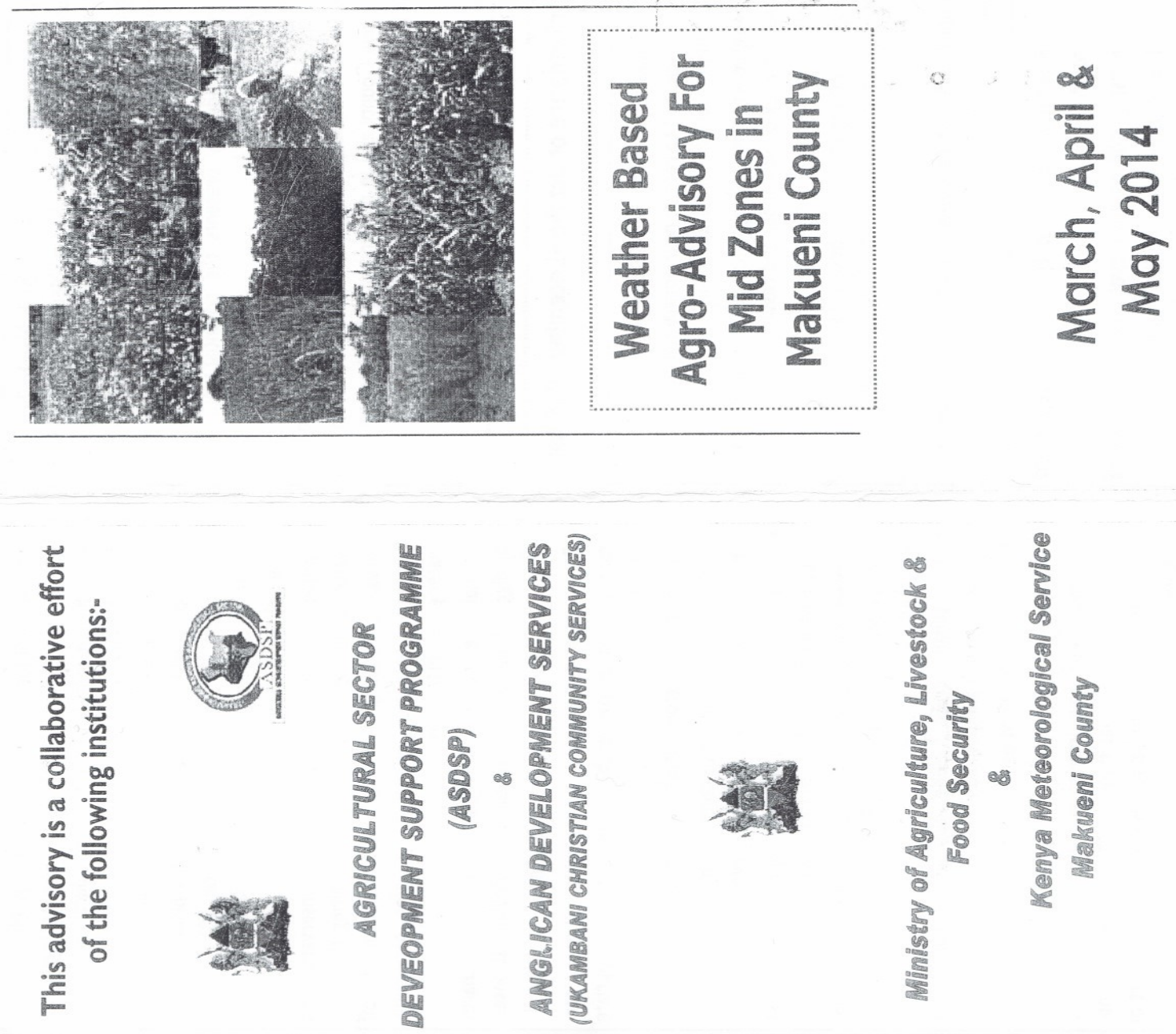

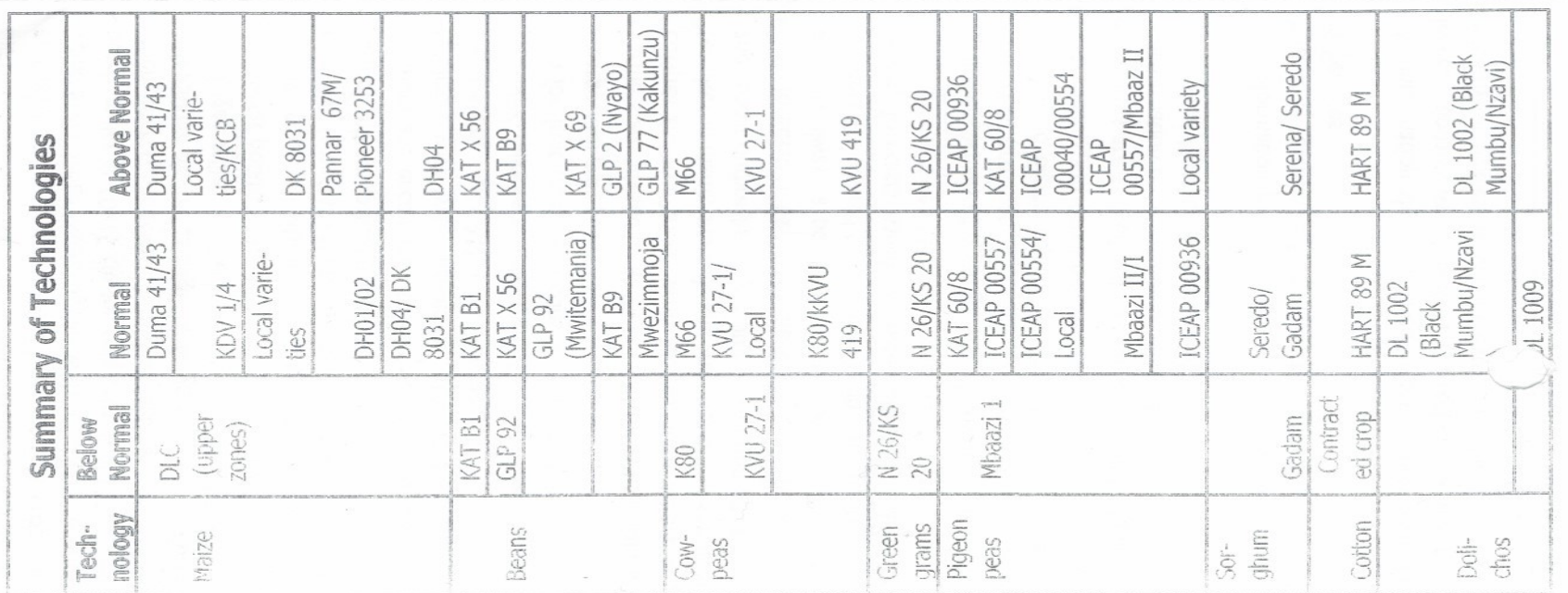




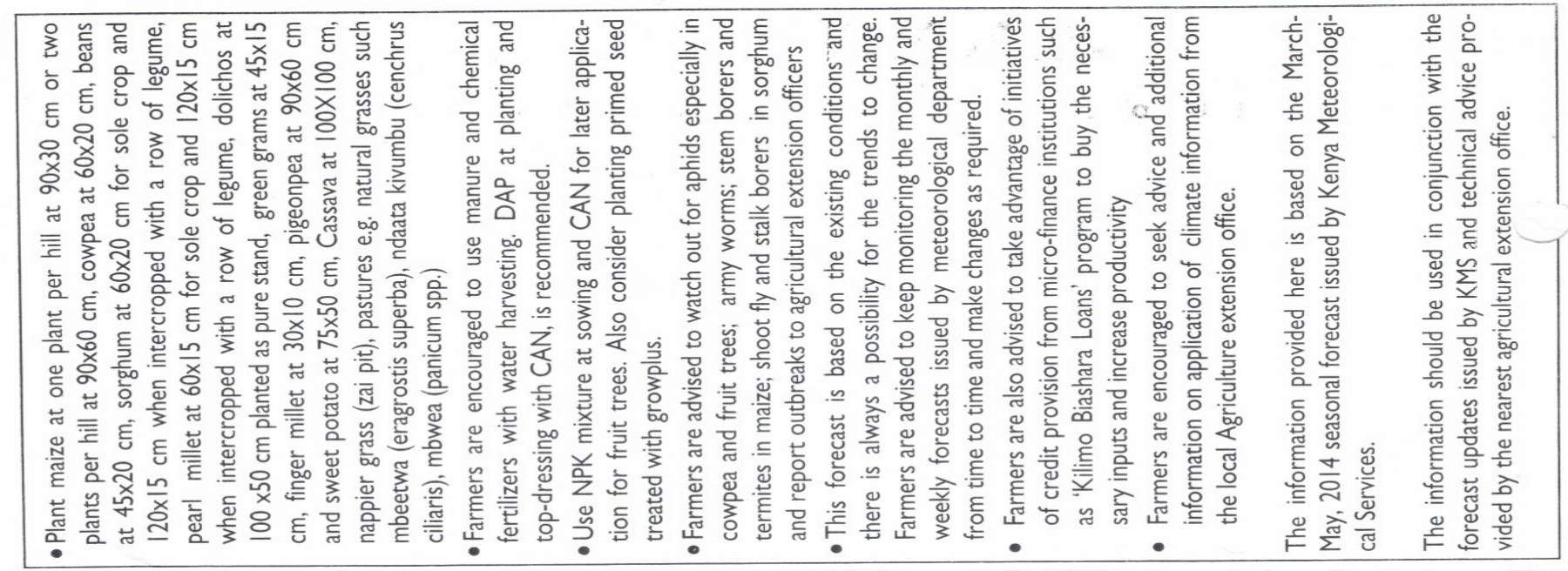

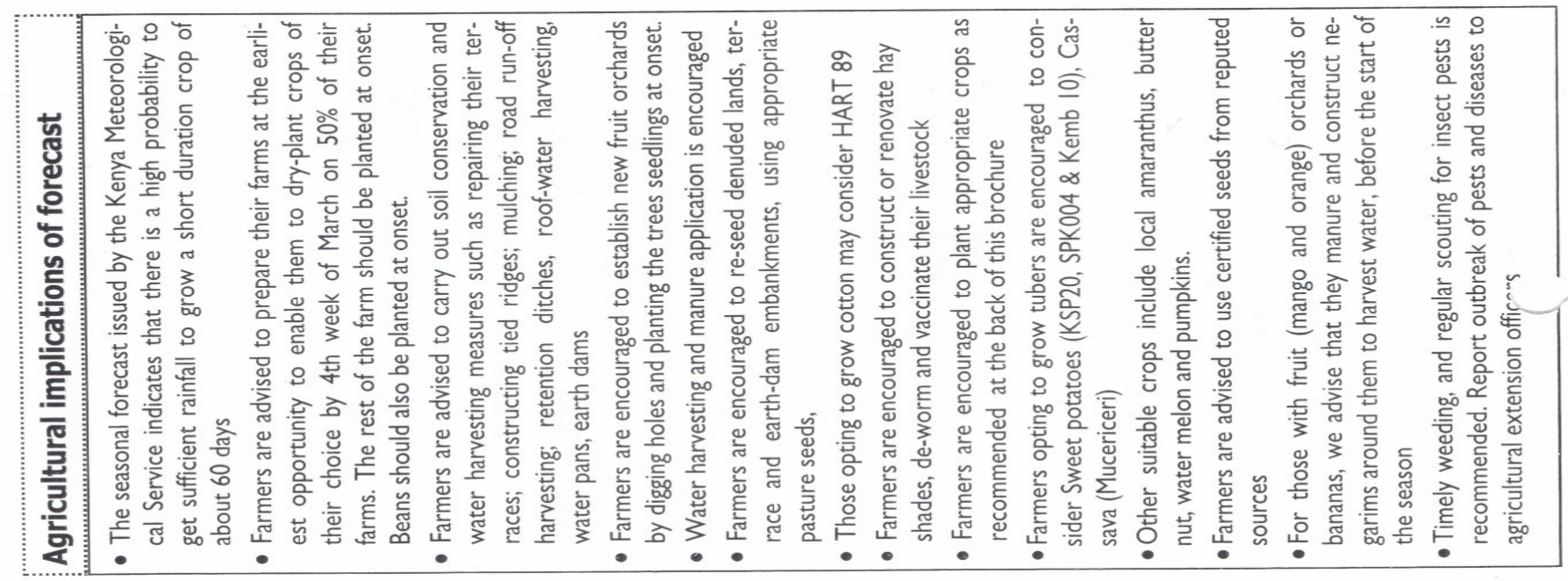

\begin{tabular}{|c|c|c|}
\hline 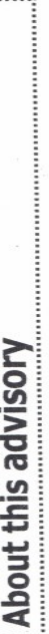 & 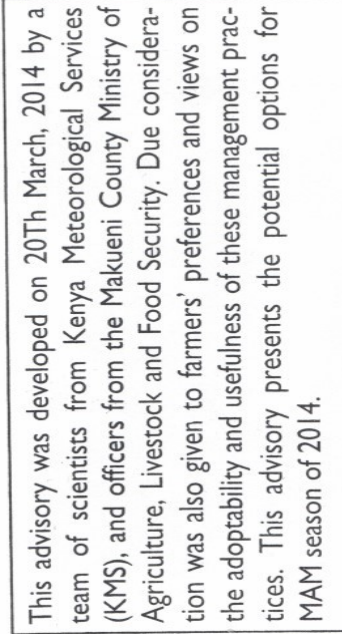 & 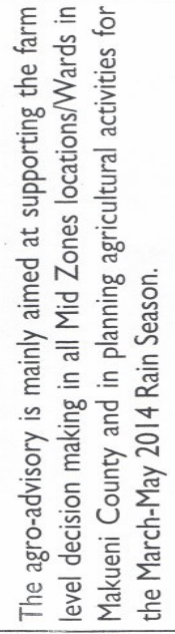 \\
\hline
\end{tabular}
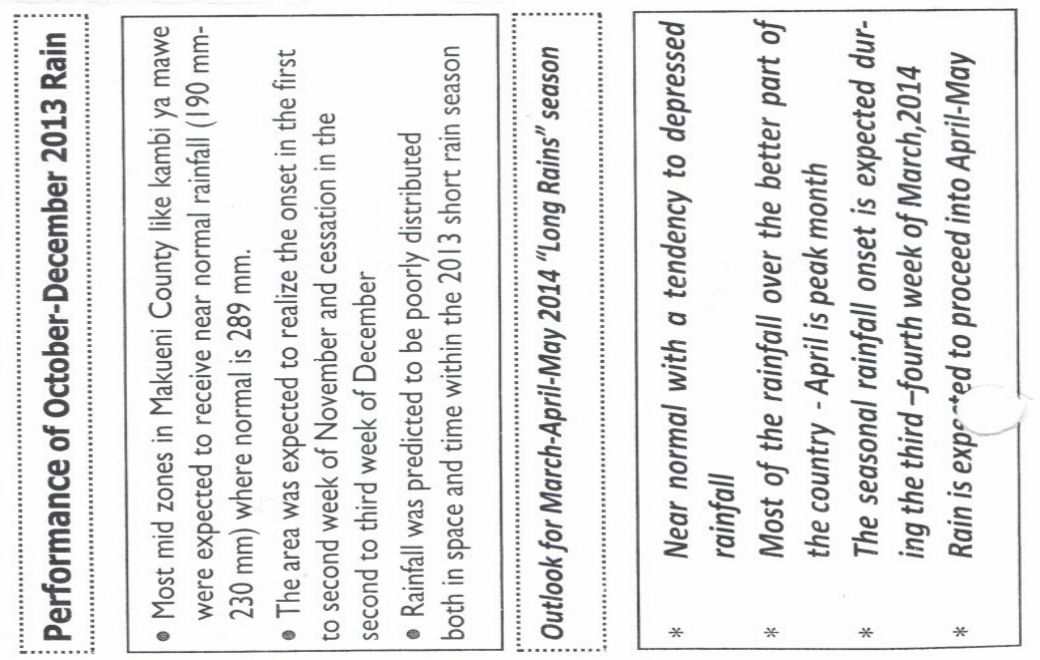